\title{
Pluripotency of multipotent adult germ-line stem cells: analysis of apoptotic and epigenetic features
}

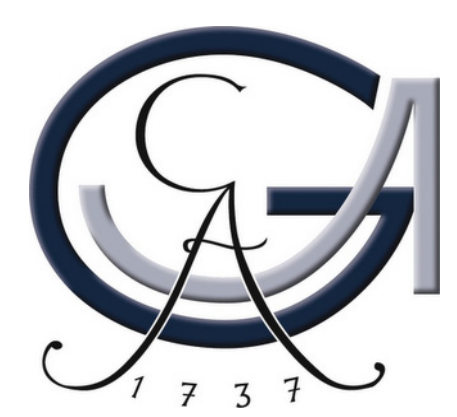

\section{DISSERTATION}

zur Erlangung des

Mathematisch-Naturwissenschaftlichen Doktorgrades

„Doctor rerum naturalium“

an der Georg-August-Universität Göttingen

vorgelegt von

Tatjana Khromov

aus

Leningrad

Göttingen, 2011 
Referent: Prof. Dr. Dr. Wolfgang Engel

Korreferent: Prof. Dr. Sigrid Hoyer-Fender

Tag der mündlichen Prüfung: 29.11.2011 


\section{Dedicated to my family}

The most beautiful thing we can experience is the mysterious.

It is the source of all true art and all science.

He to whom this emotion is a stranger, who can no longer pause to wonder and stand rapt in awe, is as good as dead: his eyes are closed.

-Albert Einstein 


\section{Table of Contents}

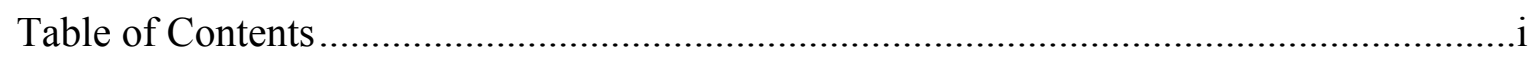

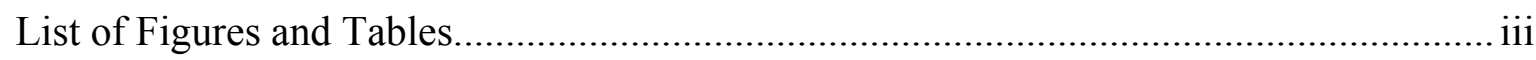

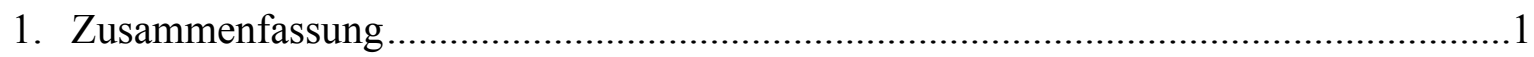

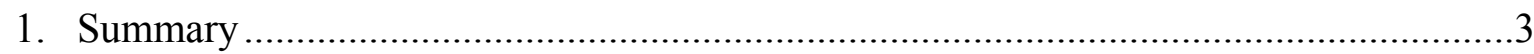

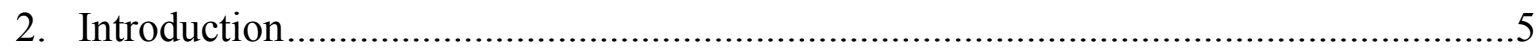

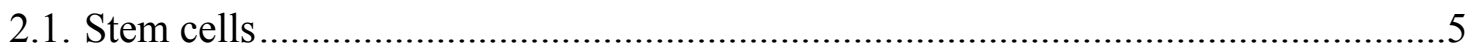

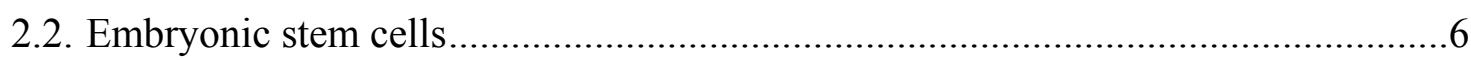

2.2.1. Molecular characteristics of ESCs ...........................................................

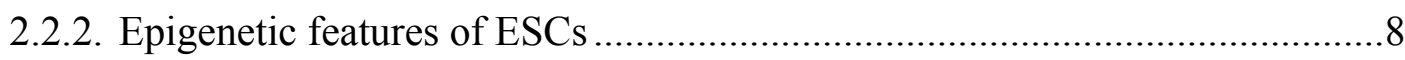

2.2.3. Apoptosis-related properties of ESCs ...................................................... 10

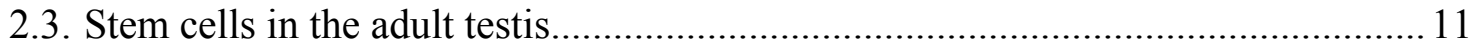

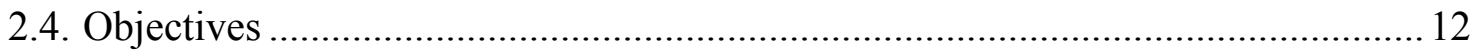

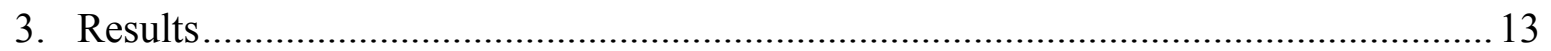

3.1. Global and gene-specific histone modification profiles of mouse multipotent

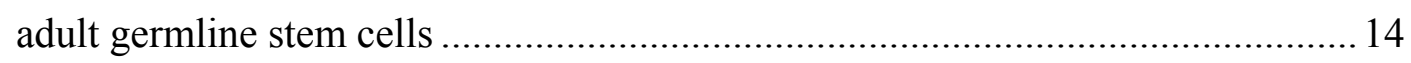

3.2. Apoptosis-related gene expression profiles of mouse ESCs and maGSCs:

Identification and implication of Fgf4 and Mnda in pluripotent cell responses to

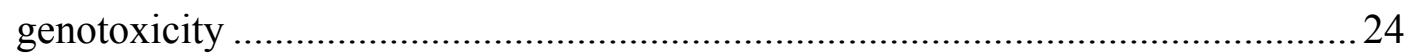

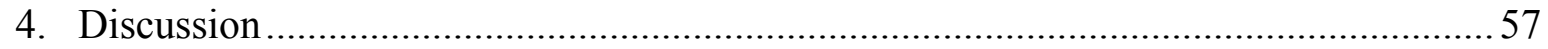

4.1. Mouse germ-line stem cell derived pluripotent stem cells .................................57

4.2. Comparative analysis of global and gene-specific histone modification profiles in maGSCs and ESCs.

4.3. Comparative analysis of the apoptosis-related gene expression profiles of mouse

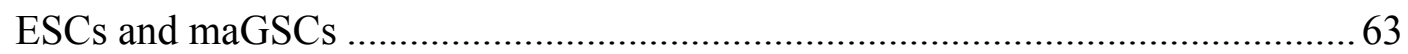

4.4. Putative apoptosis related genes in pluripotent ESCs and maGSCs.....................6 68

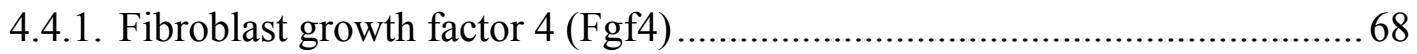

4.4.2. Myeloid cell nuclear differentiation antigen (Mnda) ................................... 68

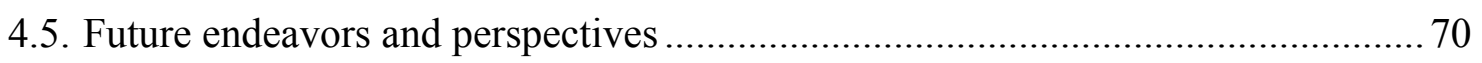

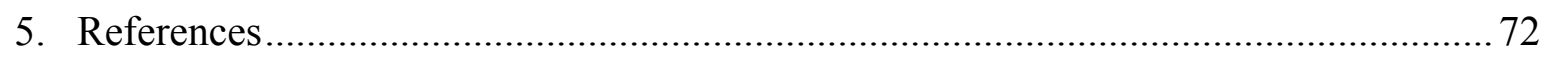

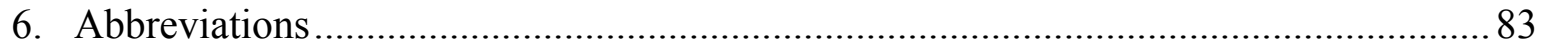

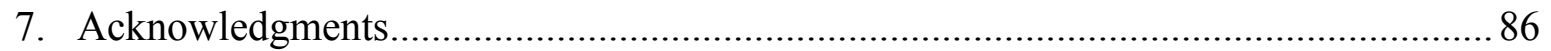




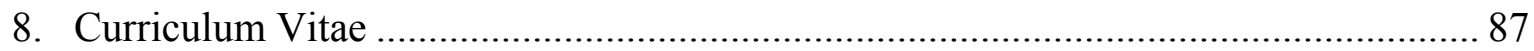

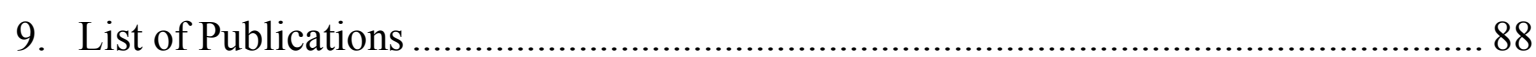

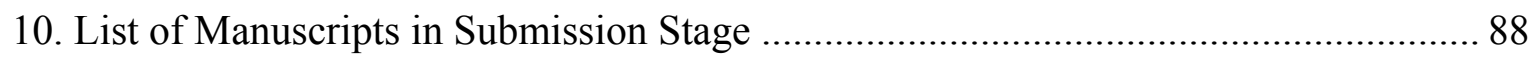




\section{List of Figures and Tables}

Figure 2.1. Developmental origin of different pluripotent stem cell types.........................7

Figure 2.2. Chromatin organisation and its post-translational histone modification............9

Figure 4.1. Chromatin remodeling processes of pluripotency genes during differentiation 60

Figure 4.2. Scheme to analyze the epigenetic features in ESC and maGSCs of three different genetic backgrounds....

Figure 4.3. Analysis of histone modification levels at Oct4, Pax5 and Zfpm2 in ESCs and maGSCs.

Figure 4.4. The bivalent chromatin signature of pluripotent cells

Figure 4.5. Western blot analysis of Casp-9 activation 67

Table 4.1. The list of pro- and anti-apoptotic genes detected in undifferentiated and differentiated ESCs and maGSCs 


\section{Zusammenfassung}

Pluripotenz ist das Potenzial der Zellen unbegrenzt zu proliferieren (SelbstErneuerung) und sich in alle Zelltypen der drei Keimblätter sowie der Keimbahn entwickeln zu können. Kürzlich etablierte sogenannte multipotente adulte KeimbahnStammzellen (maGSC) sind pluripotente Zellen, die sich aus den unipotenten Spermatogonalen Stammzellen (SSC) ableiten und in vitro ähnliche Eigenschaften wie Embryonale Stammzellen (ESCs) erwerben. Da pluripotente maGSCs ein therapeutisches Potenzial in der regenerativen Medizin haben könnten und dadurch die ethisch problematischen ESCs ersetzen könnten, verglichen mehrere Gruppen diese Zellen mit den "Gold-Standards der Pluripotenz", den ESCs. Vergleichende Analysen an verschiedenen Aspekten wie miRNA- Expression, Analyse des globalen Transkriptoms und des Proteoms sowie DNA-Methylierung konnten die Ähnlichkeit zwischen maGSCs und ESCs bestätigen. Um die pluripotenten Eigenschaften der maGSCs weiterführend auszuarbeiten, führten wir vergleichende Studien mit ESCs bezüglich epigenetischer und apoptotischer Merkmale durch.

Im ersten Teil dieser Arbeit untersuchten wir den epigenetischen Aspekt der HistonModifikationen auf der globalen und Gen-spezifischen Ebene für aktivierende (H3K4me3 und H3K9ac) und reprimierende (H3K27me3 und H3K9me3) Modifikationen. Die mittels Durchflusszytometrie erhaltenen Ergebnisse zu globalen Histonmodifikationen konnten durch unabhängige Methoden wie Western Blot und die Immunzytochemie bestätigt werden und zeigten ein ähnliches Profil und Muster in beiden untersuchten ESCs und maGSCs. Die Gen-spezifische Analyse der Histonmodifikationen der Promotor-Regionen von Pluripotenz- und Entwicklungsbezogenen Genen zeigte die erwarteten aktiven und bivalenten Chromatinmuster. Demzufolge zeigte sich auch in diesem Aspekt eine hohe Ähnlichkeit zwischen ESCs und maGSCs.

Im zweiten Teil dieser Studie untersuchten wir die Expression von Apoptose-Genen in undifferenzierten ESCs und maGSCs und fanden eine große Übereinstimmung zwischen diesen Zelltypen. Darüber hinaus sind die Expressionsmuster von differenzierten ESCs und maGSCs miteinander identisch; ebenso ist die Expression von anti-apoptotischen Genen in dem Zelltyp stark herunter reguliert. Des Weiteren zeigte die Induktion von Apoptose durch Citrinin (CTN) keine offenkundigen Unterschiede zwischen den beiden Zelllinien. Die ,whole genome“ Transkriptom-Analyse der frühen apoptotischen ESC und maGSC Zellen ergab weiter eine große Übereinstimmung in der Antwort auf die Apoptose- 
Induktion. Darüber hinaus identifizierten wir Fgf4 und Mnda als Kandidatengene für die Regulation der Reaktion in den pluripotenten Zellen auf die Genotoxizität und Apoptose und untersuchten deren funktionelle Rolle bei diesen Prozessen. Fgf4 defiziente Zellen (Fgf4 KO) zeigten eine erhöhte Resistenz gegen induzierte Genotoxizität, wohingegen die überexprimierenden Zellen keine Veränderung aufwiesen. Im Gegensatz dazu zeigte sowohl die Überexpression als auch die Herunterregulation von Mnda (Mnda OE und Mnda DN) einen Effekt, nämlich einen Zellzyklusarrest in der G2/M Phase.

Insgesamt unterstreichen diese Studien die Ähnlichkeit der maGSCs zu ESCs auf epigenetischen und apoptotische Ebenen. Durch die funktionelle Analyse von Fgf4 und Mnda während der Reaktion der ESCs auf die induzierte Genotoxizität und Apoptose, vermuten wir weiterhin, dass diese vielleicht als erste Indikatoren für die Apoptose dienen und daher eine wichtige Rolle in der genomischen Integrität von pluripotenten Zellen spielen könnten. 


\section{Summary}

Pluripotency is the potential of cells to proliferate incessantly (self-renewal) and to develop into all cell types of the three germ layers as well as to the germ line. Recently established multipotent adult Germ-line Stem Cell (maGSC) lines are pluripotent cells derived from the unipotent Spermatogonial Stem Cells (SSCs) which acquire Embryonic Stem Cells (ESCs) properties in vitro. Since pluripotent maGSCs can have therapeutic potential in regenerative medicine by replacing the ethical problematic ESCs, several groups have studied the similarity of these cells to the "gold standard of pluripotency" the ESCs. Comparative analysis on different aspects such as miRNA expression, global transcriptome and proteome, and DNA methylation has reported the similarity between maGSCs and ESCs. To further elaborate the pluripotent cell characteristics of maGSCs, we performed comparative studies with ESCs on epigenetic and apoptotic features.

In the first part of this thesis, we analyzed the epigenetic histone modifications on global and gene-specific level for activation (H3K4me3 and $\mathrm{H} 3 \mathrm{~K} 9 \mathrm{ac})$ and repression marks (H3K27me3 and H3K9me3). The global histone modification analysis using flow cytometry, Western blot and immunocytochemistry revealed a similar profile and pattern in both ESCs and maGSCs. The gene-specific histone modification analysis at the promoter regions of pluripotency related and lineage committed genes revealed the active and bivalent chromatin signature, respectively, in both the cell types indicating the high similarity between ESCs and maGSCs.

In the second part of this study, we examined the expression pattern of apoptosis related genes in undifferentiated ESCs and maGSCs and found a very high similarity between these cell types. Moreover, the expression patterns of differentiated ESCs and maGSCs are identical to each other, while the expression of anti-apoptotic genes is highly down-regulated in these differentiated cell types. Further, induction of apoptosis using Citrinin (CTN) demonstrated no overt differences between both cell lines. The whole genome transcriptome analysis of early-apoptotic ESCs and maGSCs further revealed a similarity during cells response to apoptosis induction. Moreover, we identified Fgf4 and Mnda as candidate genes during pluripotent cells response to genotoxicity and apoptosis and investigated their functional role during these processes. Fgf4 depleted cells (Fgf4 KO) were protected against induced genotoxity, whereas alteration of Mnda expression (Mnda OE nad Mnda DN) in ESCs influence the cell cycle arrest in G2/M phase. 
Collectively, these studies emphasize the similarity of maGSCs to ESCs at epigenetic and apoptotic levels. Further, through the functional analysis of Fgf4 and Mnda in ESCs response to induced genotoxicity and apoptosis, we hypothesize that these might serve as first indicators of apoptosis and might play an important role in genomic integrity of pluripotent cells. 


\section{Introduction}

Multipotent adult Germ-line Stem Cells (maGSCs) are derived from Spermatogonial Stem Cells (SSCs) of the adult mouse testis and acquire Embryonic Stem Cells (ESCs) properties in vitro. Because maGSCs are obtained from an adult organism, they can be used as an alternative to ESCs in future regenerative medicine approaches, avoiding ethical and immunological concerns. The goal of this thesis was to characterise maGSCs concerning epigenetic and apoptotic features in comparison to ESCs, the "gold standard" for pluripotency. Hence, the ESCs molecular, epigenetic, and apoptosis-related features are described in more detail.

\subsection{Stem cells}

Stem Cells (SCs), which are found in multicellular organisms, are characterised by their ability to divide indefinitely (self renewal), while maintaining the capability to differentiate into multiple distinct cell types.

According to their differentiation potential, mammalian stem cells can be categorized into totipotent, pluripotent, multipotent, and unipotent stem cells. Totipotent stem cells derived from the fertilized oocyte or until 16-cell stage of an embryo have the potential to generate a viable organism after transfer into uterus and thereby have the unique ability to develop into embryonic germ layers (mesoderm, endoderm, and ectoderm) as well as into extraembryonic trophoblast (Suwinska et al., 2008). The totipotent cells of the 16-cell stage of morula will eventually become either the inner cell mass of the blastocyst (epiblast and hypoblast) or outer trophoblast, which will form part of placenta. Those stem cells which are derived from the inner cell mass (ICM) of the preimplantation blastocyst at around embryonic day E3.5 in the mouse are called pluripotent stem cells. These pluripotent stem cells have the ability to proliferate indefinitely, while maintaining their pluripotency. They can differentiate into all three germ layers but they are not capable to form the complete viable organism due to their inability to develop extraembryonic structures such as the placenta. The first embryo derived pluripotent stem cells are termed as ESCs and were established by Evans and Kaufman in 1981 based on culture conditions of pluripotent stem cells derived from embryonic germ cell tumors. Multipotent stem cells are restricted in their differentiation potential to only a few or all cell types of one germ layer, for example hematopoietic SCs, which give rise to all blood cell lineages (Orkin and Zon, 2008), and epidermal SCs, 
which ensure homeostasis of the skin epidermis (Blanpain and Fuchs, 2009). Lastly, unipotent stem cells are characterized by self-renewal and differentiation into only one type of cell or tissue such as SSCs in the adult testis producing only sperms. Among all these stem cells, pluripotent stem cells hold the great promise for future regenerative medicine applications because of their high proliferation capacity, self renewal and differentiation potential.

Apart from ESCs, there are several types of pluripotent stem cells that have been established: Embryonic carcinoma cells (ECCs) derived from germ-cell tumors from either testis or ovary (Kleinsmith and Pierce, 1964; Finch and Ephrussi, 1967; Kahan and Ephrussi, 1970), epiblast stem cells (EpiSCs) derived from epiblast of post-implantation embryo (E5.5-E6.5) (Brons et al., 2007; Tesar et al., 2007) and embryonic germ cells (EGCs) which are derived from in vitro culture of primordial germ cells (PGCs) (Matsui et al., 1992; Resnick et al., 1992). Moreover, the pluripotent stem cells derived from neonatal mouse testis are termed as multipotent germ-line stem cells (mGSCs) (KanatsuShinohara et al., 2004), while the adult mouse testis derived cells are called maGSCs (Guan et al., 2006). Recent groundbreaking discovery in the field of stem cell biology has defined a cock-tail of transcription factors (Oct4, Sox2, Klf4, c-Myc, Nanog, and Lin28) whose forced expression is sufficient to reprogram mouse and human fibroblasts into pluripotent cells termed as induced pluripotent stem cells (iPSCs) (Takahashi et al., 2007; Takahashi and Yamanaka, 2006; Yu et al., 2007). The developmental origin of various pluripotent stem cells are depicted in figure 2.1. The defining molecular, epigenetic and apoptotic features of pluripotent cells particularly in ESCs will be highlighted further. Apart from ESCs, the pluripotent maGSCs and their characteristics are summarized.

\subsection{Embryonic stem cells}

Embryonic stem cells (ESCs) are pluripotent in nature and have the ability to differentiate into all three germ layers (Suda et al., 1987; Chambers and Smith, 2004; O'Shea, 2004) as well as to germ cells (Geijsen et al., 2004; Nayernia et al., 2006). ESCs have three characteristic features: self-renewal, pluripotency and chimera formation (Evans and Kaufman, 1981; Martin, 1981). Even after prolonged culture periods, they retain full responsiveness to differentiation signals and do not show any bias in the differentiation potential. 


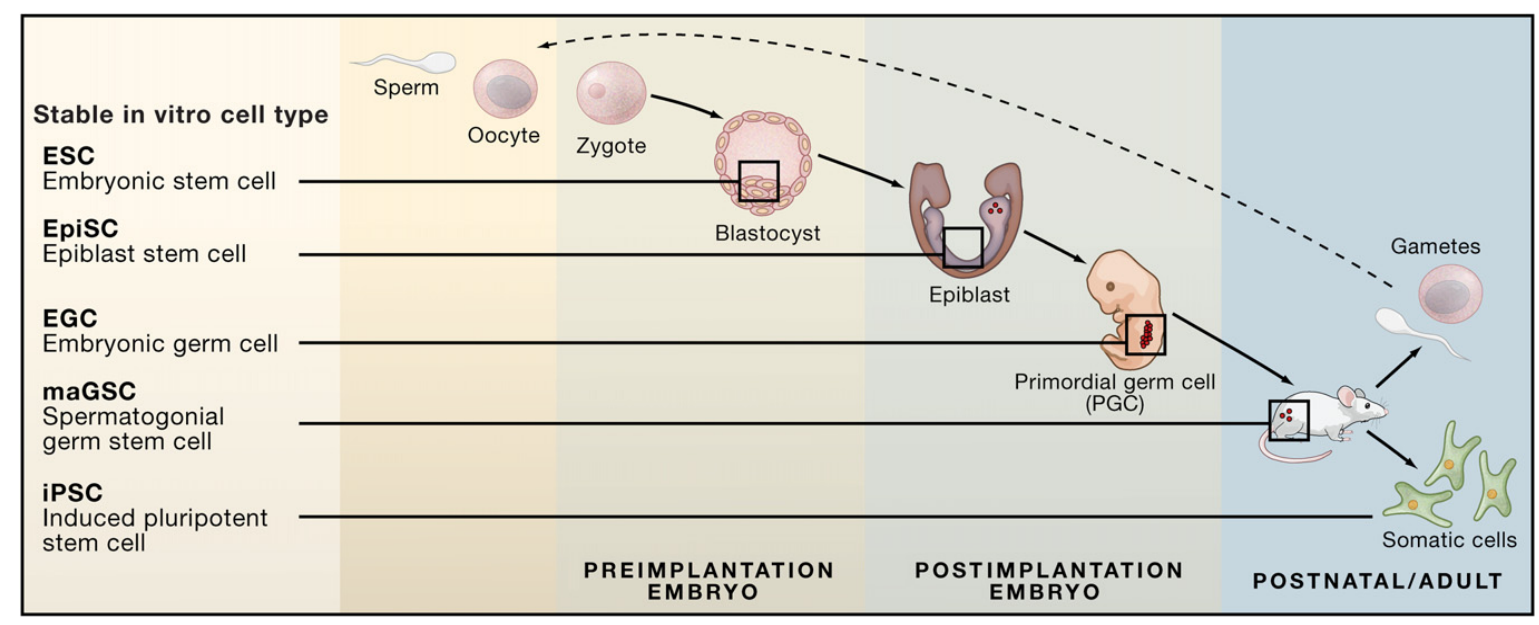

Figure 2.1. Developmental origin of different pluripotent stem cell types. Different types of pluripotent cells can be derived by explanting cells at various stages of early embryonic development or adult testis and cultured under defined culture conditions. Induced pluripotent stem cells (iPSCs) can be derived by direct reprogramming of somatic cells in vitro by forced expression of defined transcription factors. (Figure adapted from: Hanna et al., 2010).

To maintain pluripotent status of ESCs and to prevent their spontaneous differentiation in culture, it requires certain culture conditions like the culture medium containing fetal bovine serum, cytokine LIF (Leukemia Inhibitory Factor) as well as feeder layer of mitotically inactive Murine Embryonic Fibroblasts (MEFs). The absence of feeder layer and LIF from culture conditions leads to spontaneous differentiation into derivates of all three germ layers. (Doetschman et al., 1985; Suda et al., 1987; Geijsen et al., 2004; Nayernia et al., 2006). Addition of retinoic acid (RA) to the culture medium induces and accelerates differentiation into several lineages (Doetschman et al., 1985; Slager et al., 1993; Dinsmore et al., 1996; Dani et al., 1997; Drab et al., 1997). Beside classical culture conditions, recent studies report feeder-free and serum-free methods by coating the culture dishes with animal derived materials, such as collagen, gelatin and complex matrix (Draper et al., 2004; Hayashi et al., 2007; Chen et al., 2008).

\subsubsection{Molecular characteristics of ESCs}

To maintain their stem cell characteristics, ESCs are endowed with complex mechanism of genetic (gene expression level) and epigenetic (DNA methylation and histone modification) regulators. A complex network of transcription factors and chromatin remodelling factors is involved in the regulation of pluripotency and selfrenewal of ESCs. 
External factors like LIF (Smith et al., 1988) contribute to the self-renewal by activating signal transduction cascades resulting in activation of $\underline{\text { Signal transducer and }}$

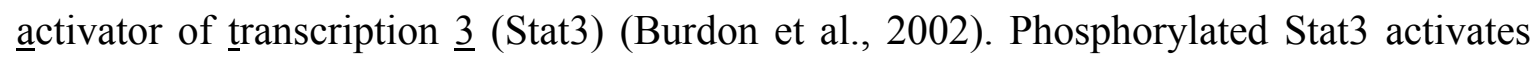
the downstream genes $c-M y c$ and Klf4 (Cartwright et al., 2005; Niwa et al., 2009) which are involved in the regulation of proliferation (Ema et al., 2008; Vole et al., 2008). Other extrinsic factors like Wnt proteins (Wnt3a, Wnt5a and Wnt6) and Fgf4 are also implicated in the regulation of pluripotency of ESCs (Sato et al., 2004; Hao et al., 2006; Ogawa et al., 2006) where Fgf4 is involved in the network regulation of differentiation (Kunath et al., 2007).

The intrinsic transcriptional circuit consisting of Oct4, Nanog, and Sox2 plays a central role in maintenance of pluripotency network in ESCs (Nichols et al., 1998; Niwa et al., 2000; Avilion et al., 2003; Chambers et al., 2003; Mitsui et al., 2003). Inactivation of any one of these genes leads to embryonic lethality and impedes the generation of ESCs (Okamoto et al., 1990; Palmieri et al., 1994; Nichols et al., 1998; Avilion et al., 2003; Mitsui et al., 2003). Apart from these transcription factors, proteins like Sall 4 (SakakiYumoto et al., 2006), Esrrb (Ivanova et al., 2006), Zfx (Galan-Caridad et al., 2007) as well as Dax1, Nr5a2 and Tcfep211 (Kim et al., 2008) are also involved in transcriptional regulatory network by interacting with Oct4 in a multiple transcriptional factor complex (Chen et al., 2008; Kim et al., 2008).

\subsubsection{Epigenetic features of ESCs}

Although the gene expression profiling provides information about the genes which are expressed by specific cell types and their relative expression, it provides us with no or only scarce information about genes which are not expressed in ESCs. Moreover, gene-expression data do not discriminate between genes that are subjected to active expression and those that are kept in primed state for expression in later stages of development (i.e., expression in response to specific differentiation cues). The mechanisms which govern gene expression without changes in DNA sequence are referred as epigenetic mechanisms mediated by chromatin and their post-translational modifications.

The emerging data suggest that chromatin functions as a key regulator in fine tuning the pluripotency of ESCs. The basic unit of chromatin structure is the nucleosome, which contains 147 bp of DNA wrapped nearly twice around a basic core histone octamer 
(two copies each of histones, H2A, H2B, H3 and H4) (Fig. 2.2A). Several posttranslational modifications such as acetylation, methylation, phosphorylation, ubiquitination and ADP-ribosylation are known to occur at the N-terminal tails of histones (Jenuwein and Allis, 2001) (Fig. 2.2B). These histone modifications are known to control structural chromatin compaction and regulate gene transcription, altering the positioning/spacing of nucleosomes, modulating contacts between histones and DNA, and recruitment of co-factors (Narlikar et al., 2002). In general, modifications like methylation at lysine 4 of histone $\mathrm{H} 3(\mathrm{H} 3 \mathrm{~K} 4)$, together with acetylation at $\mathrm{H} 3 \mathrm{~K} 9$ (H3K9ac) are associated with gene activation, whereas methylation at $\mathrm{H} 3 \mathrm{~K} 9$ and $\mathrm{H} 3 \mathrm{~K} 27$ is linked to gene repression (Martin and Zhang, 2005; Sims et al., 2003).

A.

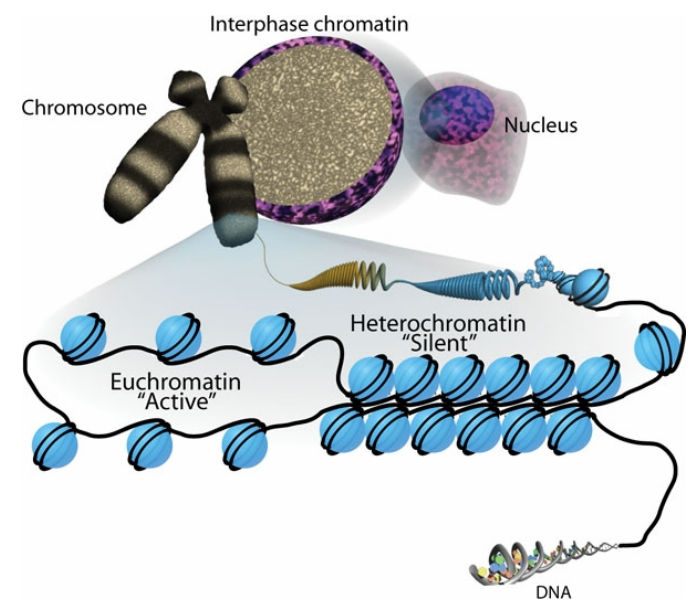

B.

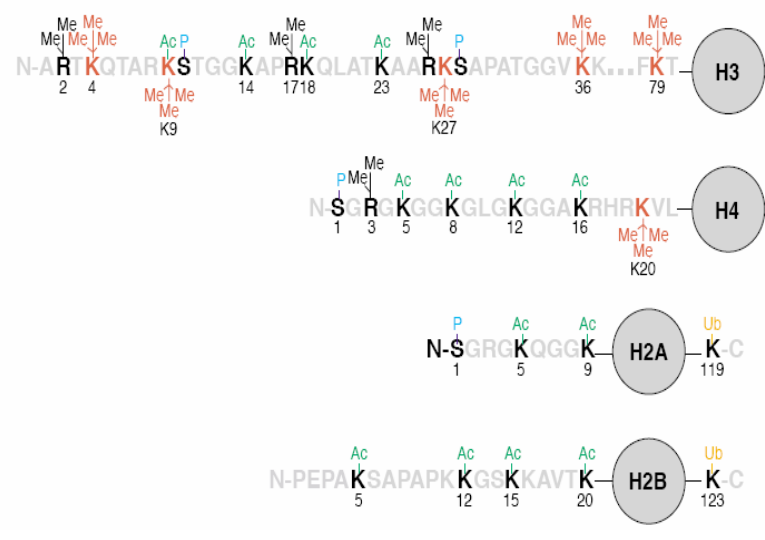

Figure 2.2. Chromatin organisation and its post-translational histone modifications. A: The basic unit of chromatin organization is the nucleosome which comprises 147 bp of DNA wrapped around a core of histone proteins. Nucleosomes can be organized into higher order structures and the level of packaging can have profound consequences on all DNA-mediated processes including gene regulation. Euchromatin is associated with an open chromatin conformation and this structure is permissible for transcription whereas heterochromatin is more compact and refractory to factors that need to gain access to the DNA template. Nucleosome positioning and chromatin compaction can be influenced by multifactorial processes including modification to both histones and DNA. (Figure adapted from: Sha and Boyer, 2009). B: Post-translational covalent modifications of histone (H2A, H2B, H3 and H4) N-terminal amino acids associated with methylations $(\mathrm{Me})$, acetylations $(\mathrm{Ac})$ and ubiquitination $(\mathrm{Ub})$ on different Lysine $(\mathrm{K})$ positions. (Figure adapted from: Sims et al., 2003)

At the global level, the chromatin of undifferentiated ESCs is characterized by less heterochromatic and more transcription permissiveness ability, with hyperacetylation of $\mathrm{H} 3$ 
and H4 proteins. During differentiation of ESCs, these characteristics are progressively lost leading to the clustering of pericentric heterochromatin and increased deacetylation of histones (Meshorer and Misteli, 2006). Characteristic for undifferentiated ESCs are the unmethylated $\mathrm{CpG}$ islands at the promoter regions of pluripotency-related genes such as Oct4, Sox2, and Nanog (Mattout and Meshorer, 2010). These pluripotency-associated genes are also associated with activating histone modification marks like acetylation at H3K9 (H3K9ac) and trimethylation at H3K4 (H3K4me3) and H3K36 (H3K36me3) (Efroni et al., 2008). Recent studies on the chromatin of ESCs at the genome-wide level and at the level of individual loci revealed that many genes in ESCs carry histone modifications associated with gene activation as well as gene repression (Bernstein et al., 2006). This unusual "bivalent" chromatin structure in which both active and repressive marks are present at key developmental regulation genes is a hallmark of ESCs.

\subsubsection{Apoptosis-related properties of ESCs}

It is well known that ESCs give rise to all cell types in the entire organism, so the mechanisms has to be highly efficient in maintaining the genomic integrity and to avoid organic failure with fatal consequences for the organism. ESCs are also known to be highly sensitive to genotoxic stress caused by radiation/UV and chemical substances leading to DNA damage. They are suggested to evolve with sensitive mechanisms to maintain genomic integrity by either efficient DNA damage repair or elimination of defective cells by apoptosis (Chuykin et al., 2008). In agreement with this hypothesis, the mutation frequencies and mitotic recombination events were shown to be 100 -fold lower in ESCs than in somatic cells (Hong et al., 2006; Stambrook, 2007). Upon induction of DNA damage, ESCs do not activate G1/S phase checkpoint (Malashicheva et al., 2002; Fluckiger et al., 2006) and G1 arrest, partly due to low p53 activation and also low expression levels of p53-target CDK inhibitor p21/Wafl gene (Aladjem et al., 1998; Malashicheva et al., 2000; Burdon et al., 2002; Stead et al., 2002). In contrast to somatic cells, which do not show any single strand breaks (SSBs), normal wild-type ESCs were shown to contain SSBs marked by $\gamma \mathrm{H} 2 \mathrm{~A} . \mathrm{X}$, but do not activate the DNA damage machinery (Chuykin et al., 2008). It was also shown that the checkpoint kinase, Chk2, normally mediating the checkpoint in somatic cells, does not phosphorylate its substrates such as p53 and Cdc25A in ESCs which leads to the lack of G1 arrest (Hong and Stambrook, 2004; Stambrook, 2007). Some studies have shown inefficient translocation of 
p53 to the nucleus after DNA damage in ESCs (Aladjem et al., 1998; Chuykin et al., 2008; Hong and Stambrook, 2004). In contrast to the known deregulated p53 function in ESCs, it was shown that activation of DNA damage leads to p53-mediated suppression of Nanog, but not to the activation of DNA damage response (Lin et al., 2005). Further, it was shown that the suppression of Nanog leads to differentiation of damaged cells and subsequent elimination of differentiated cell by p53 mediated mechanisms (Lin et al., 2005).

In non-apoptotic condition, the cell cycle of ESCs differs from that of somatic cells to maintain the self-renewal. Opposed to $\sim 24$ hours duration of cell cycle in somatic cells, the cell cycle of ESCs is shorten to $\sim 11-16$ hours of rapid proliferation rate with the abbreviated G1 phase. The activity of cyclin E-CDK2 is constitutive and independent from cell-cycle phase, which allows ESCs to transit from M phase directly to late G1 phase. This is in contrast to somatic cells, where the cyclin E-CDK2 activity is periodic with the peak at the G1 to S transition (Becker et al., 2006). Furthermore, the absence of early G1 from ESCs allows them to avoid the differentiation-induction effects of mutagen activated protein kinase (MAPK) pathway which is active during early G1 in somatic cells (Burdon et al., 1999; Burdon et al., 2002).

\subsection{Stem cells in the adult testis}

Unipotent stem cells in mammalian adult testis, the so called SSCs are located in the seminiferous tubule and are responsible for maintaining spermatogenesis throughout life of the male. Previous studies have shown the derivation of pluripotent stem cells from SSCs obtained from neonatal mouse testis (Kanatsu-Shinohara et al., 2004) as well as from adult mouse testis (Guan et al., 2006). SSCs isolated from adult mouse testis and cultured under certain culture conditions acquire ESCs properties and are named maGSCs. This pluripotent cell type is able to differentiate into derivatives of the three germ layers. After injection into blastocysts, maGSCs contribute to chimera formation with germ line transmission and after injection into immunodeficient mice they form teratoma (Guan et al., 2006). Subsequently, the derivation of pluripotent stem cells from adult mouse testis was reported by other groups (Seandel et al., 2007; Izadyar et al., 2008; KanatsuShinohara et al., 2008; Ko et al., 2009). Furthermore, the derivation of pluripotent stem cells from human SSCs was also reported recently (Conrad et al., 2008; Golestaneh et al., 2009; Kossack et al., 2009; Mizrak et al., 2010). 
The therapeutic potential held by maGSCs as they can circumvent ethical and immunological concerns prompted for detailed characterisation of these cells in comparison to ESCs. Towards this end, our group has studied maGSCs at the level of microRNA expression, global mRNA and protein expression (transcriptome and proteome, respectively) and found high similarity between ESCs and maGSCs (Qin et al., 2007; Zovoilis et al., 2008; Dihazi et al., 2009; Meyer et al. 2010). Furthermore, analysis of the epigenetic features of maGSCs by global and gene-specific DNA methylation revealed that maGSCs are highly similar to pluripotent ESCs (Zechner et al., 2009).

\subsection{Objectives}

The aim of this study was to further characterise the pluripotent cell features of maGSCs at the epigenetic and apoptotic level in comparison to ESCs with the following objectives:

1. At the epigenetic level, analysis of global histone modification profiles of maGSCs in comparison to ESCs.

2. Elucidating the patterns of histone modifications at pluripotency-related and developmentally regulated genes in maGSCs and ESCs.

3. Analysis of apoptosis-related gene expression profiles of undifferentiated and differentiated maGSCs in comparison to undifferentiated and differentiated ESCs.

4. Finding the similarities between undifferentiated maGSCs and ESCs regarding their response to the induction of apoptosis.

5. Identification of novel apoptosis-related genes in pluripotent cells using transcriptome analysis of early-apoptotic maGSCs and ESCs.

6. Elucidating the role of novel apoptosis-related genes in induced apoptosis/genotoxicity. 


\section{Results}

The present thesis is concentrated on the detailed molecular characterisation of maGSCs at apoptotic and epigenetic features in comparison to ESCs. The results of this thesis are summarised in two following manuscripts, where one has been published and the other has been submitted.

3.1. Global and gene-specific histone modification profiles of mouse multipotent adult germline stem cells.

3.2. Apoptosis-related gene expression profiles of mouse ESCs and maGSCs: Identification and implication of Fgf4 and Mnda expression in pluripotent cell responses to genotoxicity. 


\subsection{Global and gene-specific histone modification profiles of mouse multipotent adult germline stem cells}

The first part of the thesis describes the comparative analysis of ESCs and maGSCs at epigenetic level. The global histone modification levels of maGSCs were analysed in comparison to ESCs using immunocytochemistry, Western blot and flow cytometry methods. The results revealed the similar levels of histone modifications (active: H3K4me3 and H3K9ac, and repressive: H3K9me3 and H3K27me3) and their identical nuclear distribution patterns in both cell lines. Gene-specific histone modification analysis also revealed comparable levels of those epigenetic marks at the promoter regions of the pluripotency regulating genes Oct4, Sox 2 and Nanog in ESCs as well as in maGSCs. In addition, Hoxa11, a key regulator of early embryonic development showed the ESCtypical bivalent chromatin conformation with enrichment for both the activating H3K4me3 and the repressive H3K27me3 modification in maGSCs. Taken together the global and gene specific histone modification analysis revealed the high similarity between ESCs and maGSCs at the epigenetic level.

Authors: Tatjana Khromov, D.V. Krishna Pantakani, Jessica Nolte, Marieke Wolf, Ralf Dressel, Wolfgang Engel, and Ulrich Zechner

Status: Published in Molecular Human Reproduction, Volume 17 (3) Mar, 2011, pp. 166174

Impact Factor: 3.506

\section{Author contributions to the work:}

1. Tatjana Khromov: Establishment of the ChIP technique, conception and design of experiment, data collection, data analysis, data interpretation, writing.

2. D.V. Krishna Pantakani: Design, data collection, data interpretation.

3. Jessica Nolte: Data interpretation, conception.

4. Marieke Wolf: Data collection.

5. Ralf Dressel: FACS data analysis, design.

6. Wolfgang Engel: Conception, financial support

7. Ulrich Zechner: Conception, design, data interpretation, financial support, writing. 


\title{
Global and gene-specific histone modification profiles of mouse multipotent adult germline stem cells
}

\author{
Tatjana Khromov', D.V. Krishna Pantakani ', Jessica Nolte', \\ Marieke Wolf ${ }^{2}$, Ralf Dressel ${ }^{3}$, Wolfgang Engel ', and Ulrich Zechner ${ }^{2, *}$ \\ 'Institute of Human Genetics, Georg-August-University Goettingen, Heinrich-Dueker-Weg 12, 37073 Goettingen, Germany ${ }^{2}$ Institute of \\ Human Genetics, Johannes Gutenberg-University Mainz, Langenbeckstraße I, 55 I0I Mainz, Germany ${ }^{3}$ Department of Cellular and Molecular \\ Immunology, Georg-August-University Göttingen, Humboldtallee 34, 37073 Göttingen, Germany \\ *Correspondence address. Tel: +49-6|3|-17-5850; Fax: +49-6|3|-17-5689; E-mail: ulrich.zechner@unimedizin-mainz.de \\ Submitted on June 6, 2010; resubmitted on October 2, 2010; accepted on October 5, 2010
}

\begin{abstract}
We previously reported the generation of multipotent adult germline stem cells (maGSCs) from spermatogonial stem cells (SSCs) isolated from adult mouse testis. In a later study, we substantiated the pluripotency of maGSCs by demonstrating their close similarity to pluripotent male embryonic stem cells (ESCs) at the epigenetic level of global and gene-specific DNA methylation. Here, we extended the comparative epigenetic analysis of maGSCs and male ESCs by investigating the second main epigenetic modification in mammals, i.e. global and gene-specific modifications of histones ( $\mathrm{H} 3 \mathrm{~K} 4$ trimethylation, $\mathrm{H} 3 \mathrm{~K} 9$ acetylation, $\mathrm{H} 3 \mathrm{~K} 9$ trimethylation and $\mathrm{H} 3 \mathrm{~K} 27$ trimethylation). Using immunofluorescence staining, flow cytometry and western blot analysis, we show that maGSCs are very similar to male ESCs with regard to global levels and nuclear distribution patterns of these modifications. Chromatin immunoprecipitation real-time PCR analysis of these modifications at the gene-specific level further revealed modification patterns of the pluripotency marker genes Oct4, Sox2 and Nanog in maGSCs that are nearly identical to those of male ESCs. These genes were enriched for activating histone modifications including H3K4me3 and $\mathrm{H} 3 \mathrm{~K} 9 \mathrm{ac}$ and depleted of repressive histone modifications including $\mathrm{H} 3 \mathrm{~K} 27 \mathrm{me} 3$ and $\mathrm{H} 3 \mathrm{~K} 9 \mathrm{me}$. In addition, Hoxal I, a key regulator of early embryonic development showed the ESC-typical bivalent chromatin conformation with enrichment of both the activating $\mathrm{H} 3 \mathrm{~K} 4 \mathrm{me} 3$ and the repressive H3K27me3 modification also in maGSCs. Collectively, our results demonstrate that maGSCs also closely resemble ESCs with regard to their chromatin state and further evidence their pluripotent nature.
\end{abstract}

Key words: multipotent adult germline stem cells / pluripotency / histone modifications / epigenetics

\section{Introduction}

Embryonic stem cells (ESCs) derived from the inner cell mass of preimplantation mouse blastocysts are pluripotent in nature (Evans and Kaufman, 198I; Martin, 198I) and have the ability to differentiate into all three germ layers (Chambers, 2004; O'Shea, 2004; Suda et al., 1987) as well as germ cells (Geijsen et al., 2004; Nayernia et al., 2006). For the maintenance of these functional properties, an ESC genome must be highly plastic to sustain pluripotency on one hand and to enable differentiation to any other cell type on the other hand. Numerous studies already demonstrated that epigenetic mechanisms play a key role in regulating stemness and lineage specification (Meshorer and Misteli, 2006).

The main components of the epigenetic code are DNA methylation (Weber and Schubeler, 2007) and post-translational modifications of histone proteins (Jenuwein and Allis, 200I; Margueron et al., 2005). The basic unit of chromatin structure is the nucleosome, which is composed of I 46 bp of DNA wrapped around a basic core histone octamer (two copies each of histones, H2A, H2B, H3 and H4). The $\mathrm{N}$-terminal tails of histones are subject to diverse post-translational modifications such as acetylation, methylation, phosphorylation, ubiquitination and ADP-ribosylation (Jenuwein and Allis, 200I). These histone modifications are known to control structural chromatin compaction and regulate gene transcription by establishing higher order interactions between neighboring nucleosomes, altering the positioning/spacing of nucleosomes, and modulating contacts between histones and DNA (Narlikar et al., 2002). Generally, modifications like methylation at H3K4 (lysine 4 of histone $\mathrm{H} 3$ ), H3K36 and H3K79 residues, together with acetylation at $\mathrm{H} 3 \mathrm{~K} 9(\mathrm{H} 3 \mathrm{~K} 9 \mathrm{ac})$ are associated with gene activation, whereas methylation at $\mathrm{H3}$ K9, H3K27 and H4K2O residues are linked to gene repression (Sims et al., 2003; Martin and Zhang, 2005).

In comparison with differentiated cells, ESCs have highly dispersed, euchromatic nuclei, increased levels of activating histone modifications 
like $\mathrm{H} 3$ and $\mathrm{H} 4$ acetylation and diminished levels of repressive histone modifications linked to heterochromatin like H3K9 trimethylation (H3K9me3) (Meshorer and Misteli, 2006). It was also evident that the promoter regions of genes active in ESCs, i.e. pluripotency genes like Oct4, Sox2 and Nanog as well as housekeeping genes like Gapdh are marked by $\mathrm{H} 3$ and H4 acetylation (Hattori et al., 2004; Kimura et al., 2004; O'Neill et al., 2006) as well as solely by H3K4 trimethylation (H3K4me3; Pan et al., 2007). In addition, bivalently marked chromatin, i.e. the co-occurrence of the activating $\mathrm{H} 3 \mathrm{~K} 4$ trimethylation and the repressive $\mathrm{H} 3 \mathrm{~K} 27$ trimethylation (H3K27me3) catalyzed by Trithorax- and Polycomb-group proteins, respectively, is a hallmark of key developmental lineage-control genes not expressed in mouse and human ESCs (Ringrose and Paro, 2004; Azuara et al., 2006; Bernstein et al., 2006). These unique bivalent histone modification patterns are assumed to be essential for simultaneously silencing and priming these lineage-control genes for later activation in ESCs. Further, this bivalent conformation was shown to be resolved during the differentiation of ESCs into neural precursor cells. Promoters of genes that are markedly induced in neural precursor cells retained H3K4me, but lost H3K27me (Bernstein et al., 2006). In contrast, promoters of genes that remain silenced in neuronal precursor cells lost H3K4me, whereas they were still associated with H3K27me. Thus, in ESCs, these key developmental lineage-control genes seem to carry a unique combination of activating and repressing histone methylation marks that are normally detected exclusively in euchromatic, respectively, heterochromatic regions of differentiated somatic cells.

Spermatogonial stem cells (SSCs) of the testis are responsible for maintaining the spermatogenesis throughout male adulthood. Several studies already reported that multipotent germline stem cells (mGSCs) that are morphologically similar to ESCs and express the same group of pluripotency-related genes can be generated from SSCs of neonatal and adult mouse testis suggesting that germline stem cells retain the ability to give rise to pluripotent cells in vitro (Kanatsu-Shinohara et al., 2004; Guan et al., 2006; Seandel et al., 2007; Izadyar et al., 2008; Kanatsu-Shinohara et al., 2008; Ko et al., 2009). These mGSCs are able to differentiate into derivatives of the three germ layers in vitro and can contribute to chimeras with germ line transmission, when injected into blastocysts. mGSCs from adult mouse testis, so-called multipotent adult germline stem cells (maGSCs) were firstly isolated and described by our group. It was recently shown that maGSCs and ESCs express the same clusters of microRNAs (miRNAs; Zovoilis et al., 2008) previously thought to be ESC-specific (Houbaviy et al., 2003) and also share the same proteomic profiles (Dihazi et al., 2009). More recently, another study described similarities between maGSCs and ESCs at the epigenetic level by investigating the DNA methylation status of several imprinted genes, pluripotency marker genes as well as global DNA methylation patterns in the undifferentiated and differentiated state (Zechner et al., 2009).

In the present study, we comparatively studied the global and genespecific histone modification profiles (H3K4me3, H3K9ac, H3K9me3 and $\mathrm{H} 3 \mathrm{~K} 27 \mathrm{me} 3$ ) of maGSCs and ESCs. We demonstrate very strong similarities between maGSCs and ESCs regarding global levels and nuclear distribution patterns of these modifications. We further show that maGSCs and ESCs display nearly identical gene-specific patterns of these modifications at the pluripotency marker genes Oct4,
Sox2 and Nanog as well as the key developmental lineage-control gene Hoxal I. Collectively, the observed similarities of maGSCs and ESCs at the chromatin level further support the pluripotent nature of maGSCs.

\section{Materials and Methods}

\section{Cell lines and cell culture}

The three mouse maGSC lines maGSC 129/Sv, maGSC C57BL/6 and maGSC Stra8 were derived from wild-type 129/Sv, wild-type C57BL/6 and transgenic Stra8-EGFP/Rosa26-LacZ-background mouse strains, respectively, without genetic selection and solely by morphological identification on the basis of formation of ESC-like colonies as previously described (Zechner et al., 2009). The corresponding male ESC lines ESC 129/Sv, ESC C57BL/6 and ESC Stra8 were isolated as described previously and used for comparison (Nagy et al., 1993; Zechner et al., 2009). The undifferentiated cell lines were maintained on Mitomycin Cinactivated mouse embryonic fibroblasts (MEFs) and cultured in standard ESC culture medium consisting of DMEM (PAN, Aidenbach, Germany) supplemented with $20 \%$ defined fetal bovine serum (PAN), I\% penicillin/streptomycin, $0.1 \mathrm{mM}$ non-essential amino acids, $2 \mathrm{mM}$ L-glutamine, I mM sodium pyruvate, $0.1 \mathrm{mM} \beta$-mercaptoethanol (all the above ingredients are from Gibco BRL, Eggenstein, Germany) and $1000 \mathrm{U} / \mathrm{ml}$ leukemia inhibitory factor (Chemicon, Temecula, CA, USA). MEFs were grown in standard fibroblast culture conditions.

\section{Flow cytometry}

Flow cytometric experiments were performed essentially as described previously (Obier and Muller, 2010). Feeder cell-depleted single cell suspensions of ESC 129/Sv and maGSC 129/Sv ( $\sim 500000$ cells per sample) were washed with phosphate-buffered saline (PBS) and resuspended in $300 \mu \mathrm{l}$ of freshly prepared fixation buffer [21.4 mM Tris$\mathrm{HCl}, \mathrm{pH} 7.1,21.4 \mathrm{mM} \mathrm{NaCl}, 80.25 \% \mathrm{v} / \mathrm{v}$ deionized formamide, $1.07 \%$ bovine serum albumin $(B S A)$ in $\mathrm{H}_{2} \mathrm{O}$ ]. The cell suspensions were then incubated for $10 \mathrm{~min}$ at $80^{\circ} \mathrm{C}$, allowed to cool down to room temperature (RT) and centrifuged for $5 \mathrm{~min}$ at $960 \mathrm{~g}$. Supernatant was removed and the transparent cell pellets were resuspended in $200 \mu \mathrm{l}$ of PBS. After another pelleting step, cells were washed two times in fluorescence-activated cell sorting (FACS) buffer (PBS, $0.3 \% \mathrm{BSA}, 0.1 \% \mathrm{NaN}_{3}, \mathrm{PH} 7.4$ ), and resuspended in $100 \mu \mathrm{l}$ of FACS buffer containing the following antibodies at I of 100 dilution: anti-H3 (ab 179I; abcam), anti-H3K3me3 (39159; Active Motif), anti-H3K9me3 (07-442; Millipore), anti-H3K9ac (ab 108I2; Abcam) and anti-H3K27me3 (07-449; Millipore). After incubation for I $h$ at RT, the cells were washed twice in I ml FACS buffer and incubated with anti-rabbit-phycoerythrin (eBioscience) at I of 100 dilution for $45 \mathrm{~min}$ at RT followed by two washings in FACS buffer and resuspension in $300 \mu$ I FACS buffer. The flow cytometric measurements were performed on a FACSCalibur flow cytometer (Becton Dickinson, Heidelberg, Germany) and analyzed with CellQuestPro software (Becton Dickinson).

\section{Immunofluorescence staining}

ESCs and maGSCs grown in the presence of feeder layers on round cover slips coated with gelatine were washed two times with PBS and fixed with 4\% paraformaldehyde in PBS for 30 min at RT. Cells were then incubated with $50 \mathrm{mM} \mathrm{NH}_{4} \mathrm{Cl}$ in PBS for 10 min and permeabilized by three incubations with $0.2 \%$ Triton $X-100$ in PBS for 4 min each at RT. The four different histone modifications were detected with the antibodies also used for flow cytometry (see above) at I of 100 dilution by incubating $\mathrm{I} h$ at RT, followed by incubation for I $\mathrm{h}$ with a secondary antibody conjugated with Cy3. Cells were also stained for OCT4 using a mouse 
monoclonal antibody (MAB4419; Millipore) followed by detection using a secondary antibody conjugated with Alexa-488 (Invitrogen, Karlsruhe, Germany). The cover slips were mounted with Vectashield DAPI mounting medium (Vector Laboratories, Burlingame, CA, USA) and images were taken using a fluorescence microscope (Olympus, Hamburg, Germany).

\section{Western blot analysis}

The cells were resuspended in a buffer containing $10 \mathrm{mM}$ Tris/ $\mathrm{HCl} \mathrm{pH}$, I mM EDTA, 2.5\% SDS supplemented with protease inhibitor cocktail tablet (Roche, Mannheim, Germany) for 30 min on ice and lysed using sonication. Following centrifugation at $16000 \mathrm{~g}$ for $30 \mathrm{~min}$ at $4^{\circ} \mathrm{C}$, the supernatant $(\sim 40 \mu \mathrm{g})$ was resolved on $4-12 \%$ SDS-PAGE (Invitrogen) and electro-transferred onto nitrocellulose membrane. Immunoblots were performed with the antibodies against histone $\mathrm{H} 3$ and the four different histone modifications also used for flow cytometry (see above except H3K9ac which was analyzed with antibody 07-352 from Millipore) at I of 2000 dilution. An antibody against alpha-tubulin was used as a loading control. After incubation with a horseradish peroxidase-conjugated secondary antibody, specific bands were detected using Western Blotting Luminol Reagent kit (Santa Cruz Biotechnology, Inc., USA).

\section{Chromatin immunoprecipitation real-time PCR assays}

The cultured cells were cross-linked with $1 \%$ formaldehyde in culture medium for 10 min at RT, and cross-linking was stopped by adding glycine (to a final concentration of $125 \mathrm{mM}$ ). Pellets containing $2 \times 10^{6}$ cells were lysed by brief incubation in buffer containing $10 \mathrm{mM}$ Tris $-\mathrm{HCl} \mathrm{pH} 7.5$, $10 \mathrm{mM} \mathrm{NaCl}, 3 \mathrm{mM} \mathrm{MgCl}, 0.5 \%$ IGEPAL and I mM phenylmethylsulphonyl fluoride (PMSF) followed by centrifugation and another incubation in lysis buffer supplemented with I $\mathrm{mM} \mathrm{CaCl}_{2}$ and $4 \%$ IGEPAL. The chromatin was then sonicated using a Branson 250 Sonifier to obtain an average DNA fragment length of $\sim 200-500$ bp. Soluble chromatin was incubated for $3 \mathrm{~h}$ at $4^{\circ} \mathrm{C}$ with and without (negative-control) antisera $(3-5 \mu \mathrm{g}$ ) against the four different histone modifications also used for flow cytometry (see above except H3K9ac which was analyzed with antibody 07-352 from Millipore) and complexed with protein-A sepharose beads overnight at $4^{\circ} \mathrm{C}$. In the next step, the beads were washed with wash buffer I $(20 \mathrm{mMTris}-\mathrm{Hcl}$ $\mathrm{pH}$ 8.0, 2 mM EDTA, I.0\% Triton X-100, $150 \mathrm{mM} \mathrm{NaCl}$ and I mM PMSF) followed by washing with wash buffer II (wash buffer I supplemented with $0.1 \% \mathrm{SDS}, 500 \mathrm{mM} \mathrm{NaCl})$ and wash buffer III $(10 \mathrm{mM}$ Tris- $\mathrm{HCl} \mathrm{pH} \mathrm{8.0,}$ I mM EDTA, $250 \mathrm{mM} \mathrm{LiCl,}$ 0.5\% IGEPAL, 0.5\% Deoxycholate). The chromatin was eluted from the beads by adding elution buffer $(25 \mathrm{mMTris}-\mathrm{HCl}$, $10 \mathrm{mM}$ EDTA, $0.5 \% \mathrm{SDS}$ ) and incubating for $\mathrm{I} \mathrm{h}$ at $65^{\circ} \mathrm{C}$. Reverse crosslinking was performed by adding elution buffer containing proteinase $\mathrm{K}$ followed by incubation for I h at $65^{\circ} \mathrm{C}$. Finally, the DNA was extracted, purified and eluted in $40 \mu$ l of Tris-EDTA buffer using the Wizard SV Gel and PCR clean-up System (Promega). Quantification of precipitated DNA was carried out using SYBR green (Invitrogen)-based real-time qPCR amplification with the following primer sets: Beta-Actin- $F$, 5'-CCCCAACACACCT AGCAAAT-3' and Beta-Actin-R, 5'-ACTGCCCCATTCAATGTCTC-3'; Oct4-F, 5'-TGGGCTGAAATACTGGGTTC-3' and Oct4-R, 5'-TTGA ATGTTCGTGTGCCAAT; Sox2-F, 5'-AGGTGGGTGGAGTAGGGAA TTAG-3' and Sox2-R, 5'-CGACTGTCCAACTAGTATTTCAGG-3'; Nanog-F, 5'-TTGGGACCAGCTAGAGCAAT-3' and Nanog-R, 5'-CCAGGCTTGTCTACCACCAT-3'; Hoxal I-F, 5'-AGAAGTGCCTCT GGCTCTGA-3' and Hoxal I-R, 5'-GATTTGCACGGTGACTTGATT-3'. The qPCR data of each two biological and two independent technical replicates were calculated and expressed as percentage of input DNA.

\section{Results}

\section{Genome-wide histone modification analysis of maGSCs}

We firstly employed FACS-based detection in formamide-fixed cells to compare the global histone modification levels of maGSCs with those of pluripotent male ESCs (each derived from the 129/Sv mouse strain). To ensure the specificity of the fixation and the immunostaining method for the flow cytometric approach, we performed control stainings without any antibody or with only secondary antibody and could not detect any fluorescent signal in both flow cytometry and fluorescence microscopy (Fig. IA and B). After immunostaining with a histone 3 (H3) specific antibody, we could observe that around $98 \%$ of both ESCs and maGSCs were stained with similar fluorescence intensities in FACS and a nuclear localization signal in fluorescence microscopy confirming the specificity of $\mathrm{H} 3$ staining (Fig. IC). Then, immunostaining of both maGSCs and ESCs for the activating histone modifications $\mathrm{H} 3 \mathrm{~K} 4 \mathrm{me} 3$ and $\mathrm{H} 3 \mathrm{~K} 9 \mathrm{ac}$ as well as the repressive histone modifications $\mathrm{H} 3 \mathrm{~K} 27 \mathrm{me} 3$ and $\mathrm{H} 3 \mathrm{~K} 9 \mathrm{me} 3$ was performed and analyzed by FACS. This analysis demonstrated that $\sim 90-98 \%$ of both cell types were positive for the four various histone modifications (Fig. ID) with very similar high fluorescence intensities (Fig. IE).

Fluorescence microscopy was also used to investigate the cellular localization and staining pattern of the four histone modifications in maGSCs compared with male ESCs (each derived from the 129/Sv mouse strain). Immunostainings with antibodies specific to H3K4me3, H3K27me3, H3K9me3 and H3K9ac were evaluated. An antibody specific to OCT4 was employed to distinguish the nuclei of pluripotent cells from those of MEFs. Overall, the staining patterns and intensities of the four histone modifications were very similar in both maGSCs and ESCs, but markedly differed from those detected in MEFs (Fig. 2). Very high levels of H3K4me3 staining were observed throughout the nuclei of both maGSCs and ESCs confirming the open chromatin state of both cell types (Fig. 2A). Similarly, staining with an H3K9ac-specific antibody showed an exclusive localization in non-DAPI-dense euchromatic regions (Fig. 2B). On the other hand, repressive modifications like $\mathrm{H} 3 \mathrm{~K} 9 \mathrm{me} 3$ and $\mathrm{H} 3 \mathrm{~K} 27 \mathrm{me} 3$ displayed discrete spots at DAPI-dense heterochromatic regions and a diffuse pattern in the nuclear periphery, respectively, present in both cell types (Fig. 2C and D).

To validate the global histone modification levels detected by FACS analysis, we isolated total protein extracts from the ESC 129/Sv and the maGSC 129/Sv cell lines as well as from MEFs and then performed western blot analysis with antibodies against $\mathrm{H} 3, \mathrm{H} 3 \mathrm{~K} 4 \mathrm{me}$, H3K27me3, H3K9me3 and H3K9ac (Fig. 3). This analysis revealed nearly equal levels of the analyzed histone modifications in both ESCs and maGSCs but also in non-pluripotent MEFs.

\section{Gene-specific comparative analysis of histone modification profiles}

Chromatin immunoprecipitation (ChIP) real-time PCR was used to comparatively analyze gene-specific active ( $\mathrm{H} 3 \mathrm{~K} 4 \mathrm{me} 3$ and $\mathrm{H} 3 \mathrm{~K} 9 \mathrm{ac})$ and repressive ( $\mathrm{H} 3 \mathrm{~K} 4 \mathrm{me} 27$ and $\mathrm{H} 3 \mathrm{~K} 9 \mathrm{me} 3$ ) histone modification levels at the pluripotency marker genes Oct4, Sox2 and Nanog as well as the key developmental lineage-control gene Hoxall in ESC and maGSC cell lines derived from three different genetic 

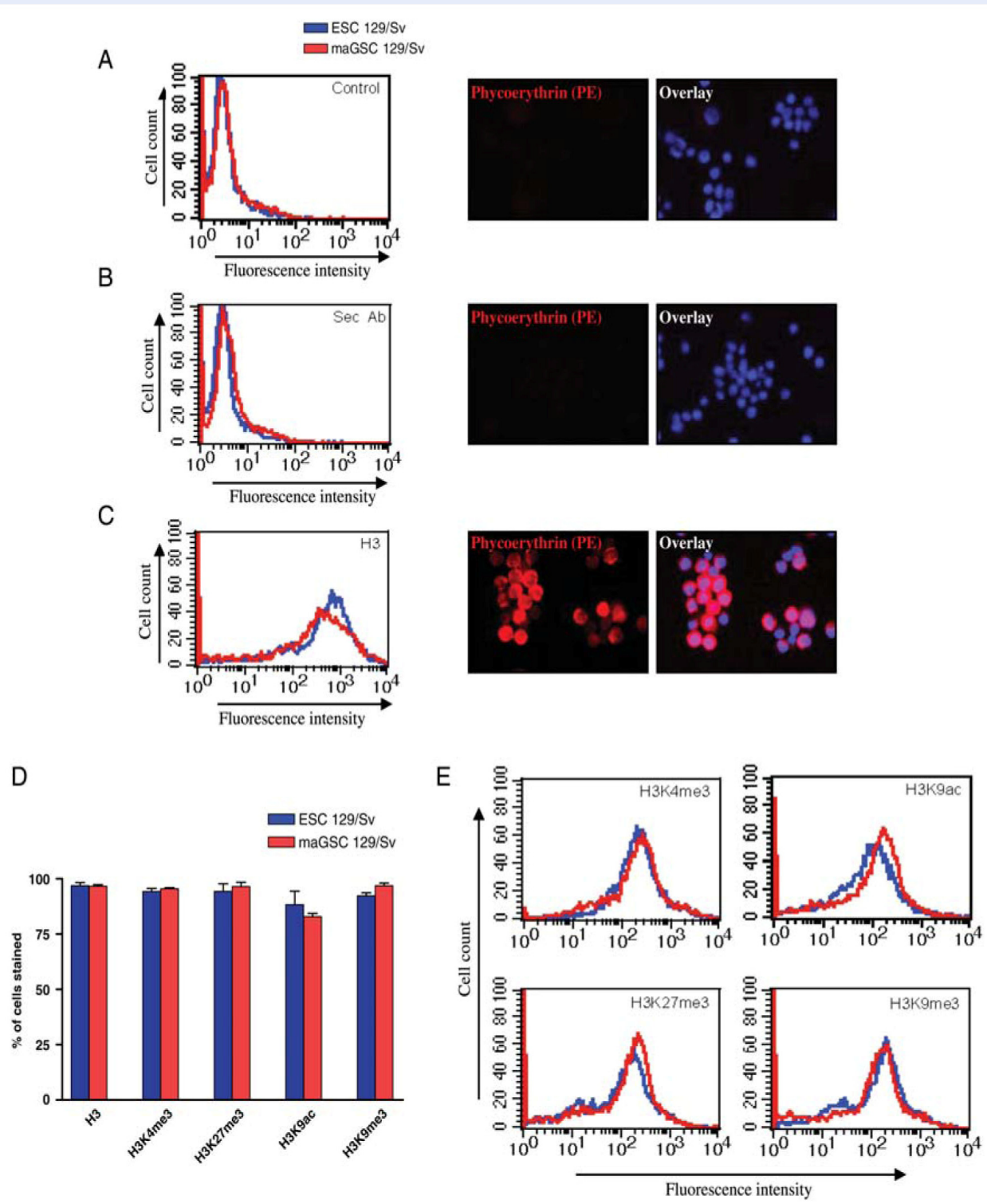

Figure I Flow cytometric analysis of global histone modification levels in maGSCs and ESCs. Control immunostainings of ESC I29/Sv (blue) and maGSC 129/Sv (red) were performed without any antibody (A), with only secondary antibody (B) or with histone3 (H3) specific antibody (C) followed by incubation with a PE-conjugated secondary antibody. The cells were counterstained with DAPI (blue) to visualize the nuclei. Bar diagram representing the percentage of cells stained for histone $\mathrm{H} 3$ and the four different histone modifications (D). Fluorescence intensities of the analyzed activating (H3K4me3 and $\mathrm{H} 3 \mathrm{~K} 9 \mathrm{ac}$ ) and repressive (H3K27me3 and H3K9me3) histone modifications in ESC I29/Sv (blue) and maGSC 129/Sv (red) (E). All the experiments were performed in three biological replicates.

backgrounds (129/Sv, C57BL/6 and Stra8) as well as MEFs. Beta-Actin (Actb), a housekeeping gene enriched for activating chromatin modifications and depleted of repressive chromatin modifications, was used as a control. Quantification was performed by normalizing the results relative to the amount of input DNA and expressing them as percentage of input DNA. In maGSCs and ESCs of all three analyzed genetic backgrounds, the two active histone modifications were highly abundant at the promoter regions of the pluripotency genes Oct4, Sox2 and Nanog and the housekeeping gene Actb and represented $\sim 20-60 \%$ of input DNA for H3K4me3 and $\sim 30-50 \%$ of input DNA for H3K9ac (Fig. 4AC). In contrast, the two repressive modifications were largely depleted at the promoters of the three pluripotency genes and the housekeeping gene and constituted generally below 10\% and in most cases even markedly below $5 \%$ of input DNA in both maGSCs and ESCs (Fig. 4A-C). The promoter region of the 

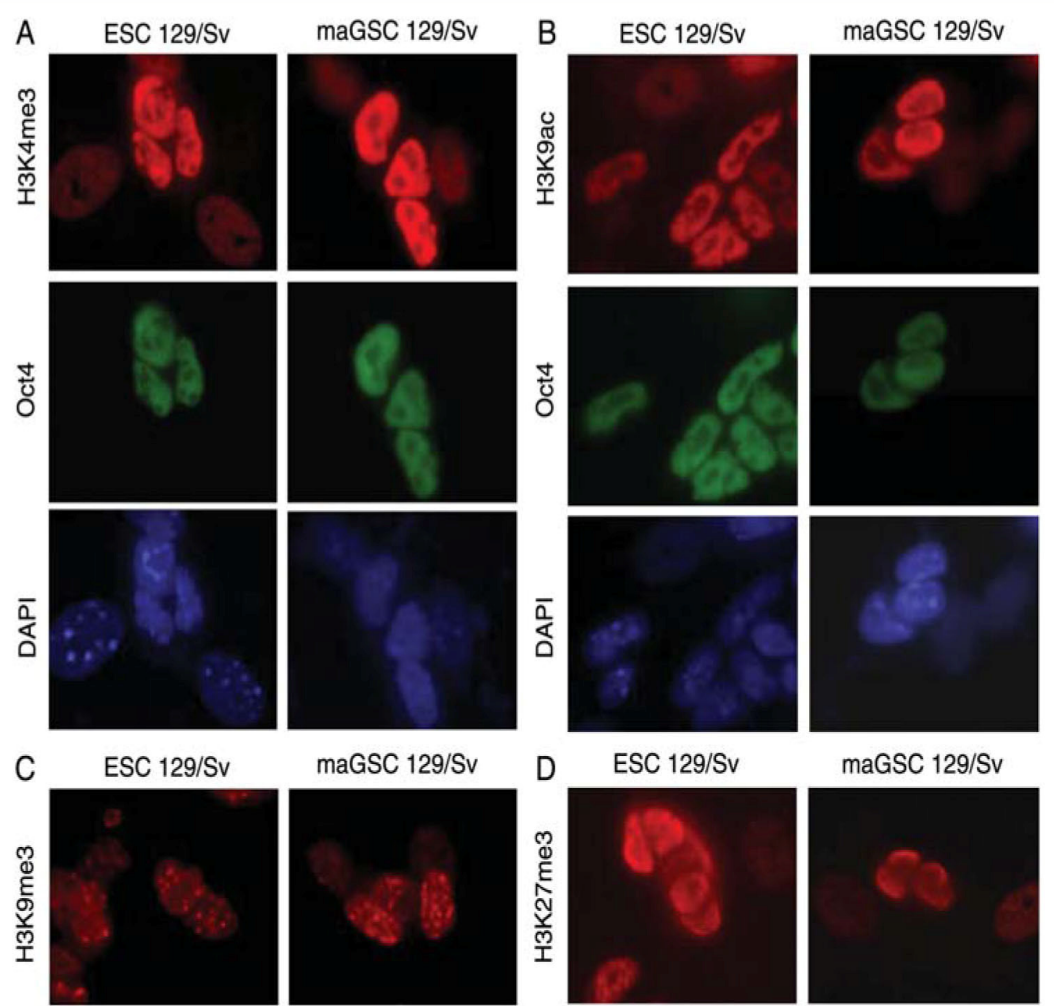

maGSC $129 / \mathrm{Sv}$
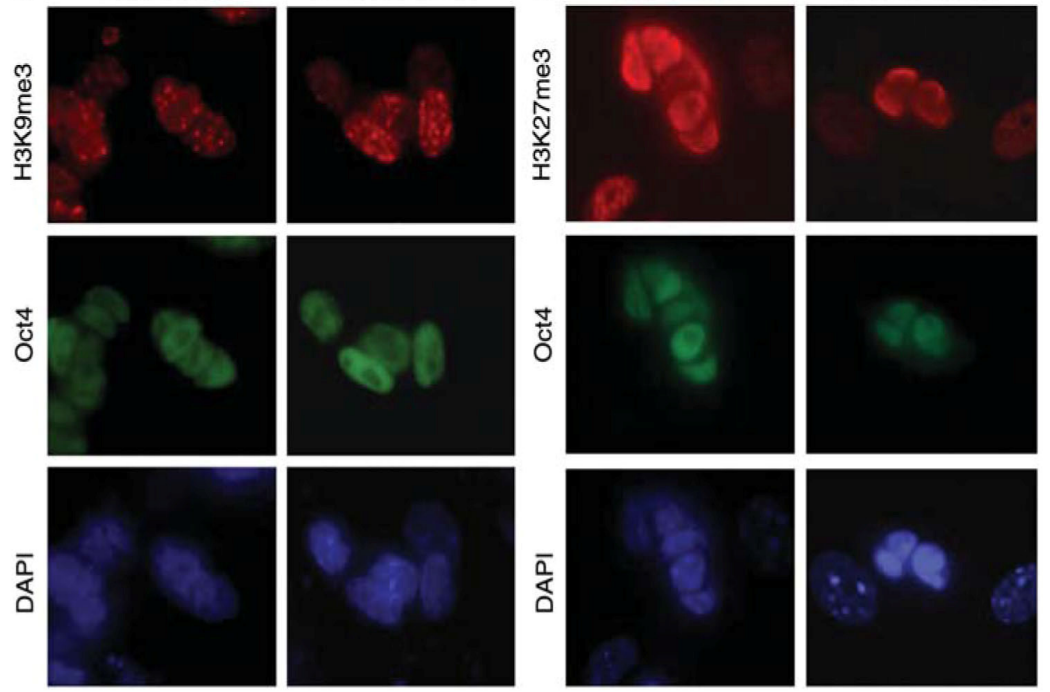

Figure 2 Immunofluorescence analysis of histone modifications. ESC 129/Sv and maGSC 129/Sv were cultured under standard ESC culture conditions and analyzed for the staining pattern and cellular localization of $\mathrm{H3K} 4 \mathrm{me} 3$ (A), $\mathrm{H3K}$ Kac (B), H3K9me3 (C) and H3K27me3 (D) (each in red). The cells were also stained with an OCT4-specific antibody (green) to distinguish the ESC and maGSC nuclei from those of feeder cells (MEFs). DAPI counterstaining (blue) was performed to visualize nuclei. DAPI-dense regions represent heterochromatin.

lineage-control gene Hoxall was associated with the two active H3K4me3 and H3K9ac as well as the repressive H3K27me3 histone modifications which accounted for $\sim 10-20 \%$ of input DNA for H3K4me3 and H3K9ac and $20-30 \%$ of input DNA for H3K27me3 in both maGSCs and ESCs (Fig. 4A-C). However, the second repressive histone modification, $\mathrm{H} 3 \mathrm{~K} 9 \mathrm{me} 3$, was not enriched at Hoxall and exclusively displayed levels below $5 \%$ of input DNA in all analyzed maGSCs and ESCs. In general, the histone modification patterns detected for all five analyzed genes were very similar in maGSC and ESCs irrespective of their genetic background. With regard to the detected histone modification levels, maGSCs and
ESCs of the same background tended to be slightly more similar than maGSCs and ESCs of different genetic backgrounds (Fig. 4AC). As expected, MEFs showed a high abundance of the two active (H3K4me3 and $\mathrm{H} 3 \mathrm{~K} 9 \mathrm{ac}$ ), and an almost complete absence of the two repressive ( $\mathrm{H} 3 \mathrm{~K} 4 \mathrm{me} 27$ and $\mathrm{H} 3 \mathrm{~K} 9 \mathrm{me}$ ), histone modifications at the expressed Actb gene (Fig. 4D). Similarly, the Hoxall gene which is also known to be expressed in MEFs ( $X_{i}$ et al., 2007) also exhibited higher levels for the active H3K4me3 and $\mathrm{H} 3 \mathrm{~K} 9 \mathrm{ac}$ modifications compared with those of the two repressive marks (Fig. 4D). The three non-expressed pluripotency marker genes, however, displayed a moderate (at Oct4 and Nanog) to 

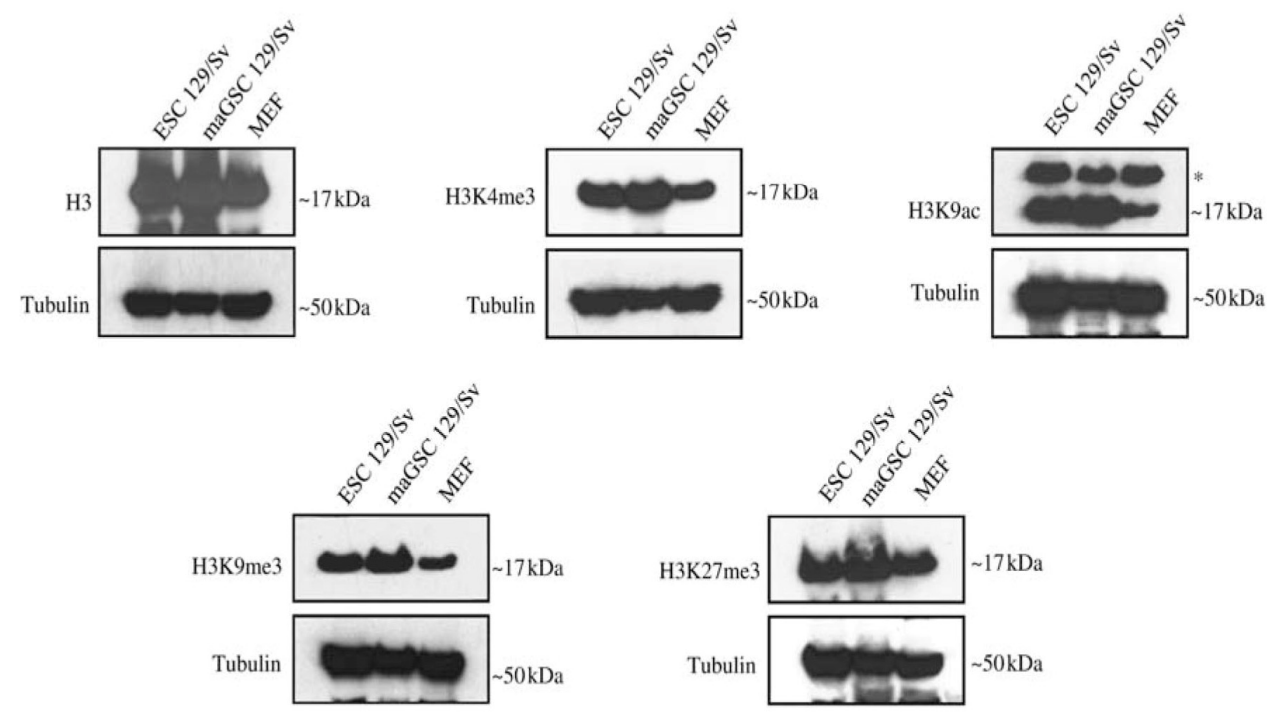

Figure 3 Western blot analysis of global histone modification levels in maGSCs, ESCs and MEFs. Total protein extracts from ESC I29/Sv, maGSC 129/Sv and MEFs were resolved by SDS-PAGE, transferred to nitrocellulose membranes and immunoblotted using antibodies specific to H3, H3K4me3, H3K9ac, H3K9me3 and H3K27me3. All immunoblots were reprobed for tubulin to validate equal loading of samples. The molecular weight $(\mathrm{Mw})$ in $\mathrm{kDa}$ of the bands is indicated on the right of each image. The utilized anti-H3K9ac antibody from Millipore has already been reported (see http://www.millipore.com/catalogue/item/07-352\#) to detect $\mathrm{H} 3 \mathrm{~K} 9 \mathrm{ac}$ at an $\mathrm{Mw}$ of $17 \mathrm{kDa}$ and an additional unknown protein at an $\mathrm{Mw}$ of $23 \mathrm{kDa}$ (indicated by the asterisk at the right of the image).

strong (at Sox2) enrichment for the repressive H3K4me27 modifcation compared with the other three histone modifications (Fig. 4D).

\section{Discussion}

SSCs representing the stem cell population of male germ cells have been repeatedly shown to be an appropriate source for deriving mGSCs that closely resemble ESCs with regard to their developmental potential including the ability to contribute to the germ lineage (Kanatsu-Shinohara et al., 2004; Guan et al., 2006; Seandel et al., 2007; Izadyar et al., 2008; Kanatsu-Shinohara et al., 2008; Ko et al., 2009). These findings opened new avenues to study the molecular control of stem cell pluripotency and differentiation, model human genetic disorders and generate patient-tailored regenerative therapies. To our knowledge, this is the first study to show that mGSCs also closely resemble male ESCs with regard to global and gene-specific histone modification levels and profiles.

In the first experiments, we analyzed global histone modification levels using a flow cytometric approach. Chromatin flow cytometry was just recently introduced as a potent method to rapidly determine global levels of chromatin marks (Obier and Muller, 20I0). Obier and Müller showed the validity of this method by profiling histone modifications such as $\mathrm{H} 3 \mathrm{~K} 4 \mathrm{me} 3, \mathrm{H} 3 \mathrm{~K} 9 \mathrm{ac}$ and $\mathrm{H} 3 \mathrm{~K} 27 \mathrm{me} 3$ in undifferentiated and differentiated murine ESCs and comparing their results with western blot data. Our flow cytometric measurements of these three modifications and, additionally, $\mathrm{H} 3 \mathrm{~K} 9 \mathrm{me} 3$ revealed almost identical levels in maGSCs and ESCs. A subsequently performed western blot analysis also including MEFs (as differentiated, somatic cells) confirmed the quantitative flow cytometric data for maGSCs and ESCs but also detected histone modification levels very similar to those of maGSCs and ESCs in non-pluripotent MEFs. These results are consistent with those of previous studies which also described the global levels of these modifications in undifferentiated murine ESCs as well as differentiated cells (Kimura et al., 2004; Meshorer et al., 2006). As, however, the histone modification levels of maGSCs and ESCs detected by western blot analysis did not differ from those of non-pluripotent MEFs, our data obtained by chromatin flow cytometry and western blot analysis are not entirely informative with regard to the pluripotency of maGSCs.

In the following immunofluorescence experiments, we focused on the nuclear localization and staining pattern of the four histone modifications in maGSCs and ESCs. These experiments revealed very similar nuclear localization patterns for the four epigenetic marks in maGSCs and ESCs that are in agreement with previous findings in murine ESCs (Lehnertz et al., 2003; Meshorer et al., 2006; Luo et al., 2009). Thus, two studies described a heterochromatic association of $\mathrm{H} 3 \mathrm{~K} 9 \mathrm{me} 3$ by costaining with DAPI and heterochromatin protein I isoform $\mathrm{HPI} \alpha$ which also indicated the role of $\mathrm{H} 3 \mathrm{~K} 9 \mathrm{me} 3$ in directing DNA methylation at pericentric heterochromatin (Lehnertz et al., 2003; Meshorer et al., 2006). The third study demonstrated H3K27me3 to be present as full or partial rims at the nuclear lamina which was assumed to reflect an enrichment of repressed genes at the nuclear periphery of mouse ESCs (Luo et al., 2009). Two of these reports also showed that, as expected from its role in gene activation, methylation of $\mathrm{H} 3 \mathrm{KK}$, similar to acetylation of $\mathrm{H} 3 \mathrm{~K}$, is not colocalized with $\mathrm{HPI} \alpha$ and intense DAPI staining but associated with transcriptionally active open chromatin structures in 

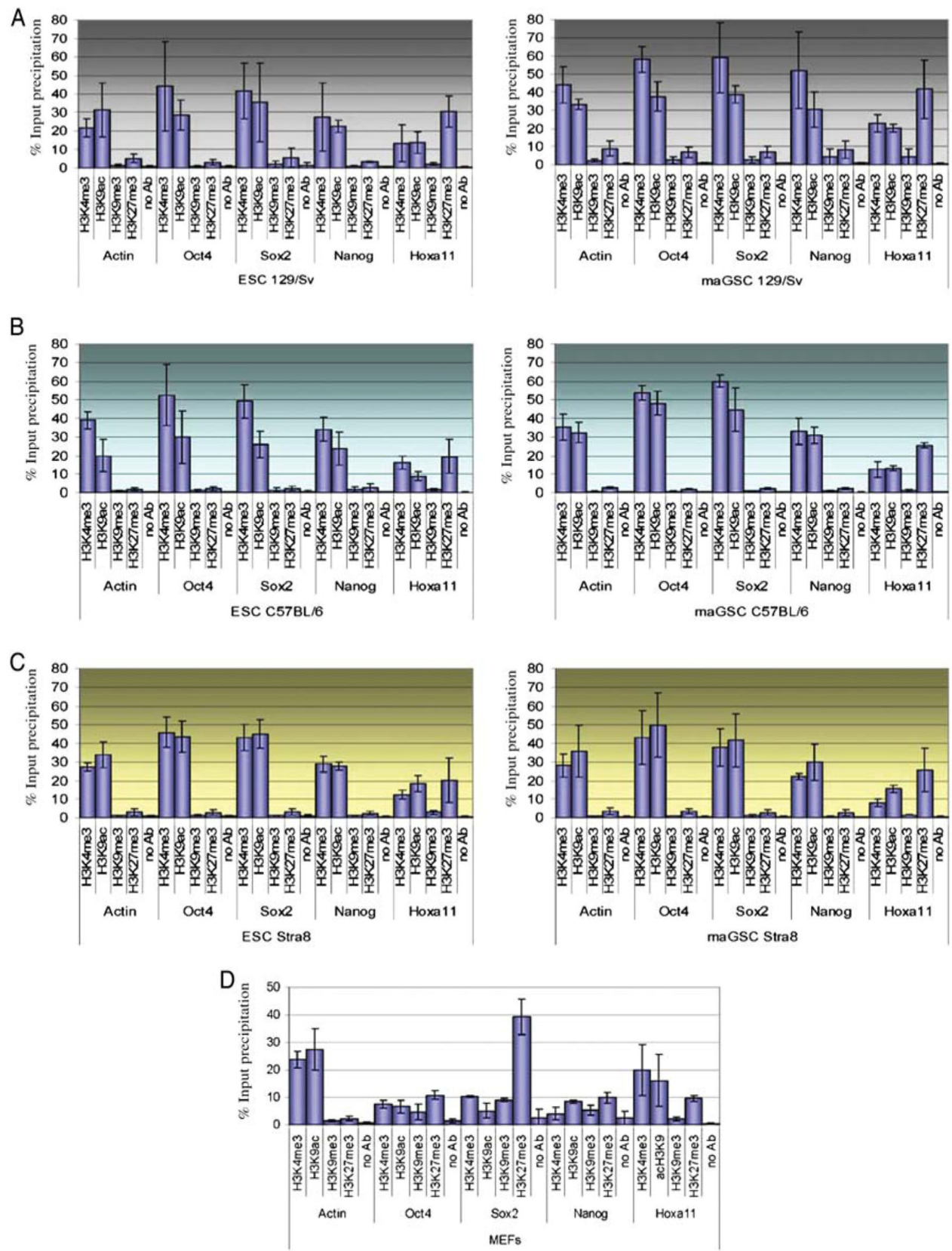

Figure 4 Analysis of histone modification levels at Oct4, Sox2, Nanog and Hoxall in maGSCs, ESCs and MEFs. The chromatin of ESC lines (each left) and maGSC lines (each right) from three different genetic backgrounds (I29/Sv, A; C57BL/6, B; Stra 8; C) as well as that of MEFs (D) were subjected to ChIP analysis using antibodies against the four different histone modifications. The precipitated DNA was analyzed by real-time qPCR for abundance of the various modifications at the promoter regions of the housekeeping gene beta-actin; the key pluripotency genes Oct4, Sox 2 and Nanog and the key developmental lineage-control gene Hoxal I. The qPCR data are presented as percentage of input DNA.

mouse ESCs (Lehnertz et al., 2003; Luo et al., 2009). In addition, the $\mathrm{H} 3 \mathrm{~K} 9 \mathrm{me} 3$ and H3K27me3 nuclear localization patterns observed in our study are reminiscent of those already shown in late embryonic day 12.5-13.5 mouse primordial germ cells (PGCs), which represent the non-pluripotent embryonic precursors of SSCs and, thus, also of
maGSCs (Hajkova et al., 2008) and can be transformed in vitro to pluripotent embryonic germ cells (EGCs) (Shamblott et al., 1998). Hence, these findings strengthen the view that maGSCs, ESCs, and also PGCs are closely related stem cells. Future immunofluorescence stainings of H3K9me3 and H3K27me3 in EGCs could possibly help to further 
elucidate if the observed nuclear localization patterns are characteristic for pluripotent stem cells.

Similar to our genome-wide studies, our ChIP real-time PCR-based gene-specfic analysis of histone modifications also revealed very similar profiles in maGSCs and ESCs. Overall, these profiles were not only similar in the maGSCs and ESCs analyzed in our study, but also closely resembled those repeatedly reported for murine ESCs. Thus, several ChIP-PCR-based studies of Oct4, Nanog and Sox2 promoters in murine ESCs also detected a hyperacetylation and hypermethylation for the two permissive marks $\mathrm{H} 3 \mathrm{~K} 9 \mathrm{ac}$ and $\mathrm{H} 3 \mathrm{~K} 4 \mathrm{me} 3$, respectively, and a strong hypomethylation for the two repressive $\mathrm{H} 3 \mathrm{~K} 9 \mathrm{me} 3$ and H3K27me3 marks (Hattori et al., 2004; Kimura et al., 2004; Azuara et al., 2006; O'Neill et al., 2006). Further, Hoxall is one of the numerous key developmental genes that were already previously shown to be associated with bivalent structure marks, i.e. the simultaneous presence of the permissive $\mathrm{H} 3 \mathrm{~K} 4 \mathrm{me} 3$ and the repressive H3K27me3 marks, in mouse ESCs (Bernstein et al., 2006). In addition, histone modification profiles very similar to those of maGSCs and ESCs were demonstrated to be present at pluripotency marker genes and other key developmental control genes of another recently described pluripotent cell type, i.e. mouse and human induced pluripotent stem cells (Takahashi et al., 2007; Wernig et al., 2007).

Taken together, this report describes the first analysis of global and gene-specific histone modifications in maGSCs. We provide evidence for a high degree of similarities in histone modification profiles between maGSCs and ESCs. After several previous studies that reported strong similarities in DNA methylation and microRNA expression profiles between maGSCs and ESCs, these novel data further extend the characterization of maGSCs at the epigenetic level and additionally support their pluripotent nature. To obtain a more detailed and clear picture of the epigenetic landscape of maGSCs, further studies will be necessary aiming at the genome-wide analysis of DNA methylation and histone modifications at single-base-pair resolution.

\section{Funding}

The work was supported by the German Research Foundation (Deutsche Forschungsgemeinschaft) in the Priority Programme SPP I356 (EN 84/22-I to W.E., ZE 442/4-I to U.Z.) and the Research Unit FOR I04I (EN 84/23-I to W.E.; ZE 442/5-I to U.Z.).

\section{Authors' roles}

T.K.: conception, data collection, writing. D.V.K.P.: data collection. J.H.: data interpretation, conception. M.W.: data collection. R.D.: data interpretation, design. W.E.: conception, financial support, writing. U.Z.: conception, financial support, design, writing.

\section{References}

Azuara V, Perry P, Sauer S, Spivakov M, Jorgensen HF, John RM, Gouti M, Casanova M, Warnes G, Merkenschlager M et al. Chromatin signatures of pluripotent cell lines. Nat Cell Biol 2006;8:532-538.

Bernstein BE, Mikkelsen TS, Xie X, Kamal M, Huebert DJ, Cuff J, Fry B, Meissner A, Wernig M, Plath $\mathrm{K}$ et al. A bivalent chromatin structure marks key developmental genes in embryonic stem cells. Cell 2006; 125:315-326.

Chambers I. The molecular basis of pluripotency in mouse embryonic stem cells. Cloning Stem Cells 2004;6:386-391.

Dihazi H, Dihazi GH, Nolte J, Meyer S, Jahn O, Muller GA, Engel W. Multipotent adult germline stem cells and embryonic stem cells: comparative proteomic approach. J Proteome Res 2009;8:5497-5510.

Evans MJ, Kaufman MH. Establishment in culture of pluripotential cells from mouse embryos. Nature 1981;292:154-156.

Geijsen N, Horoschak M, Kim K, Gribnau J, Eggan K, Daley GQ. Derivation of embryonic germ cells and male gametes from embryonic stem cells. Nature 2004;427:|48-I54.

Guan K, Nayernia K, Maier LS, Wagner S, Dressel R, Lee JH, Nolte J, Wolf $\mathrm{F}$, Li M, Engel $\mathrm{W}$ et al. Pluripotency of spermatogonial stem cells from adult mouse testis. Nature 2006;440:1199-1203.

Hajkova P, Ancelin K, Waldmann T, Lacoste N, Lange UC, Cesari F, Lee C, Almouzni G, Schneider R, Surani MA. Chromatin dynamics during epigenetic reprogramming in the mouse germ line. Nature 2008:452:887-881.

Hattori N, Nishino K, Ko YG, Hattori N, Ohgane J, Tanaka S, Shiota K. Epigenetic control of mouse Oct-4 gene expression in embryonic stem cells and trophoblast stem cells. J Biol Chem 2004; 279:17063-17069.

Houbaviy HB, Murray MF, Sharp PA. Embryonic stem cell-specific MicroRNAs. Dev Cell 2003:5:35I-358.

Izadyar F, Pau F, Marh J, Slepko N, Wang T, Gonzalez R, Ramos T, Howerton K, Sayre C, Silva F. Generation of multipotent cell lines from a distinct population of male germ line stem cells. Reproduction 2008; 135:77|-784.

Jenuwein T, Allis CD. Translating the histone code. Science 200I; 293:1074-1080.

Kanatsu-Shinohara M, Inoue K, Lee J, Yoshimoto M, Ogonuki N, Miki H, Baba S, Kato T, Kazuki Y, Toyokuni S et al. Generation of pluripotent stem cells from neonatal mouse testis. Cell 2004; II9:1001-1012.

Kanatsu-Shinohara M, Lee J, Inoue K, Ogonuki N, Miki H, Toyokuni S, Ikawa M, Nakamura T, Ogura A, Shinohara T. Pluripotency of a single spermatogonial stem cell in mice. Biol Reprod 2008;78:681-687.

Kimura H, Tada M, Nakatsuji N, Tada T. Histone code modifications on pluripotential nuclei of reprogrammed somatic cells. Mol Cell Biol 2004:24:5710-5720.

Ko K, Tapia N, Wu G, Kim JB, Bravo MJ, Sasse P, Glaser T, Ruau D, Han DW, Greber B et al. Induction of pluripotency in adult unipotent germline stem cells. Cell Stem Cell 2009;5:87-96.

Lehnertz B, Ueda Y, Derijck AA, Braunschweig U, Perez-Burgos L, Kubicek S, Chen T, Li E, Jenuwein T, Peters AH. Suv39h-mediated histone $\mathrm{H} 3$ lysine 9 methylation directs DNA methylation to major satellite repeats at pericentric heterochromatin. Curr Biol 2003; 13:1192-1200.

Luo L, Gassman KL, Petell LM, Wilson CL, Bewersdorf J, Shopland LS. The nuclear periphery of embryonic stem cells is a transcriptionally permissive and repressive compartment. I Cell Sci 2009; 122:3729-3737.

Margueron R, Trojer P, Reinberg D. The key to development: interpreting the histone code? Curr Opin Genet Dev 2005; 15:163-176.

Martin GR. Isolation of a pluripotent cell line from early mouse embryos cultured in medium conditioned by teratocarcinoma stem cells. Proc Natl Acad Sci USA 1981;78:7634-7638.

Martin C, Zhang Y. The diverse functions of histone lysine methylation. Nat Rev Mol Cell Biol 2005;6:838-849.

Meshorer E, Misteli T. Chromatin in pluripotent embryonic stem cells and differentiation. Nat Rev Mol Cell Biol 2006;7:540-546. 
Meshorer E, Yellajoshula D, George E, Scambler PJ, Brown DT, Misteli T. Hyperdynamic plasticity of chromatin proteins in pluripotent embryonic stem cells. Dev Cell 2006; 10:105-116.

Nagy A, Rossant J, Nagy R, Abramow-Newerly W, Roder JC. Derivation of completely cell culture-derived mice from early-passage embryonic stem cells. Proc Natl Acad Sci USA 1993;90:8424-8428.

Narlikar GJ, Fan HY, Kingston RE. Cooperation between complexes that regulate chromatin structure and transcription. Cell 2002; 108:475-487

Nayernia K, Nolte J, Michelmann HW, Lee JH, Rathsack K, Drusenheimer N, Dev A, Wulf G, Ehrmann IE, Elliott DJ et al. In vitro-differentiated embryonic stem cells give rise to male gametes that can generate offspring mice. Dev Cell 2006; I I: 125-132.

Obier N, Muller AM. Chromatin flow cytometry identifies changes in epigenetic cell states. Cells Tissues Organs 2010;191:167-174.

O'Neill LP, VerMilyea MD, Turner BM. Epigenetic characterization of the early embryo with a chromatin immunoprecipitation protocol applicable to small cell populations. Nat Genet 2006;38:835-84I.

O'Shea KS. Self-renewal vs. differentiation of mouse embryonic stem cells. Biol Reprod 2004;7I: I755-1765.

Pan G, Tian S, Nie J, Yang C, Ruotti V, Wei H, Jonsdottir GA, Stewart R, Thomson JA. Whole-genome analysis of histone $\mathrm{H} 3$ lysine 4 and lysine 27 methylation in human embryonic stem cells. Cell Stem Cell 2007; I:299-312.

Ringrose L, Paro R. Epigenetic regulation of cellular memory by the Polycomb and Trithorax group proteins. Annu Rev Genet 2004;38:4I3-443.

Seandel M, James D, Shmelkov SV, Falciatori I, Kim J, Chavala S, Scherr DS, Zhang F, Torres R, Gale NW et al. Generation of functional multipotent adult stem cells from GPRI25+ germline progenitors. Nature 2007; 449:346-350.
Shamblott MJ, Axelman J, Wang S, Bugg EM, Littlefield JW, Donovan P], Blumenthal PD, Huggins GR, Gearhart JD. Derivation of pluripotent stem cells from cultured human primordial germ cells. Proc Natl Acad Sci USA 1998;95:13726-13731.

Sims RJ 3rd, Nishioka K, Reinberg D. Histone lysine methylation: a signature for chromatin function. Trends Genet 2003;19:629-639.

Suda Y, Suzuki M, lkawa Y, Aizawa S. Mouse embryonic stem cells exhibit indefinite proliferative potential. I Cell Physiol 1987;133: 197-201.

Takahashi K, Tanabe K, Ohnuki M, Narita M, Ichisaka T, Tomoda K, Yamanaka S. Induction of pluripotent stem cells from adult human fibroblasts by defined factors. Cell 2007;| 31:86| -872.

Weber M, Schubeler D. Genomic patterns of DNA methylation: targets and function of an epigenetic mark. Curr Opin Cell Biol 2007; 19:273-280

Wernig M, Meissner A, Foreman R, Brambrink T, Ku M, Hochedlinger K, Bernstein BE, Jaenisch R. In vitro reprogramming of fibroblasts into a pluripotent ES-cell-like state. Nature 2007;448:3I8-324.

Xi S, Zhu H, Xu H, Schmidtmann A, Geiman TM, Muegge K. Lsh controls Hox gene silencing during development. Proc Natl Acad Sci USA 2007; 104:|4366- |437|.

Zechner U, Nolte J, Wolf M, Shirneshan K, Hajj NE, Weise D, Kaltwasser B, Zovoilis A, Haaf T, Engel W. Comparative methylation profiles and telomerase biology of mouse multipotent adult germline stem cells and embryonic stem cells. Mol Hum Reprod 2009; I 5:345-353.

Zovoilis A, Nolte J, Drusenheimer N, Zechner U, Hada H, Guan K, Hasenfuss G, Nayernia K, Engel W. Multipotent adult germline stem cells and embryonic stem cells have similar microRNA profiles. Mol Hum Reprod 2008; 14:52I-529. 


\subsection{Apoptosis-related gene expression profiles of mouse ESCs and maGSCs: Identification and implication of Fgf4 and Mnda in pluripotent cell responses to genotoxicity.}

The second part of the thesis describes the comparative analysis of ESCs and maGSCs at apoptosis level. Genotoxicity is the damage to the DNA of a cell caused by various external or internal factors leading to the activation of repair processes or elimination of damaged cells by apoptosis. As apoptosis or programmed cell death is the effective means to eliminate damaged cells from ESCs pool, we analyzed the apoptosisrelated gene expression profiles of ESCs and maGSCs. Expression analysis revealed high similarity of apoptosis-related gene expression in both ESCs and maGSCs, with the specific expression of intrinsic, but not extrinsic apoptotic pathway genes in both cell types. Comparative analysis revealed the specific expression of many pro- and antiapoptotic genes in pluripotent ESCs and maGSCs, whereas they were highly downregulated in their differentiated counterparts. The apoptotic response of ESCs and maGSCs to Citrinin was also very similar in the amount of apoptosis undergoing cells $(\sim 35 \%)$. The global gene transcriptome analysis of early-apoptotic cells also showed a high similarity ( $94 \%$ ) of the gene expression in both cell types. Collectively, our results demonstrate that maGSCs genomic integrity properties are highly similar to ESCs. In addition, we were able to identify candidate genes, which might play an important role in genomic integrity properties of pluripotent cells.

Authors: Tatjana Khromov, D.V. Krishna Pantakani, Ralf Dressel, Iliana Siamishi, Jessica Nolte and Wolfgang Engel

Status: submitted to BMC Genomics,

Author contributions to the work:

1. Tatjana Khromov: Conception and design of experiments, data collection, data interpretation, writing.

2. D.V. Krishna Pantakani: Conception, design, data interpretation, writing

3. Ralf Dressel: FACS data analysis, design.

4. Iliana Siamishi: Data collection.

5. Jessica Nolte: Data interpretation.

6. Wolfgang Engel: Conception, data interpretation, financial support, writing. 


\section{Apoptosis-related gene expression profiles of mouse ESCs and maGSCs: Identification and implication of Fgf4 and Mnda in pluripotent cell responses to genotoxicity}

Tatjana Khromov, D.V. Krishna Pantakani ${ }^{\ddagger}$, Ralf Dressel, Iliana Siamishi, Jessica Nolte and Wolfgang Engel

${ }^{\ddagger}$ Correspondence:

Krishna Pantakani D. V., Tel: +49-551-399302; Fax: +49-551-399303; E-mail: krishna.if1@gmail.com; pkrishn@gwdg.de

\section{Author details:}

\section{Tatjana Khromov}

Institute of Human Genetics, University of Goettingen, Heinrich-Dueker-Weg 12, 37073 Goettingen, Germany.

E-mail: tatjanakhromov@googlemail.com

\section{D.V. Krishna Pantakani}

Institute of Human Genetics, University of Goettingen, Heinrich-Dueker-Weg 12, 37073 Goettingen, Germany.

E-mail: krishna.if1@gmail.com,pkrishn@gwdg.de

\section{Ralf Dressel}

Department of Cellular and Molecular Immunology, University of Goettingen, Humboldtallee 34, 37073 Goettingen, Germany.

E-mail: rdresse@gwdg.de

\section{Iliana Siamishi}

Institute of Human Genetics, University of Goettingen, Heinrich-Dueker-Weg 12, 37073 Goettingen, Germany.

E-mail: iliana.siamishi@stud.uni-goettingen.de

\section{Jessica Nolte}

Institute of Human Genetics, University of Goettingen, Heinrich-Dueker-Weg 12, 37073

Goettingen, Germany.

E-mail: jnolte1@gwdg.de 


\title{
Wolfgang Engel
}

Institute of Human Genetics, University of Goettingen, Heinrich-Dueker-Weg 12, 37073 Goettingen, Germany.

E-mail: wengel@gwdg.de

\begin{abstract}
Background

Stem cells in the developing embryo proliferate and differentiate while maintaining genomic integrity, failure of which may lead to accumulation of mutations and subsequent damage to the embryo. Embryonic stem cells (ESCs), the in vitro counterpart of embryo stem cells are highly sensitive to genotoxic stress. Defective ESCs undergo either efficient DNA damage repair or apoptosis, thus maintaining genomic integrity. However, the genotoxicity- and apoptosis-related processes in germ-line derived pluripotent cells, multipotent adult germ-line stem cells (maGSCs), are currently unknown.
\end{abstract}

\section{Results}

Here, we analyzed the expression of apoptosis-related genes using OligoGEArray in undifferentiated maGSCs and ESCs and identified a similar set of genes expressed in both cell types. We detected the expression of intrinsic, but not extrinsic, apoptotic pathway genes in both cell types. Further, we found that apoptosis-related gene expression patterns of differentiated ESCs and maGSCs are identical to each other. Comparative analysis revealed that several pro- and anti-apoptotic genes are expressed specifically in pluripotent cells, but markedly downregulated in the differentiated counter parts of these cells. Activation of the intrinsic apoptotic pathway cause approximately $\sim 35 \%$ of both ESCs and maGSCs to adopt an early-apoptotic phenotype, demonstrating a strong similarity between these cell types. Moreover, we performed transcriptome studies using early-apoptotic cells to identify novel pluripotency- and apoptosis-related genes. From these transcriptome studies, we selected Fgf4 and Mnda, which are highly downregulated in early-apoptotic cells, as novel candidates and analyzed their roles in apoptosis and genotoxicity responses in ESCs.

\section{Conclusions}

Collectively, our results show that maGSCs are very similar to ESCs, suggesting common molecular mechanisms for maintaining the pristine stem cell pool. Moreover, 
responses to the activation of the intrinsic apoptotic pathway and the transcriptomes of early-apoptotic cells are identical in both pluripotent cell types. Further, we analyzed the role of Fgf4 and Mnda in pluripotent cells response to genotoxic stress and suggest that these genes play an essential role in maintaining genomic integrity and regulating survival in the very early stages of apoptosis before the intrinsic pathway becomes activated. This study will further advance our knowledge of the genomic integrity properties of ESCs as well as maGSCs.

\section{Background}

Embryonic stem cells (ESCs) derived from mouse pre-implantation blastocysts are pluripotent $[1,2]$ and have the ability to differentiate into all the germ layers [3-6]. During embryogenesis, stem cells proliferate and differentiate, while maintaining the genomic integrity to avoid the accumulation of mutations, which may subsequently damage the embryo. In line with this view, it has been proposed that ESCs might have evolved with mechanisms to protect against genotoxic stress by employing either very efficient DNA repair machinery or by inducing apoptosis when even low levels of DNA damage are encountered [7-9]. Moreover, mutation frequencies and mitotic recombination events in ESCs were shown to be 100-fold lower than in somatic cells, thus supporting the existence of efficient mechanisms against genotoxicity [10,11].

ESCs are highly proliferative and display a distinct, short cell cycle (10-12h) with a very brief G1 phase [7, 12]. Unlike somatic cells, ESCs were shown to contain DNA strand breaks (DSBs) marked by $\gamma \mathrm{H} 2 \mathrm{~A} . \mathrm{X}$ but do not activate the DNA repair system [12], suggesting their tolerance to DSBs. Moreover, ESCs do not undergo G1 arrest upon DNA damage partly due to the inactivation of p53 and low levels of cyclin dependent kinase (CDK) inhibitor p21/Waf1 [7]. Consistent with these data, it has been reported that in ESCs the checkpoint kinase, Chk2, does not phosphorylate its substrates, such as p53 and Cdc25A, leading to the lack of G1 arrest [13]. In contrast to the expected general function of p53 in DNA damage response, it has been reported that p53 mediates the repression of pluripotency gene Nanog upon DNA damage [14]. Repression of this core pluripotency factor therefore allows the differentiation of damaged cells and subsequent elimination through p53-mediated mechanisms [14].

Our group has derived pluripotent cells termed as multipotent adult germline stem cells (maGSCs) from spermatogonial stem cells (SSCs) of adult mouse testis [15]. These 
maGSCs are able to differentiate into all the germ layers in vitro and can contribute to chimeras with germ-line transmission. Previously, to further investigate the pluripotencyrelated properties of maGSCs, we have examined the microRNA expression, global gene expression and proteomics analysis and have found similarities with ESCs [16-18]. Furthermore, analysis of the epigenetic features of maGSCs by global and gene-specific DNA methylation and histone modification profiling also demonstrated the similarity of both pluripotent cell types $[19,20]$. The generation of human maGSCs might provide an alternative to ESCs in regenerative medicine, as the use of maGSCs can bypass both ethical and immunological issues.

In the present study, we analyzed apoptosis-related gene expression in maGSCs and found the expression pattern to be comparable to that of ESCs. Further, we induced apoptosis in ESCs and maGSCs using citrinin, a known, mitochondrial-mediated apoptosis-inducing mycotoxin, and compared their responses. We also performed gene expression profiling on early-apoptotic cells and identified two candidate genes, namely fibroblast growth factor 4 (Fgf4) and myeloid cell nuclear differentiating antigen (Mnda), which are highly downregulated upon induction of apoptosis. Further experiments revealed that Fgf4-knock-out (Fgf4-KO) cells are partially protected against induced genotoxicity.

\section{Results}

\section{Apoptosis-related gene expression profiling of ESCs and maGSCs}

Genotoxic stress leads to the activation of p53-dependent mechanisms to either repair DNA damage or undergo apoptosis. The high sensitivity of ESCs to genotoxic stress is presumed to be due to their particular expression of pro-apoptotic and antiapoptotic genes. To compare the apoptosis-related gene expression profiles of ESCs and maGSCs, we used OligoGEArray consisting of 112 genes implicated in the process of apoptosis (Fig. 1A). The comparison between undifferentiated ESCs and maGSCs of the $129 \mathrm{~Sv}$ genetic background revealed similar gene expression patterns without any cell type-specific gene expression (Fig. 1B). The majority of the expressed genes are involved in the mitochondrial apoptotic pathway (intrinsic) and included no genes, such as Fas and Fadd, which are involved in the extrinsic apoptotic pathway. Among all the analyzed caspases, only casp-2 was expressed at detected level in both cell types. Quantification of the signal intensities using the OligoGEArray suite and scatterplot analysis revealed that, 
although many genes are equally expressed (below the fold difference threshold of 2) in ESCs and maGSCs, the pro-apoptotic protein Bok and three anti-apoptotic/tumor suppressor genes (p53, Birc2, and Birc5) showed significant upregulation in maGSCs (Fig. 1C). Next, we compared the apoptosis-related gene expression profile of ESCs and maGSCs generated from Stra8-EGFP transgenic mice, hereafter referred as ESCs-Stra8 and maGSCs-Stra8, respectively. The gene expression profiles of ESCs-Stra8 and maGSCs-Stra8 are identical to each other (Fig. 1D) and are also similar to those of ESCs and maGSCs of the 129Sv background. The quantification and subsequent scatterplot analysis showed the slight downregulation of two pro-apoptotic genes, Bnip3 and Tnfsrf12a, in maGSCs (Fig. 1E).

We also analyzed the expression profile of pro-apoptotic and anti-apoptotic genes in ESCs and maGSCs that have been induced to differentiate for 20 days with retinoic acid (RA). The expression pattern of apoptosis-related genes is quite similar in both differentiated cell types (Fig. 2A) and is markedly distinct from the expression pattern of undifferentiated cells (Fig. 1B-E). The scatterplot analysis revealed the upregulation of Nfkb1 and the downregulation of Pycard and Bnip3 genes in differentiated maGSCs in comparison to differentiated ESCs (Fig. 2B). To further show the differences between undifferentiated and differentiated cells and also to identify the genes that are specifically expressed in undifferentiated ESCs and maGSCs, we generated a heat map of all the data sets (Fig. 2C). All undifferentiated cells possessed similar gene expression patterns and are clustered together, whereas differentiated cells possessed an expression pattern that is quite distinct and are clustered separately (Fig. 2C). Further analysis of the heat map revealed strong and specific expression of Mcl1, Bax, Hells, and Nfkb1 genes in undifferentiated ESCs and maGSCs, whereas the expression of these genes was highly downregulated or absent in their differentiated counterparts (Fig. 2C'). The expression of p53, Api5, Birc2, Cradd, and Bid genes was moderately high in undifferentiated pluripotent cells compared to RA-differentiated cells (Fig. 2C'). Interestingly, the majority of the genes that are specifically expressed in undifferentiated cells are known to inhibit apoptosis, whereas the rest are pro-apoptotic. 
A.

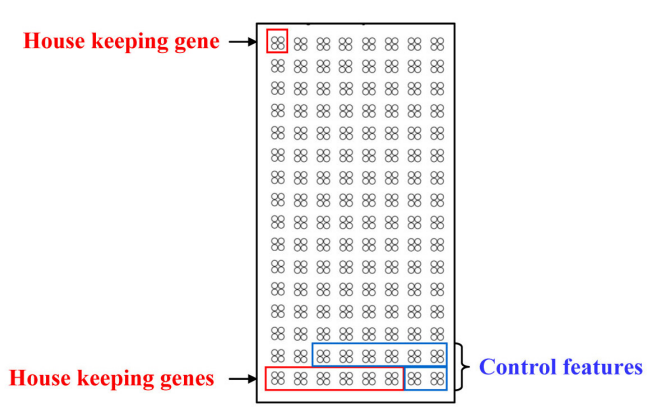

B.

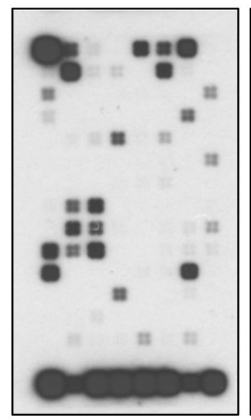

ESCs-129Sv

D.

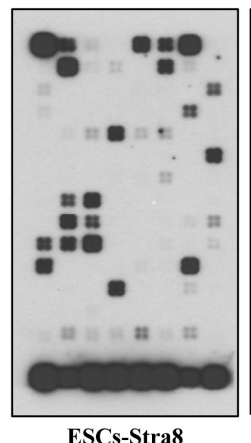

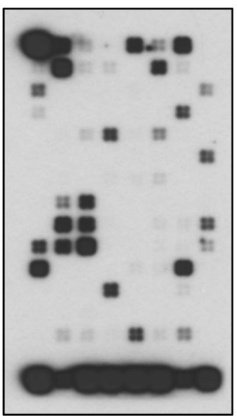

maGSCs-129Sv

C.

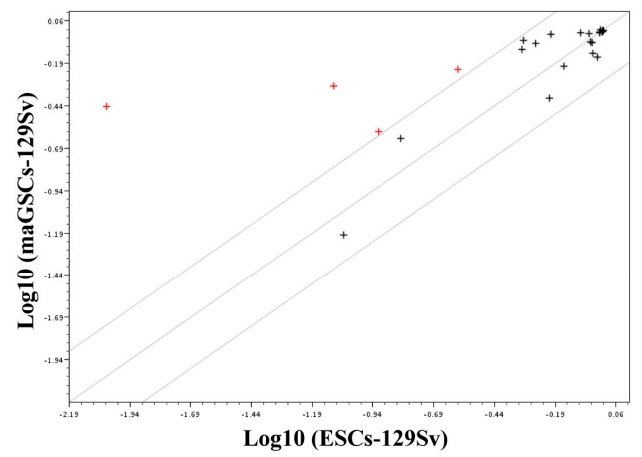

E.

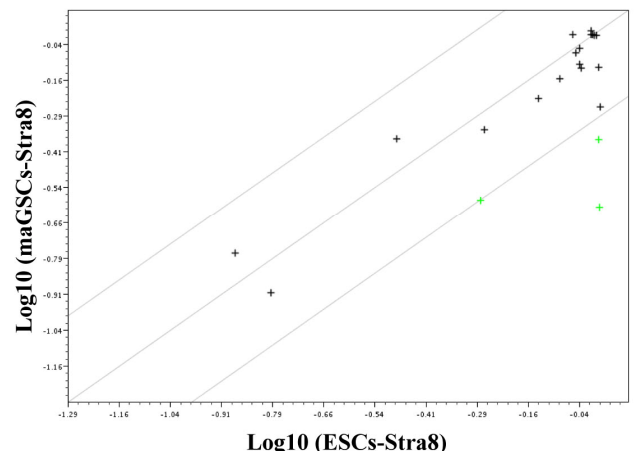

Figure 1. Comparative analysis of apoptosis-related genes expression profiles in undifferentiated ESCs and maGSCs. (A) The format of the Mouse Apoptosis OligoGEArray spotted with oligos against 112 genes known to be involved in apoptosis-related processes. Additionally, oligos spotted against housekeeping genes (red) and blank or plasmid controls (blue) are also shown. (B) OligoGEArray blot showing the expression profile of apoptosis-related genes in undifferentiated ESCs and maGSCs of the 129Sv genetic background. (C) Scatterplot analysis of genes expressed in undifferentiated ESCs and maGSCs of the $129 \mathrm{~Sv}$ background. Expression of pro-apoptotic gene Bok and three anti-apoptotic genes (p53, Birc2, and Birc5) were upregulated in maGSCs relative to ESCs, but the expression of most genes did not substantially differ between the cell types (D) OligoGEArray blot showing the expression profile of apoptosis-related genes in undifferentiated ESCs and maGSCs of the Stra8-EGFP transgenic background. (E) Scatterplot analysis of genes expressed in undifferentiated ESCs and maGSCs of the Stra8-EGFP background. Two pro-apoptotic genes, Bnip3 and Tnfsrf12a, were slightly downregulated in maGSCs relative to ESCs, but most genes did not substantially differ between the cell types. 


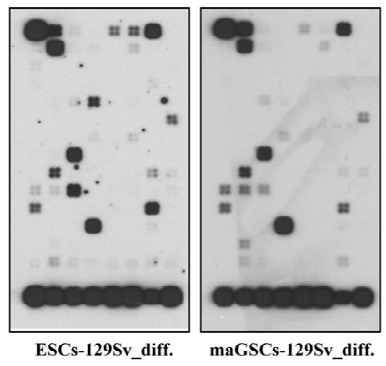

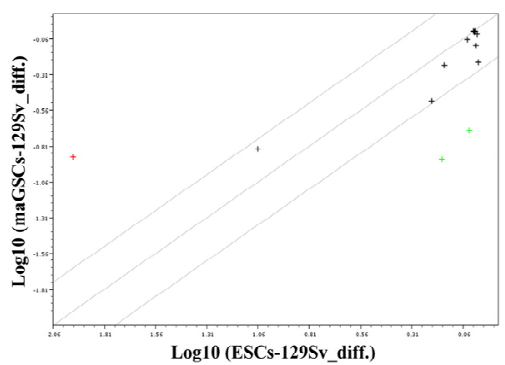

C.

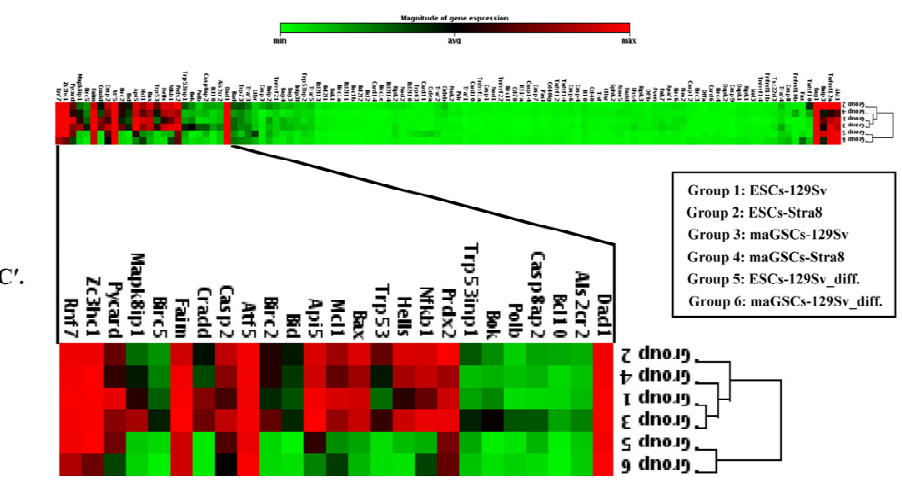

Figure 2. Expression profiling of apoptosis-related genes in differentiated ESCs and maGSCs. (A) OligoGEArray blot showing the expression pattern of apoptosis-related genes in ESCs and maGSCs of the 129Sv background that had been differentiated for 21 days with retinoic acid. (B) Scatterplot analysis of differentiated ESCs and maGSCs revealing similar gene expression patterns in both differentiated cell types with upregulation of Nfkb1 and downregulation of Pycard and Bnip3 in differentiated maGSCs. (C) Heat map analysis of undifferentiated ESCs and maGSCs (from both the 129Sv and the Stra8-EGFP backgrounds) as well as differentiated ESCs and maGSCs, revealeing all undifferentiated cell types in one cluster, while differentiated cell types are distant and clustered together. $\left(\mathbf{C}^{\prime}\right)$ Specific and strong expression of several anti-apoptotic and pro-apoptotic genes in undifferentiated ESCs and maGSCs relative to differentiated cells.

\section{Citrinin-induced apoptosis and transcriptome analysis of early-apoptotic ESCs and maGSCs}

The particular expression pattern of intrinsic apoptotic pathway-related genes led us to evaluate how both ESCs and maGSCs react to the induction of apoptosis through the intrinsic pathway. Citrinin (CTN), a mycotoxin, is known to induce apoptosis through the intrinsic pathway in ESCs and to generate reactive oxygen species (ROS), which cause DNA damage and subsequent p53- induced apoptosis [21]. In this context, we induced apoptosis in ESCs and maGSCs with CTN $(200 \mu \mathrm{M})$ for $24 \mathrm{~h}$ and analyzed the percentage 
of apoptotic cells by annexin-V and 7-AAD staining (Fig. $3 \mathrm{~A}^{\prime}, \mathrm{B}^{\prime}$ ). After $24 \mathrm{~h}$ of CTN treatment, both ESCs and maGSCs had lost the characteristic colony morphology and appeared as typical apoptotic cells (Fig. 3A, B). Flow cytometric analysis after annexin-V and 7-AAD staining revealed a substantial presence of early-apoptotic cells ( $\sim 35 \%$ of the total cell population, annexin- $\mathrm{V}^{+\mathrm{ve}} / 7-\mathrm{AAD}^{-\mathrm{ve}}$ ) in CTN-treated ESCs and maGSCs, but only $\sim 8-15 \%$ of un-treated and DMSO control cells displayed an early-apoptotic phenotype (Fig. $3 \mathrm{~A}^{\prime}, \mathrm{B}^{\prime}$ ). The percentage of late apoptotic (annexin- $\mathrm{V}^{+\mathrm{ve}} / 7-\mathrm{AAD}^{+\mathrm{ve}}$ ) and viable (annexin- $\mathrm{V}^{\text {-ve }} / 7-\mathrm{AAD}^{-\mathrm{ve}}$ ) cells were also significantly similar between CTN-treated ESCs and maGSCs. Overall, these results indicate that maGSCs, like ESCs, are reactive to CTN and undergo apoptosis at a similar rate.

The intrinsic-pathway related gene expression pattern in our OligoArray suggests that this pathway is constitutively active in pluripotent cells and might play a role in resistance to genotoxicity. Because, CTN is also known to induce DNA damage through the generation of reactive oxygen species (ROS) and the subsequent activation of the intrinsic apoptotic pathway, we performed transcriptome analysis using early-apoptotic cells as outlined (Fig. 3C) to identify the factors that are responsible for maintaining genomic integrity. Transcriptome analysis of early-apoptotic ESCs and maGSCs revealed that the majority of genes were equally expressed in both cell types ( $\sim 94 \%$ similarity), but 1257 ( $\sim 6 \%$ ) genes were differentially expressed (Fig. 3D). Comparison of early-apoptotic ESCs transcriptome with our previously described transcriptome of undifferentiated ESCs [17] showed $\sim 80 \%$ similarity, indicating that $\sim 20 \%$ genes are differentially regulated in early-apoptotic cells (Supplementary Fig. S1A). Similarly, early-apoptotic maGSCs showed $\sim 67 \%$ similarity to their undifferentiated counterparts and $\sim 33 \%$ differentially regulated genes (Supplementary Fig. S1B). Further comparison of differentially regulated genes in early-apoptotic ESCs and maGSCs showed $\sim 44 \%$ of commonly upregulated and $\sim 55 \%$ commonly downregulated genes (Supplementary Fig. S1C, D). The principle component analysis (PCA) of the transcriptome of early-apoptotic cells and our previously described transcriptomes of undifferentiated and differentiated cells [17] clearly showed the clustering of early-apoptotic ESCs and maGSCs, which are quite distant from their undifferentiated and differentiated counterparts (Fig. 3E). Similar results were obtained when we analyzed the transcriptome data using a hierarchical clustering model (Supplementary Fig. S2). 
A.

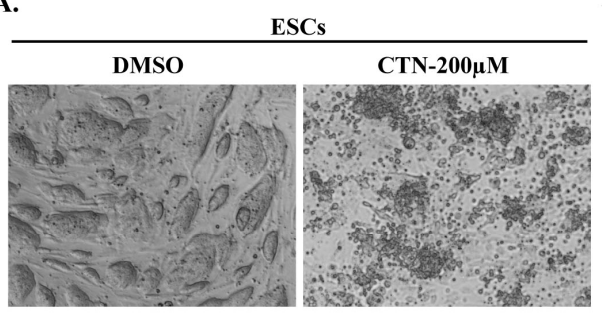

$A^{\prime}$.

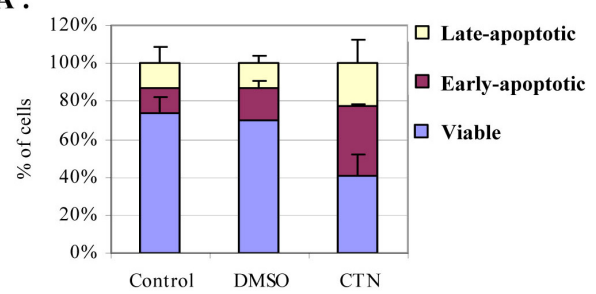

B.

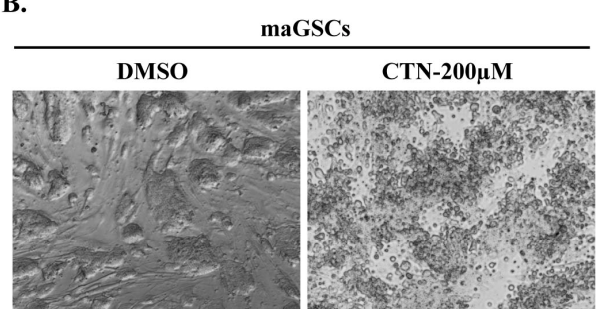

B'.

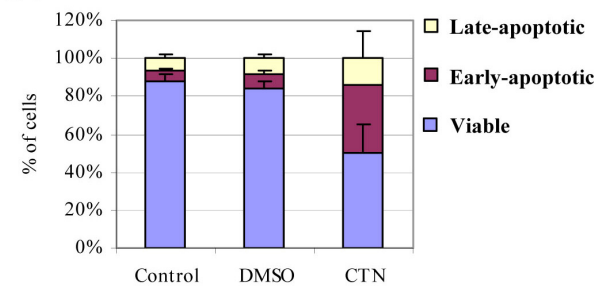

D.

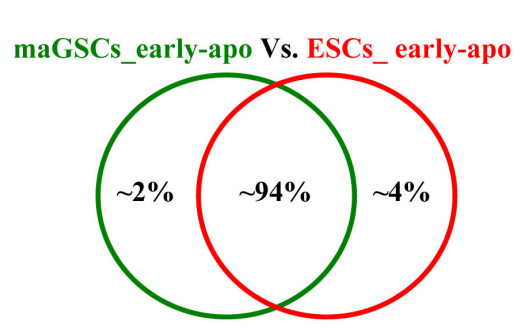

C.

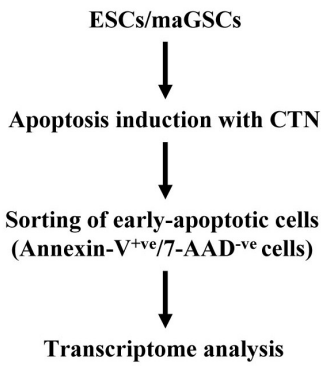

E.

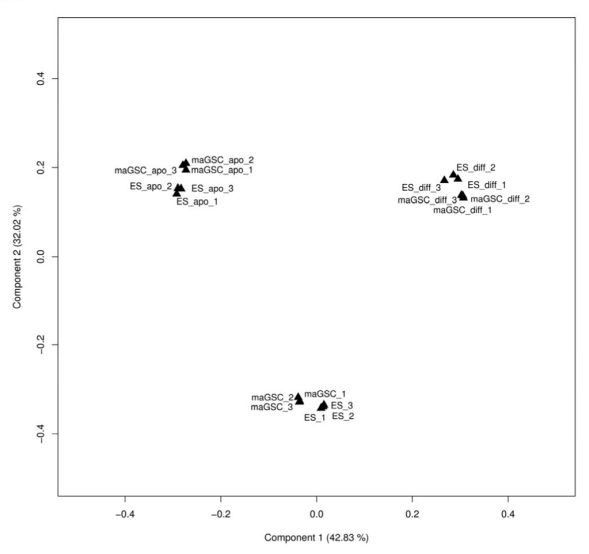

Figure 3. Induction of apoptosis and transcriptome analysis of early-apoptotic ESCs and maGSCs.

ESCs (A) and maGSCs (B) treated with DMSO for 24h showed typical colony morphology, whereas cells treated with CTN for $24 \mathrm{~h}$ lost their typical colony morphology and appeared as blebs. (A') Stacked bar graph showing the flow cytometric data of annexin-V and 7-AAD staining on control (non-treated), DMSOtreated, and CTN-treated ESCs. (B') Stacked bar graph showing the flow cytometric data of annexin-V and 7-AAD staining on control (non-treated), DMSO-treated, and CTN-treated maGSCs. (C) Outline of the strategy to identify pluripotency- as well as apoptosis-related genes in pluripotent cells. ESCs and maGSCs were treated with $\mathrm{CTN}$, and early apoptotic cells (annexin- $\mathrm{V}^{+\mathrm{ve}} / 7-\mathrm{AAD}^{\text {-ve }}$ cells) were collected by flow cytometry. The sorted early-apoptotic cells were then used for transcriptome analysis. (D) The transcriptomes of early-apoptotic ESCs and maGSCs were $\sim 94 \%$ identical during the apoptotic response, 
whereas 1257 genes were differentially expressed. (E) Principle component analysis showing the clustering of early apoptotic ESCs and maGSCs transcriptomes, which are distant to previously generated transcriptomes of undifferentiated as well as differentiated ESCs and maGSCs.

\section{Identification of new pluripotent cell-specific and apoptosis-related candidate genes}

The transcriptome analysis of early-apoptotic ESCs and maGSCs facilitated the identification of new candidate genes that might be specifically expressed in pluripotent cells and might play a role in genotoxicity-triggered cell death. We focused on genes that are highly modulated in early-apoptotic cells (Table 1) to characterize their role in the response to genotoxicity. Further, we performed quantitative real-time PCR (qPCR) for the selected candidate genes and found matrix metalloproteinase-10 (Mmp10) and Fibroblast growth factor 4 (Fgf4) to be specifically expressed in pluripotent cells but not in any of the analyzed adult mouse tissues (Fig. 4A). Another candidate gene that we selected is myeloid cell nuclear differentiating agent (Mnda) which bears a death domain with an unknown function. Although Mnda is expressed in heart and liver, apart from pluripotent cells, it is expressed in no other mouse tissue (Fig. 4A). We choose Fgf4 and Mnda for further analysis and performed qPCR to validate the downregulation seen in the transcriptome. The qPCR data further confirmed the downregulation of Fgf4 and Mnda in early-apoptotic cells (Fig. 4B, C).

Table 1. List of selected upregulated and downregulated candidate genes in earlyapoptotic ESCs and maGSCs.

\begin{tabular}{|c|c|c|c|}
\hline \multicolumn{2}{|c|}{ Upregulated genes } & \multicolumn{2}{c|}{ Downregulated genes } \\
\hline Gene Name & $\begin{array}{c}\text { Expressed mainly in } \\
\text { pluripotent cells }\end{array}$ & Gene Name & $\begin{array}{c}\text { Expressed mainly in } \\
\text { pluripotent cells }\end{array}$ \\
\hline Hspa1a & No & Mnda & $* * *$ \\
\hline Mia2 & No & Adm & No \\
\hline Dnaia1 & No & Mmp10 & Yes \\
\hline Hist2h2be & No & Fgf4 & Yes \\
\hline Sycp3 & N/A & Fbln2 & No \\
\hline & & Hist1h1b & No \\
\hline
\end{tabular}

Yes: Specific expression in pluripotent cells

No: Expressed in pluripotent cells as well as in analyzed adult mouse tissue.

***: Expressed in pluripotent cells, heart and liver, but still considered as a candidate gene. 


\section{Role of Fgf4 in response to apoptosis and genotoxicity induction}

To study the role of Fgf4 in response to induced genotoxicity and apoptosis, we generated an ESC line with stable Fgf4 overexpression (Fgf4-OE) that expressed Fgf4 at levels approximately 15-fold higher levels than those found in control cells (Supplementary Fig. S3A) and also used a previously described Fgf4 ${ }^{-/}$ESC line (Fgf4KO) [22]. Both Fgf4-OE and Fgf4-KO cell lines showed normal colony morphology and proliferation under standard ESC culture conditions (data not shown). Moreover, when induced to differentiate for 12 days with RA treatment, both cell types demonstrated differentiation potential comparable to control cells, as assessed by qPCR of differentiation marker genes (Supplementary Fig. S4). Further, we challenged these cells with CTN for $12 \mathrm{~h}$ and $24 \mathrm{~h}$, and assayed for survival with annexin-V and 7-AAD staining. Analysis of these results indicated that both Fgf4-OE and Fgf4-KO cells responded to CTN in a similar manner with no noticeable differences from the wild-type cells response (Fig. 4D-F).

To analyze the DNA damage response in Fgf4-OE and Fgf4-KO, we induced DNA damage with neocarzinostatin (NCS), a known, potent inducer of DSBs, similar to $\gamma$ irradiation, in various cell types. Currently, there are no reports of NCS treatment on ESCs or other pluripotent cell lines. To verify the DSBs induction in ESCs, we stained the control and NCS treated ESCs with $\gamma$-H2A.X, a marker for DSBs (Supplementary Fig. S5). Analysis of these results indicated the presence of a weak but significant amount of $\gamma$ H2A.X staining in control cells and higher signal intensities in NCS-treated cells (Supplementary Fig. S5). The $\gamma$-H2A.X foci gradually decreased by $24 \mathrm{~h}$ of recovery (Supplementary Fig. S5) indicating DNA damage by NCS and subsequent activation of DNA repair machinery. Thereafter, we treated Fgf4-OE, Fgf4-KO, and wild-type control ESCs with NCS and analyzed cell cycle parameters at various time points (Fig. 5A-C). We found that control ESCs displayed a G2/M arrest, as previously shown with $\gamma$ irradiation [12]. The number of cells in G1 and S phase began to increase by $36 \mathrm{~h}$ and were further increased by $48 \mathrm{~h}$, indicating a resumption of the cell cycle (Fig. 5A). Moreover, approximately $35-40 \%$ of control cells were subG1/apoptotic cells by $48 \mathrm{~h}$ (Fig. 5A). Strikingly, very few Fgf4-KO cells were apoptotic at $48 \mathrm{~h}(\sim 20 \%)$, whereas approximately $35-40 \%$ of both control and Fgf4-OE cells were apoptotic at this time point (Fig. 5C). Moreover, Fgf4-KO cells appeared to resume the cell cycle by $36 \mathrm{~h}$, as it was observed in control cells (Fig. 5C). 
A.
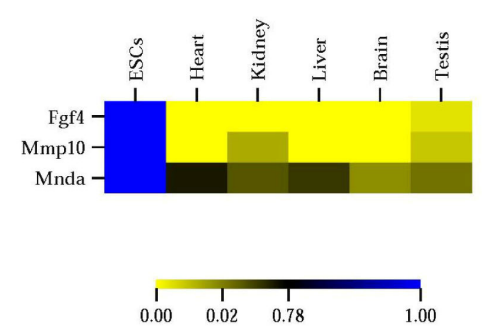

B.

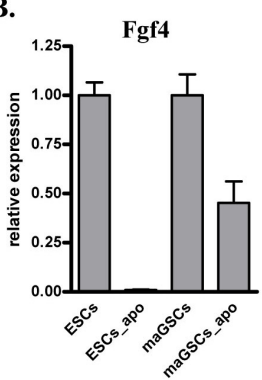

C.

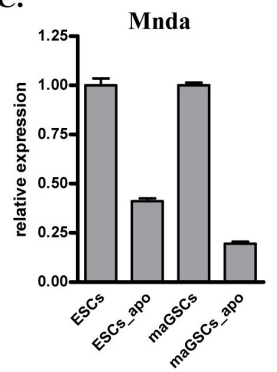

E.

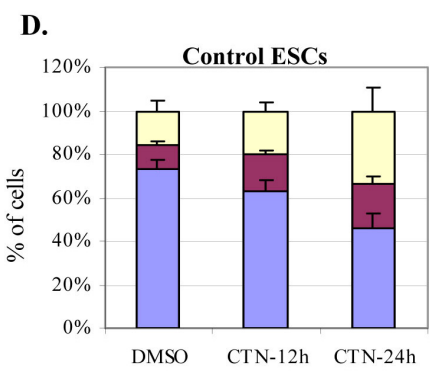

$\square$ Late Apoptotic

$\square$ Early Apoptotic

$\square$ Vital
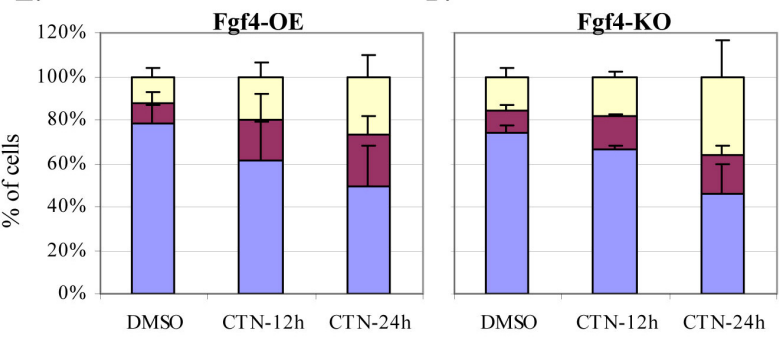

H.

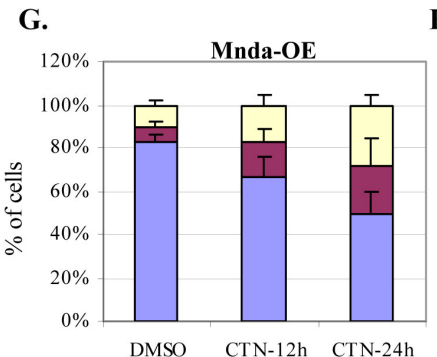

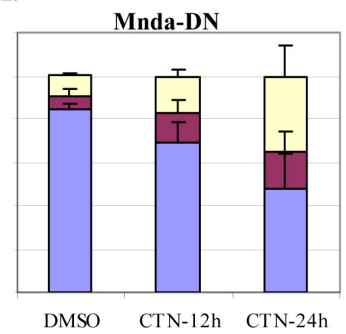

Figure 4. Identification and characterization of novel pluripotency- and apoptosis-related genes. (A) Heat map representation of qPCR data of selected candidate genes in ESCs and adult mouse tissues. (B) The qPCR analysis confirming the downregulation of Fgf4 in early apoptotic ESCs and maGSCs. (C) The qPCR analysis confirming the downregulation of Mnda in early apoptotic ESCs and maGSCs. (D-H) Stacked bar graphs showing the percentage of viable, early-apoptotic, and late-apoptotic cells in either DMSO- or CTNtreated cells. Induction of apoptosis and analysis by annexin-V/7-AAD staining after $12 \mathrm{~h}$ and $24 \mathrm{~h}$ of CTN treatment in wild-type ESCs. (D), Fgf4-OE (Fgf4-overexpressing) cells (E), Fgf4-KO (Fgf4-knock-out) cells (F), Mnda-OE (Mnda-overexpressing) cells (G), Mnda-DN (Mnda-downregulated) cells (H).

\section{Role of Mnda in response to apoptosis and genotoxicity induction}

To study the role of Mnda in response to genotoxicity- and apoptosis-inducing stimuli, we generated a stable Mnda-overexpressing cell line (Mnda-OE), in which Mnda is expressed at levels $\sim 3$-fold higher than in wild-type cells (Supplementary Fig. S3B). We also generated a cell line (Mnda-DN), in which Mnda is downregulated through stable expression of shRNA against Mnda, resulting in approximately $90 \%$ downregulation (Supplementary Fig. S3B). These two cell lines displayed normal colony morphology and 
proliferation under standard ESC culture conditions (data not shown) and also differentiated to all three germ layers when treated with RA (Supplementary Fig. S4). We challenged Mnda-DN and Mnda-OE cells with CTN for $12 \mathrm{~h}$ and $24 \mathrm{~h}$, and analyzed for the survival rate. No overt differences in cell survival rates were observed between control, Mnda-OE, and Mnda-DN cells (Fig. 4D, G, H).

A.
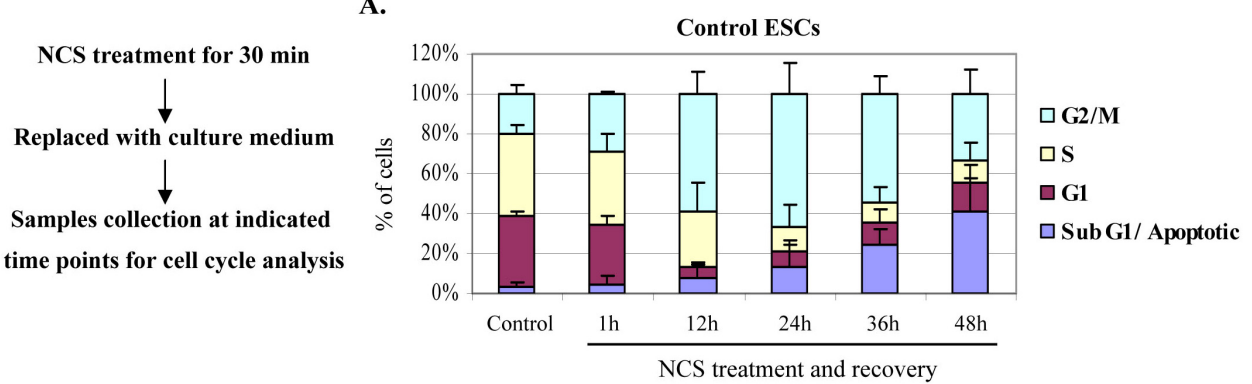

B.

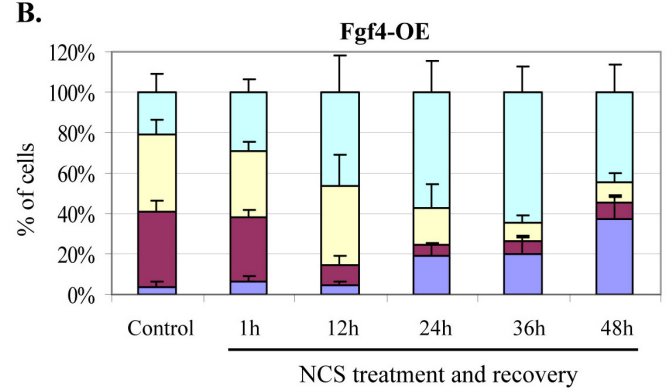

D.

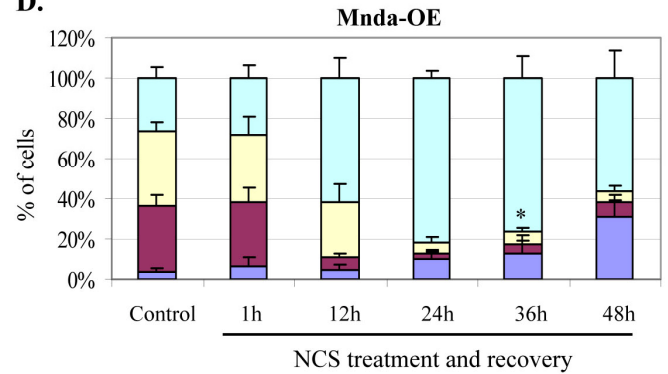

C.

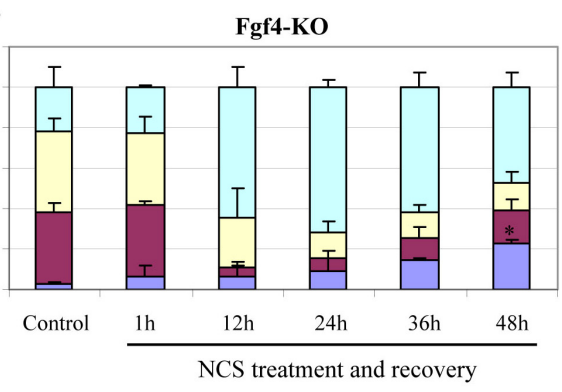

E.

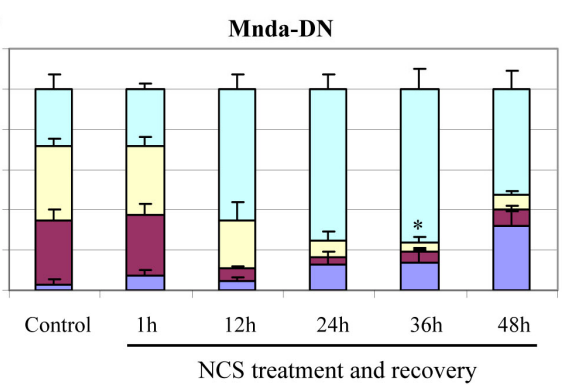

Figure 5. Role of Fgf4 and Mnda in genotoxic stress response of ESCs. Genotoxic stress was induced by treatment with NCS and the cells were recovered at indicated time points for cell cycle analysis as outlined. (A-E) Stacked bar graphs showing the percentage of cells in various stages of cell cycle (SubG1/Apoptotic, G1, S and G2/M) in either control or NCS-treated cells. The cell cycle analyses of (A) Fgf4-OE cells, (B) Fgf4-KO cells, (C) control cells, (D) Mnda-OE cells, and (E) Mnda-DN cells. The cell cycle data of three or more replicates were calculated and represented as a mean $\pm \mathrm{SD}$. The values which are statistically significant, are indicated with asterisks $(* \mathrm{p}<0.05)$. 
Additionally, we treated Mnda-OE and Mnda-DN cells with NCS and analyzed the cell cycle parameters at various time points (Fig. 5D, E). Cell cycle analysis indicated that a majority ( $\sim 80 \%$ ) of both Mnda-OE and Mnda-DN cells undergo G2/M arrest by $24 \mathrm{~h}$ and that this arrest persisted even after $36 \mathrm{~h}$ of recovery with further delay in the cell cycle resumption (Fig. 5D, E). Finally, we did not observe any differences in the percentage of apoptotic cells between Mnda-OE, Mnda-DN, and control cells (Fig. 5A, D, E).

\section{Discussion}

Several studies have reported that multipotent germline stem cells (mGSCs) that are morphologically and functionally similar to ESCs can be generated from SSCs of neonatal and adult mouse testis, suggesting that SSCs have the ability to give rise to pluripotent cells in vitro $[15,22-26]$. mGSCs from adult mouse testis, termed multipotent adult germline stem cells (maGSCs), were first isolated and described in 2006 by our group [15]. To further evaluate the pluripotent cell characteristics of maGSCs, we extensively studied maGSCs alongside ESCs and demonstrated the similarities between these two cell types [16-20]. In the present study, we investigated the apoptosis-related gene expression profiles and also the cellular responses to apoptosis induction. Further, we selected two candidate genes, namely Mnda and Fgf4, and elucidated their roles in apoptosis or genotoxicity responses in pluripotent cells.

ESCs are characterized by self-renewal, a high rate of proliferation, a characteristic short cell cycle, and the potential to differentiate into all cell lineages of the organism. It is essential to understand how ESCs maintain genome stability and integrity during this rapid proliferation. It has been suggested that ESCs might have evolved with conserved and precise mechanisms to prevent the accumulation of mutations. The existence of such protective mechanisms is further supported by the following evidence: (1) the mutation and somatic recombination frequencies of mouse ESCs are 100-fold lower than in adult somatic cells (fibroblasts) [10], (2) human and mouse ESCs bear a very efficient antioxidant defense against DNA damage mediated by ROS [27], and (3) ESCs are hypersensitive to genotoxicity and can undergo apoptosis without the activation of cell cycle checkpoints, leading to the effective elimination of defective cells [7].

To evaluate the pluripotent cell-specific, apoptosis-related properties of maGSCs, we analyzed the expression of apoptosis-related genes and found an expression profile similar to ESCs. Both cell types displayed the expression of genes involved in the intrinsic 
apoptotic pathway, suggesting a strong similarity between undifferentiated ESCs and maGSCs. However, there are some differences in gene expression among different backgrounds; the ESCs and maGSCs of the 129Sv background are similar to one another, and the cells from the Stra8-EGFP background are identical to one another. Interestingly, we could not detect the expression of genes involved in extrinsic pathway of apoptosis (death receptors and their ligands) suggesting the inactivity or weak activity of this pathway in both pluripotent cell types. Consistent with this data, an earlier study showed the expression of Fas receptor only after inducing apoptosis through O6-methylguanine $(\mathrm{O} 6 \mathrm{MeG})$ [28]. Further, we compared the gene expression profile in RA-differentiated ESCs and maGSCs to evaluate the patterns and similarities of apoptotic genes during differentiation. In agreement with our previous findings from gene expression analysis of RA-differentiated cells [17], both differentiated ESCs and maGSCs possessed an apoptosis-related gene expression profile similar to each other but in sharp contrast to that of undifferentiated cells. The expression of many anti-apoptotic and pro-apoptotic genes are downregulated in RA-differentiated cells, indicating that expression of these genes is specific to pluripotent cells. As ESCs are known to be highly sensitive to genotoxic stress and effectively eliminate damaged cells through apoptosis, the specific expression of these anti-apoptotic and pro-apoptotic genes may suggest a role in the elimination of defective cells.

To study the response of maGSCs to apoptotic stimuli, we treated both ESCs and maGSCs with CTN, a potent inducer of apoptosis with pleiotropic effects in ESCs [21]. CTN is known to induce apoptosis via several mechanisms, such as the generation of DNA-damaging ROS, loss of mitochondrial membrane potential, cytochrome $c$ release, activation of caspase 3 and caspase 9 [21]. Because of this, CTN is a suitable compound to study mitochondrial as well as p53-mediated apoptosis. Treatment of ESCs and maGSCs with CTN induced apoptosis, causing approximately $35 \%$ of both cell types to display an early-apoptotic phenotype. In comparison to ESCs, fewer maGSCs became apoptotic and more remained viable. This could be partly due to high levels of anti-apoptotic or tumor suppressor proteins such as p53, which we observed in OligoArray. To identify novel genes that are significantly upregulated or downregulated during mitochondrial and genotoxicity mediated apoptosis, we sorted early-apoptotic cells after CTN treatment and performed whole genome transcriptome analysis. The transcriptome data further revealed the similarity between early-apoptotic ESCs and maGSCs, and is quite distinct from our 
previous transcriptome data on untreated undifferentiated and differentiated ESCs and maGSCs [17].

The transcriptome analysis of early-apoptotic cells led to the identification of Fgf4 and Mnda as highly downregulated genes that might play a role in mitochondrial or p53mediated apoptotic response. Fgf4 belongs to the FGF superfamily of proteins and is involved in various stages of embryonic development [29]. Although Fgf4 is highly expressed in ESCs relative to differentiated cells, alteration of its expression in undifferentiated ESCs has only slight effects on survival and morphology [30]. Fgf4deficient ESCs show reduced survival of differentiated cells and this could be reversed by the addition of Fgf4 to the culture medium, suggesting that Fgf4 plays an essential role in differentiation [30]. Because the role of Fgf4 during induced apoptosis or genotoxicity in undifferentiated ESCs had not yet been explored, we induced apoptosis or genotoxicity in Fgf4-overexpressing and knock-out (Fgf4-OE and Fgf4-KO, respectively) ESCs. Interestingly, Fgf4-KO cells appeared to be partially protected against DNA damageinduced apoptosis, whereas Fgf4-OE cells did not display any abnormalities. These results are in contrast to previous findings, which showed that induced expression of Fgf4 functions as an anti-apoptotic factor of male germ cells and protects them from hyperthermia-induced apoptosis [31]. These contrasting results could partly be due to different cell types or due to the resistance of Fgf4-KO cells to differentiation. It has been reported that ESCs with DNA damage can induce differentiation by p53-dependent suppression of Nanog that leads to the effective elimination of those differentiated cells by p53-dependent cell cycle arrest and apoptosis [14]. Hence, we hypothesize that Fgf4-KO cells might be resistant to DNA damage-induced differentiation and subsequent apoptosis by p53-dependent mechanisms, as deficiency of Fgf4 blocks differentiation and increases cell survival. These results are in parallel with the observed downregulation of Fgf4 during early- apoptosis, possibly to maintain their survival.

Mnda is a member of the interferon (IFN)-regulated 200 family of proteins that contain a partially conserved 220-amino acid domain, and is thought to interact specifically with other transcriptional regulators [32]. The members of this family also contain a pyrin domain at the amino-terminus, which is proposed to function in programmed cell death and inflammation [33]. Moreover, several proteins of this family, including human MNDA, were shown to promote programmed cell death in several experimental conditions [34-38]. Until now, the expression of human MNDA was 
reported only in hematopoietic cells [35]. Moreover, the expression of hMNDA is most significantly downregulated in myelodysplastic syndrome (MDS), in which elevated levels of apoptosis are detected in granulocyte-macrophage progenitors [39]. Since the expression pattern and the role of mouse Mnda is not yet known and it is highly downregulated during CTN-induced apoptosis, we sought to analyze the function of this protein in responses to genotoxicity. We did not observe any significant differences in protection or sensitivity to apoptosis between control and either Mnda-OE or Mnda-DN cells when apoptosis was induced through CTN. These results parallel those of a previous report, in which it was shown that both deletion and forced expression of MNDA in K562 myeloid leukemia cells revealed extensive degenerative changes to cell morphology when exposed to $\mathrm{H} 2 \mathrm{O} 2$, causing the activation of the intrinsic apoptotic pathway [35]. On the other hand, induction of DNA damage in Mnda-OE and Mnda-DN cells exhibited prolonged G2/M arrest and delayed cell cycle progression. These results suggest that the expression level of Mnda in ESCs is critical to respond against DNA damage and in the decision to resume the cell cycle, where it might provide a wide window for repairing the damaged DNA thus conferring genomic stability.

\section{Conclusions}

Collectively, our results show that maGSCs display an apoptosis-related gene expression profile that is similar to ESCs, suggesting common molecular mechanisms for maintaining the pristine stem cell pool. Notably, responses to the activation of the intrinsic apoptotic pathway are also similar in both cell types. Further, the transcriptome analysis of early apoptotic cells revealed several candidate genes, including Fgf4 and Mnda, which may be involved in this response. As we did not observe any changes after apoptosis induction in ESCs with altered expression of Fgf4 or Mnda but observed changes after DNA damage, we suggest that these genes play an essential role in maintaining genomic integrity and regulating survival in the very early stages of apoptosis before the cascade of the intrinsic pathway becomes activated. Fgf4 and Mnda might be the first indicators of apoptosis or genomic integrity responses in pluripotent cells. 


\section{Methods}

\section{Generation of constructs}

The mouse Mnda expression construct, pUNO1-mMnda (Invivogen) was linearized with ApaLI and then transfected into ESCs by electroporation. The shRNA expression constructs against mouse Mnda (Qiagen) was linearized with ScaI and used for transfection. To generate the Fgf4 overexpression construct with an HA epitope tag (phEF1 $\alpha$-Fgf4_HA), the ORF of Fgf4 was PCR-amplified from pBluescript-mFgf4 (Addgene) using primer pair 5'-GAATTCTGATGGCGAAACGCGGGCCG-3' and 5'GCGGCCGCTCAAGCGTAATCTGGAACATCGTATGGGTAACCACCCAGTCTAGG AAGGAAGTG-3' and cloned into the phEF1 $\alpha$ expression vector, using the EcoRI and NotI restriction sites.

\section{Cell culture}

The derivation of the mouse maGSC and the respective ESC lines from the $129 \mathrm{~Sv}$ and Stra8-EGFP backgrounds were described previously [20]. The Fgf4-KO ESC line was a kind gift from Prof. Rizzino. ${ }^{22}$ Mouse embryonic fibroblasts (MEFs) were grown in standard fibroblast culture conditions. To generate Mnda and Fgf4 overexpression clones (Mnda-OE and Fgf4-OE, respectively), the constructs were electroporated into ESCs and the cells were selected for neomycin resistance. To generate Mnda downregulation clones (Mnda-DN), the shRNA expression constructs against Mnda were electroporated into ESCs and the cells were selected for neomycin resistance. For differentiation experiments, the cells were cultured in medium containing retinoic acid for the indicated time points without leukemia inhibitory factor (LIF) and feeder cells.

\section{Oligonucleotide microarray for detection of apoptosis-specific gene expression}

Expression of apoptosis-specific genes in undifferentiated or differentiated maGSCs and ESCs was examined using Mouse Apoptosis OligoGEArray following the manufacturer's protocol (SABiosciences). Briefly, total RNA extracted from maGSCs and ESCs was used to prepare cDNA followed by biotin 16-dUTP labeling using a GEArray True Amp Labeling kit (SABiosciences). The Mouse Apoptosis OligoGEArray membranes were then hybridized overnight with biotin-labeled cDNA. Signals were detected using a CDP-Star chemiluminescence kit (SABiosciences). Data were analyzed 
using the GEArray Expression Analysis Suite 2.0 (SABiosciences). For fold differences, an arbitrary threshold of 2 was chosen to signify a substantial fold change in either direction. All experiments were done in duplicate.

\section{Apoptosis induction, annexin-V staining, and flow cytometry}

To induce apoptosis through the mitochondrial pathway, maGSCs and ESCs were cultured in medium containing citrinin (CTN) (Sigma) or DMSO (Sigma) (as a control) for either 12 or $24 \mathrm{~h}$. To verify and quantify CTN-induced apoptosis in maGSCs and ESCs, annexin- $\mathrm{V}$ and 7-amino-actinomycin $\mathrm{D}$ (7-AAD) staining was performed using an Annexin V-PE Apoptosis Detection Kit I (BD Biosciences). After staining, flow cytometric measurements were performed on a FACSCalibur flow cytometer (BD Biosciences) and analyzed with CellQuestPro software (BD Biosciences). Early apoptotic cells were sorted using a FACSCanto II (BD Biosciences).

\section{DNA damage induction and cell cycle analysis}

For induction of DNA damage, the cells were treated with $50 \mathrm{ng} / \mathrm{ml} \mathrm{NCS}$ diluted in PBS. After 30min of treatment, the cells were washed with PBS and supplemented with culture medium. For cell cycle analysis, the cells were trypsinized after indicated time points and were washed with PBS followed by ethanol fixation at $-20^{\circ} \mathrm{C}$ for a minimum of 2h. After fixation, the cells were washed with PBS, resuspended in PBS containing 10 $\mu \mathrm{g} / \mathrm{ml}$ propidium iodide (PI) and $1 \mathrm{mg} / \mathrm{ml}$ RNase A, and incubated at $37^{\circ} \mathrm{C}$ for $30 \mathrm{~min}$. After the incubation, cells were measured on a FACSCalibur flow cytometer and analyzed after exclusion of cell doublets. All experiments were performed in three or more biological replicates.

\section{RNA extraction and $q P C R$}

Total RNA was isolated with Nucleospin miRNA kit (Macherey Nagel) and $5 \mu \mathrm{g}$ DNase-I treated total RNA was used to prepare cDNA using the Superscript-II Reverse Transcriptase kit (Invitrogen). Real-time qPCR was performed in triplicate using $1 \mu \mathrm{l}$ cDNA (1:20 dilution) with SYBR green (Invitrogen). Primer sequences used for qPCR are listed in Table S1. The qPCR data were analyzed by the delta-delta-Ct method. All experiments were performed in two or more biological replicates. 


\section{Whole genome microarray analysis and statistical interpretation}

Whole genome microarray analysis was performed essentially as described earlier [17]. Briefly, total RNA isolated from cells undergoing apoptosis that had been sorted by FACS. The total RNA was used to prepare cDNA. The Cy3- or Cy5-labeled cDNA was hybridized to Agilent Technologies 44K Mouse Whole Genome Microarrays (G4122A). Data intensities were extracted using the software 'Feature Extraction 9.1' (Agilent Technologies, Germany), and the raw microarray data were normalized with a non-linear loess regression method [40]. Differentially regulated genes were identified by ANOVA, and the resulting data were adjusted with the Benjamini-Hochberg method to control the False-Discovery-Rate [41]. All experiments were performed in three biological replicates. 


\section{List of Abbreviations}

ESCs - Embryonic stem cells

maGSCs- multipotent adult germ-line stem cells

CTN - Citrinin

NCS - Neocarzinostatin

DSBs - DNA strand breaks

Fgf4 - Fibroblast growth factor 4

Mnda - Myeloid cell nuclear differentiating agent

RA - Retinoic acid

\section{Author's contribution}

TK participated in the design, carried out the experiments and drafted the manuscript.

DVKP participated in the design and coordination of the study, drafted the manuscript.

RD carried out the experiments and helped in interpretation of the results.

JN participated in the design and coordination of the study.

IS carried out the experiments.

WE participated in the design and helped in drafting the manuscript.

All authors read and approved the final manuscript.

\section{Acknowledgments}

The authors would like to thank Dr. Salinas-Riester, Mr. Opitz, and Dr. Meyer for their great support with microarray experiments and Prof. Rizzino for kindly providing Fgf4 $^{-/-}$ESCs. This work was partly supported by the German Research Foundation (Deutsche Forschungsgemeinschaft) DFG SPP1356 (EN 84/22-1) and DFG FOR 1041 (EN 84/23-1). 


\section{References}

1. Evans MJ, Kaufman MH: Establishment in culture of pluripotential cells from mouse embryos. Nature 1981, 292(5819):154-156.

2. Martin GR: Isolation of a pluripotent cell line from early mouse embryos cultured in medium conditioned by teratocarcinoma stem cells. Proc Natl Acad Sci U S A 1981, 78(12):7634-7638.

3. Chambers I: The molecular basis of pluripotency in mouse embryonic stem cells. Cloning Stem Cells 2004, 6(4):386-391.

4. Geijsen N, Horoschak M, Kim K, Gribnau J, Eggan K, Daley GQ: Derivation of embryonic germ cells and male gametes from embryonic stem cells. Nature 2004, 427(6970):148-154.

5. O'Shea KS: Self-renewal vs. differentiation of mouse embryonic stem cells. Biol Reprod 2004, 71(6):1755-1765.

6. Suda Y, Suzuki M, Ikawa Y, Aizawa S: Mouse embryonic stem cells exhibit indefinite proliferative potential. J Cell Physiol 1987, 133(1):197-201.

7. Aladjem MI, Spike BT, Rodewald LW, Hope TJ, Klemm M, Jaenisch R, Wahl GM: ES cells do not activate p53-dependent stress responses and undergo p53independent apoptosis in response to DNA damage. Curr Biol 1998, 8(3):145155 .

8. Fluckiger AC, Marcy G, Marchand M, Negre D, Cosset FL, Mitalipov S, Wolf D, Savatier P, Dehay C: Cell cycle features of primate embryonic stem cells. Stem Cells 2006, 24(3):547-556.

9. Hong Y, Cervantes RB, Tichy E, Tischfield JA, Stambrook PJ: Protecting genomic integrity in somatic cells and embryonic stem cells. Mutat Res 2007, 614(1-2):48-55.

10. Cervantes RB, Stringer JR, Shao C, Tischfield JA, Stambrook PJ: Embryonic stem cells and somatic cells differ in mutation frequency and type. Proc Natl Acad Sci U S A 2002, 99(6):3586-3590.

11. Stambrook PJ: An ageing question: do embryonic stem cells protect their genomes? Mech Ageing Dev 2007, 128(1):31-35. 
12. Chuykin IA, Lianguzova MS, Pospelova TV, Pospelov VA: Activation of DNA damage response signaling in mouse embryonic stem cells. Cell Cycle 2008, 7(18):2922-2928.

13. Hong Y, Stambrook PJ: Restoration of an absent G1 arrest and protection from apoptosis in embryonic stem cells after ionizing radiation. Proc Natl Acad Sci U S A 2004, 101(40):14443-14448.

14. Lin T, Chao C, Saito S, Mazur SJ, Murphy ME, Appella E, Xu Y: p53 induces differentiation of mouse embryonic stem cells by suppressing Nanog expression. Nat Cell Biol 2005, 7(2):165-171.

15. Guan K, Nayernia K, Maier LS, Wagner S, Dressel R, Lee JH, Nolte J, Wolf F, Li $\mathrm{M}$, Engel W et al: Pluripotency of spermatogonial stem cells from adult mouse testis. Nature 2006, 440(7088):1199-1203.

16. Dihazi H, Dihazi GH, Nolte J, Meyer S, Jahn O, Muller GA, Engel W: Multipotent adult germline stem cells and embryonic stem cells: comparative proteomic approach. J Proteome Res 2009, 8(12):5497-5510.

17. Meyer S, Nolte J, Opitz L, Salinas-Riester G, Engel W: Pluripotent embryonic stem cells and multipotent adult germline stem cells reveal similar transcriptomes including pluripotency-related genes. Mol Hum Reprod 2010, 16(11):846-855.

18. Zovoilis A, Nolte J, Drusenheimer N, Zechner U, Hada H, Guan K, Hasenfuss G, Nayernia K, Engel W: Multipotent adult germline stem cells and embryonic stem cells have similar microRNA profiles. Mol Hum Reprod 2008, 14(9):521529.

19. Khromov T, Pantakani DV, Nolte J, Wolf M, Dressel R, Engel W, Zechner U: Global and gene-specific histone modification profiles of mouse multipotent adult germline stem cells. Mol Hum Reprod 2011, 17(3):166-174.

20. Zechner U, Nolte J, Wolf M, Shirneshan K, Hajj NE, Weise D, Kaltwasser B, Zovoilis A, Haaf T, Engel W: Comparative methylation profiles and telomerase biology of mouse multipotent adult germline stem cells and embryonic stem cells. Mol Hum Reprod 2009, 15(6):345-353.

21. Chan WH: Citrinin induces apoptosis in mouse embryonic stem cells. IUBMB Life 2008, 60(3):171-179. 
22. Izadyar F, Pau F, Marh J, Slepko N, Wang T, Gonzalez R, Ramos T, Howerton K, Sayre C, Silva F: Generation of multipotent cell lines from a distinct population of male germ line stem cells. Reproduction 2008, 135(6):771-784.

23. Kanatsu-Shinohara M, Inoue K, Lee J, Yoshimoto M, Ogonuki N, Miki H, Baba S, Kato T, Kazuki Y, Toyokuni $\mathrm{S}$ et al: Generation of pluripotent stem cells from neonatal mouse testis. Cell 2004, 119(7):1001-1012.

24. Kanatsu-Shinohara M, Lee J, Inoue K, Ogonuki N, Miki H, Toyokuni S, Ikawa M, Nakamura T, Ogura A, Shinohara T: Pluripotency of a single spermatogonial stem cell in mice. Biol Reprod 2008, 78(4):681-687.

25. Ko K, Tapia N, Wu G, Kim JB, Bravo MJ, Sasse P, Glaser T, Ruau D, Han DW, Greber $\mathrm{B}$ et al: Induction of pluripotency in adult unipotent germline stem cells. Cell Stem Cell 2009, 5(1):87-96.

26. Seandel M, James D, Shmelkov SV, Falciatori I, Kim J, Chavala S, Scherr DS, Zhang F, Torres R, Gale NW et al: Generation of functional multipotent adult stem cells from GPR125+ germline progenitors. Nature 2007, 449(7160):346350 .

27. Saretzki G, Armstrong L, Leake A, Lako M, von Zglinicki T: Stress defense in murine embryonic stem cells is superior to that of various differentiated murine cells. Stem Cells 2004, 22(6):962-971.

28. Roos WP, Christmann M, Fraser ST, Kaina B: Mouse embryonic stem cells are hypersensitive to apoptosis triggered by the DNA damage O(6)methylguanine due to high E2F1 regulated mismatch repair. Cell Death Differ 2007, 14(8):1422-1432.

29. Kosaka N, Sakamoto H, Terada M, Ochiya T: Pleiotropic function of FGF-4: its role in development and stem cells. Dev Dyn 2009, 238(2):265-276.

30. Wilder PJ, Kelly D, Brigman K, Peterson CL, Nowling T, Gao QS, McComb RD, Capecchi MR, Rizzino A: Inactivation of the FGF-4 gene in embryonic stem cells alters the growth and/or the survival of their early differentiated progeny. Dev Biol 1997, 192(2):614-629.

31. Hirai K, Sasaki H, Yamamoto H, Sakamoto H, Kubota Y, Kakizoe T, Terada M, Ochiya T: HST-1/FGF-4 protects male germ cells from apoptosis under heatstress condition. Exp Cell Res 2004, 294(1):77-85. 
32. Johnstone RW, Trapani JA: Transcription and growth regulatory functions of the HIN-200 family of proteins. Mol Cell Biol 1999, 19(9):5833-5838.

33. Stehlik C, Fiorentino L, Dorfleutner A, Bruey JM, Ariza EM, Sagara J, Reed JC: The PAAD/PYRIN-family protein ASC is a dual regulator of a conserved step in nuclear factor kappaB activation pathways. $J$ Exp Med 2002, 196(12):16051615.

34. Aglipay JA, Lee SW, Okada S, Fujiuchi N, Ohtsuka T, Kwak JC, Wang Y, Johnstone RW, Deng C, Qin J et al: A member of the Pyrin family, IFI16, is a novel BRCA1-associated protein involved in the p53-mediated apoptosis pathway. Oncogene 2003, 22(55):8931-8938.

35. Briggs RC, Shults KE, Flye LA, McClintock-Treep SA, Jagasia MH, Goodman SA, Boulos FI, Jacobberger JW, Stelzer GT, Head DR: Dysregulated human myeloid nuclear differentiation antigen expression in myelodysplastic syndromes: evidence for a role in apoptosis. Cancer Res 2006, 66(9):4645-4651.

36. D'Souza S, Xin H, Walter S, Choubey D: The gene encoding p202, an interferon-inducible negative regulator of the p53 tumor suppressor, is a target of p53-mediated transcriptional repression. J Biol Chem 2001, 276(1):298-305.

37. Fotouhi-Ardakani N, Kebir DE, Pierre-Charles N, Wang L, Ahern SP, Filep JG, Milot E: Role for myeloid nuclear differentiation antigen in the regulation of neutrophil apoptosis during sepsis. Am J Respir Crit Care Med 2010, 182(3):341-350.

38. Wen Y, Yan DH, Spohn B, Deng J, Lin SY, Hung MC: Tumor suppression and sensitization to tumor necrosis factor alpha-induced apoptosis by an interferon-inducible protein, p202, in breast cancer cells. Cancer Res 2000, 60(1):42-46.

39. Pradhan A, Mijovic A, Mills K, Cumber P, Westwood N, Mufti GJ, Rassool FV: Differentially expressed genes in adult familial myelodysplastic syndromes. Leukemia 2004, 18(3):449-459.

40. Yang YH, Dudoit S, Luu P, Lin DM, Peng V, Ngai J, Speed TP: Normalization for cDNA microarray data: a robust composite method addressing single and multiple slide systematic variation. Nucleic Acids Res 2002, 30(4):e15. 
Results

41. Bretz F, Landgrebe $J$, Brunner E: Multiplicity issues in microarray experiments. Methods Inf Med 2005, 44(3):431-437. 


\section{Supplementary data}

A.

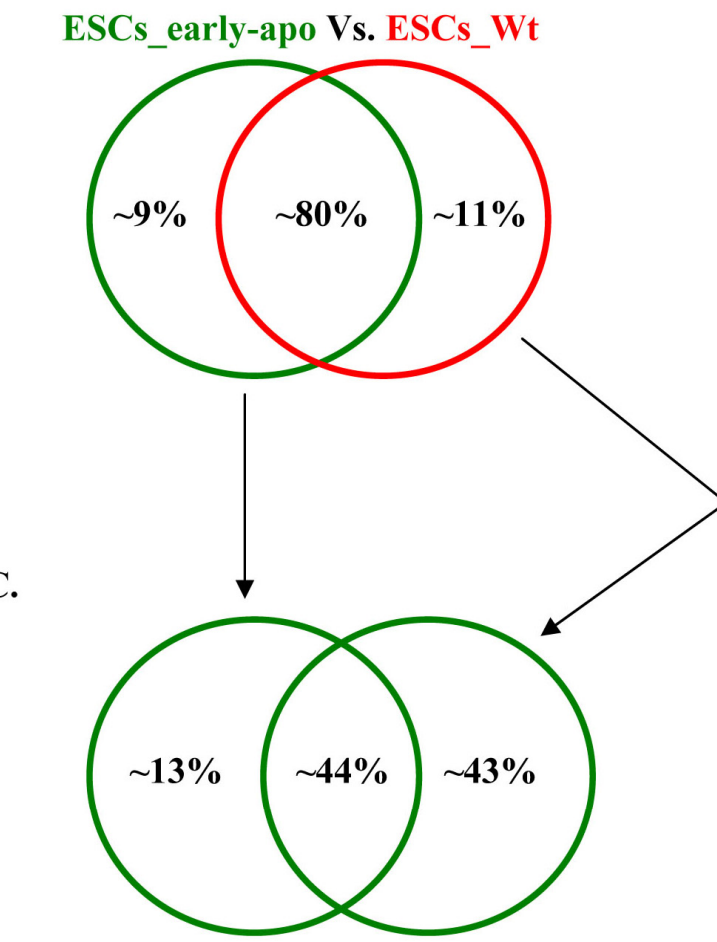

Upregulated genes in

ESCs_early-apo and maGSCs_early-apo
B.

maGSCs_early-apo Vs. maGSCs_Wt

D.

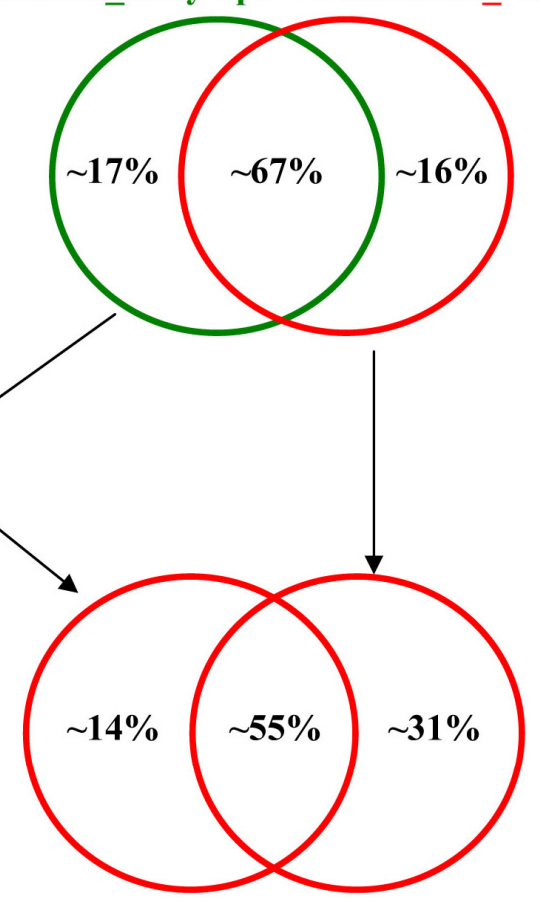

Doenregulated genes in

ESCs_early-apo and maGSCs_early-apo

Figure S1. Comparison of undifferentiated, and early-apoptotic ESCs and maGSCs transcriptomes. Venn diagram showing the comparison of early-apoptotic (early-apo) and undiffrenetiated (Wt) cells transcriptomes of ESCs (A) and maGSCs (B). Venn diagram showing the upregulated genes in earlyapoptotic ESCs and maGSCs and their similarities and differences (C). Venn diagram showing the downregulated genes in early-apoptotic ESCs and maGSCs and their similarities and differences (D). 


\section{Hierarchical clustering (Pearsons Corr.,Av. Linkage)}

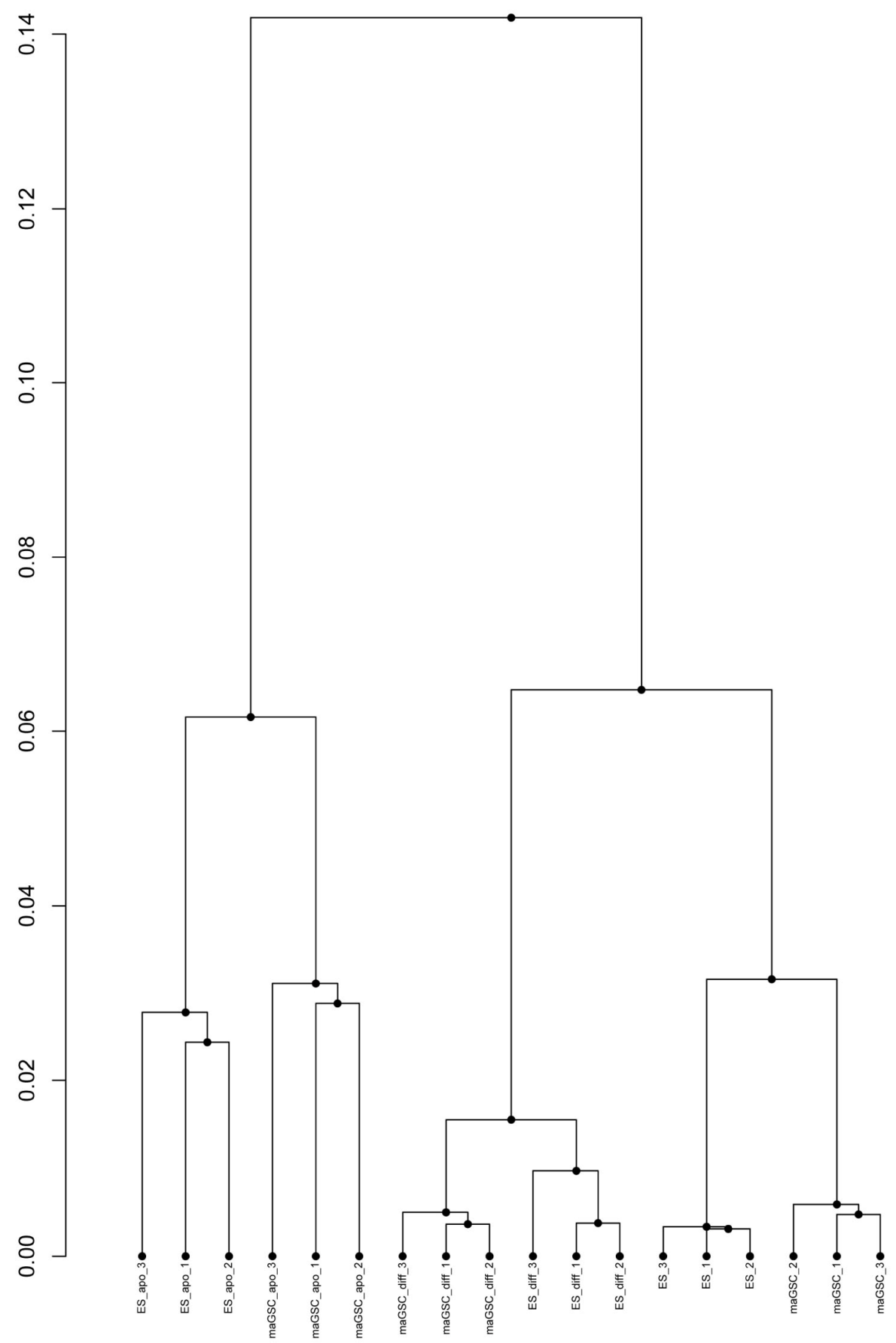

Figure S2. Hierarchical clustering of undifferentiated, differentiated, and early-apoptotic ESCs and maGSCs transcriptomes. The clustering showing the similarities within three replicates of early-apoptotic ESCs and maGSCs as well as undifferentiated and differentiated cell types. The transcriptomes of earlyapoptotic cells is again clustered together and is distinct from both undifferentiated and differentiated cells transcriptomes. 
A.

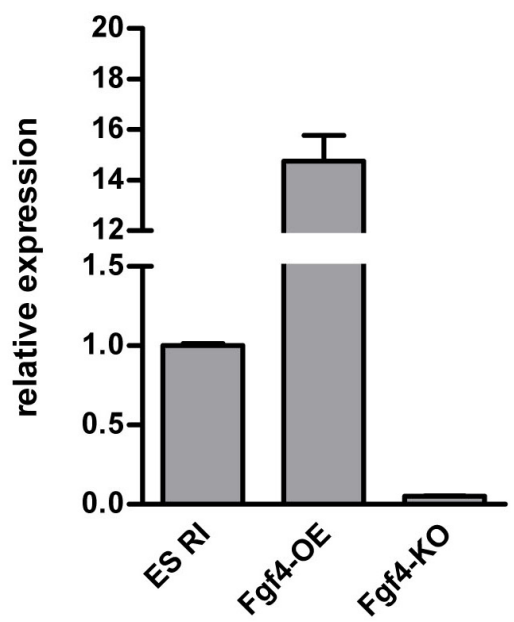

B.

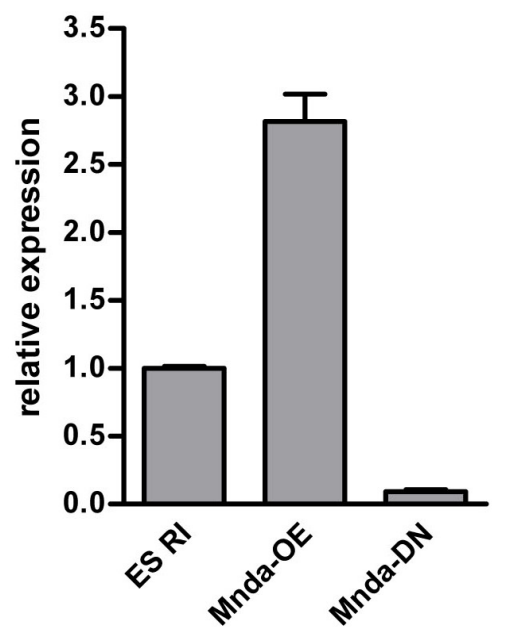

Figure S3. Expression analysis of overexpressing, knockdown, and knockout cell lines. (A) Real-time qPCR analysis showing the expression of Fgf4 in control, Fgf4-OE, and Fgf4-KO cells. (B) Real-time qPCR analysis showing the expression of Mnda in control, Mnda-OE, and Mnda-DN cells. 

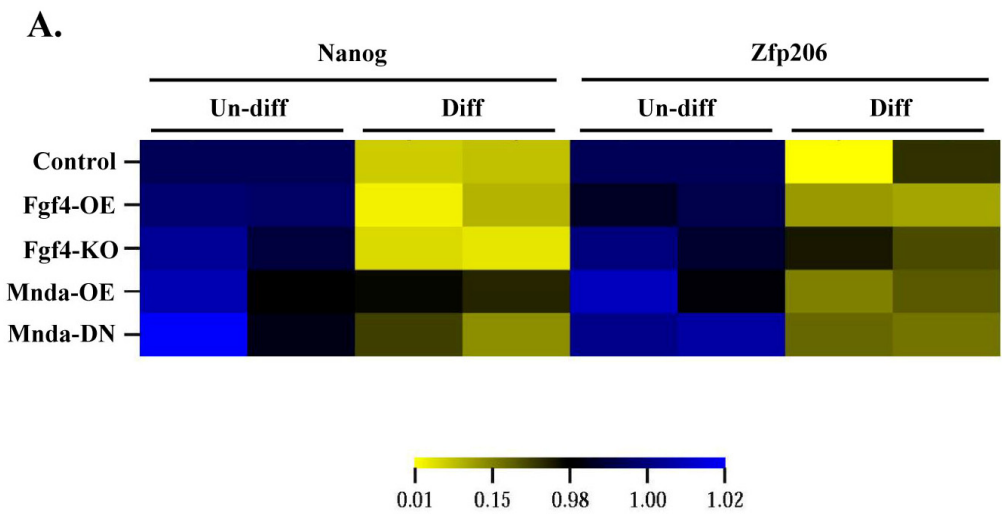

B.

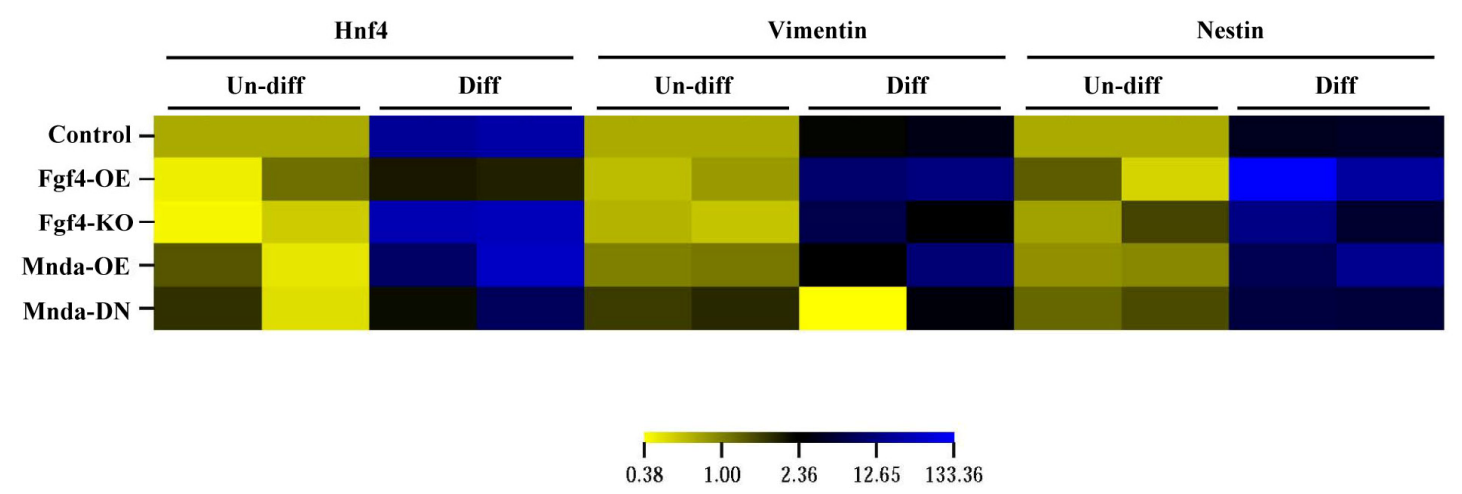

Figure S4. Differentiation potential of overexpression and knockdown cell lines. (A) Heat map representing the qPCR data of Nanog and Zp206 expression in undifferentiated and differentiated control ESCs, Fgf4-OE, Fgf4-KO, Mnda-OE, and Mnda-DN cell lines. The expression of pluripotency-related genes, Nanog and Zfp206 was reduced or absent in differentiated cells as expected. (B) Heat map representing the qPCR data of $\mathrm{Hnf4}$, vimentin, and nestin expression in undifferentiated and differentiated control ESCs, Fgf4-OE, Fgf4-KO, Mnda-OE, and Mnda-DN cell lines. Expression of Hnf4, vimentin, and nestin was upregulated, indicating differentiation. 


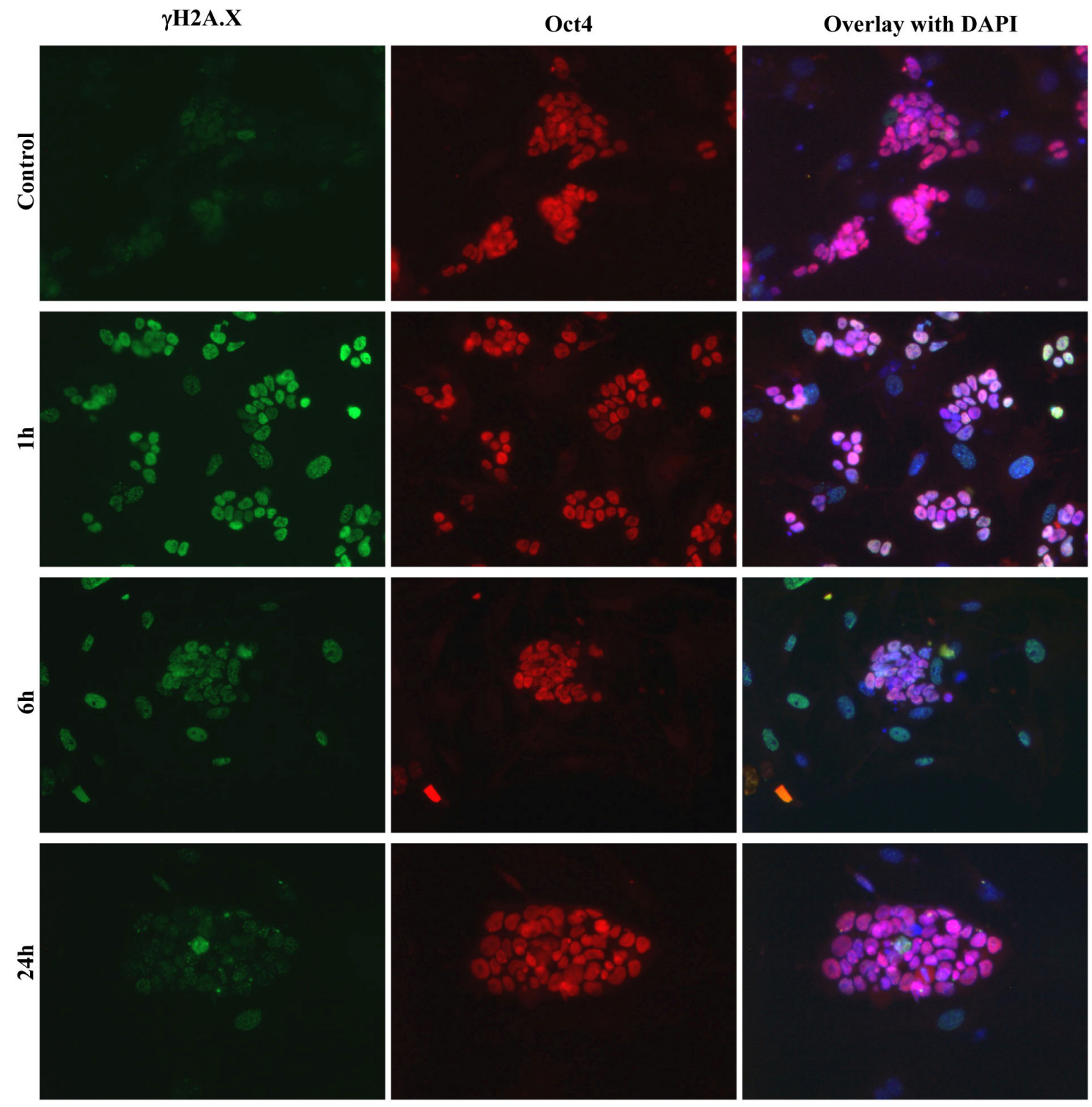

Figure S5. Analysis of NCS induced DNA damage in ESCs. Wild-type ESCs were treated with NCS for $30 \mathrm{~min}$ and allowed to recover for $24 \mathrm{~h}$. Immunostaining at indicated time points using $\gamma \mathrm{H} 2 \mathrm{~A} . \mathrm{X}$ (green) indicated the strong induction of DSBs by $1 \mathrm{~h}$ and gradual disappearance by $24 \mathrm{~h}$, indicating DNA repair. Oct4 (red) was used to distinguish the ESCs from feeder cells, and DAPI (blue, overlay) was used to stain the nucleus. 
Table S1. Primers used in this study

$\begin{array}{lll}\text { Gene } & \text { Forward primer sequence } & \text { Reverse primer sequence } \\ \text { Rpl13 } & \text { 5'-GCTCCAAGCTCATCCTGTTC-3' } & \text { 5'-CTCTGGCCTTTTCCTTTTTG-3' } \\ \text { Hprt } & \text { 5'-CGTCGTGATTAGCGATGATG-3' } & \text { 5'-TATGTCCCCCGTTGACTGAT-3' } \\ \text { Fgf4 } & \text { 5'-GTGGTGAGCATCTTCGGAGT-3' } & \text { 5'-GTACGCGTAGGCTTCGTAGG-3' } \\ \text { Nanog } & \text { 5'-TTACAAGGG TCTGCTACTGAGATG-3' } & \text { 5'-CAGGACTTGAGAGCTTTTGTTTG-3' } \\ \text { Zfp206 } & \text { 5'-GAGAGGAGGTGGTACAGCTATTG-3' } & \text { 5'-AGGTGGAGGTAACTCATTCAGTG-3' } \\ \text { Hnf4 } & \text { 5'-CCACATGTACTCCTGCAGGTTTAG-3', } & \text { 5'-CGCTCATTTTGGACAGCTTC-3' } \\ \text { Nestin } & \text { 5'-CTGCAGGCCACTCAAAACTT-3' } & \text { 5'-ATTAGGCAAGGGGGAAGAGA-3' } \\ \text { Vimentin } & \text { 5'-TGCAGTCATTCAGACAGGATGT-3' } & \text { 5'-ATCTCTTCATCGTGCAGTTTCTTC-3' } \\ \text { Mmp10 } & \text { 5'-TGGATAAAGGCTTCCCAAGA-3' } & \text { 5'-GGGGTCAAACTCGAACTGTG-3' }\end{array}$




\section{Discussion}

The therapeutic potential held by maGSCs prompted for further detailed characterisation of these cells in comparison to ESCs, the "gold standard of pluripotency". Towards this end, our group has extensively characterized maGSCs and found high similarities between ESCs and maGSCs on the level of miRNA expression, transcriptome, proteome, as well as DNA methylation (Dihazi et al., 2009; Zechner et al., 2009; Zovoilis et al., 2008; Meyer et al. 2010). To further elaborate the characteristics of maGSCs, in this thesis we analysed the epigenetic and apoptotic properties of maGSCs in comparison to ESCs.

In the first part, through the epigenetic analysis, we found similar profiles in ESCs and maGSCs for activating histone modifications such as $\mathrm{H} 3 \mathrm{~K} 4 \mathrm{me} 3, \mathrm{H} 3 \mathrm{~K} 9 \mathrm{ac}$ as well as for repressive modifications such as $\mathrm{H} 3 \mathrm{~K} 27 \mathrm{me} 3$ and $\mathrm{H} 3 \mathrm{~K} 9 \mathrm{me} 3$ at the global chromatin level. Further, the gene-specific chromatin modification analysis using ChIP assay demonstrated an active chromatin state at the promoter regions of pluripotency-related genes and a bivalent chromatin structure at the promoters of lineage committed genes in both cell lines.

In the second part of the thesis, the expression profiling of apoptosis-related genes using OligoGEArray in undifferentiated and differentiated ESCs and maGSCs showed similar gene expression patterns. During and after induction of apoptosis, the morphological features, early-apoptotic response as well as the gene expression profiles were nearly identical in both cell types. The global transcriptome of early-apoptotic ESCs and maGSCs revealed a high similarity of gene expression which differs from the transcriptome of their undifferentiated and differentiated counterparts. Moreover, the geneexpression analysis of early-apoptotic cells led us to identify two putative candidate genes, which may play a crucial role in the survival of pluripotent stem cells.

\subsection{Mouse germ-line stem cell derived pluripotent stem cells}

Pluripotency can be induced in embryonic, neonatal or adult germ-line stem cells (GSCs) by defined in vitro culture conditions. Of particular importance is the derivation of pluripotent stem cells from neonatal and adult GSCs, as they can be used in tailor-made regenerative medicine applications by avoiding the ethical and immunological concerns. Although the generation of pluripotent stem cells from embryonic GSCs was reported in 1992 (Matsui et al., 1992; Resnick et al., 1992), the derivation of pluripotent cells from neonatal GSCs was reported 12 years later by Kanatsu-Shinohara et al., (2004). 
Subsequently, our group Guan et al. (2006) reported the generation of pluripotent cells from adult mouse GSCs which are termed as multipotent adult germ-line stem cells (maGSCs). In the following years, several independent research groups have generated pluripotent cells from either neonatal or adult GSCs, thus highlighting the reproducibility and the capacity of GSCs to yield pluripotent cells (Seandel et al., 2007; Izadyar et al., 2008; Kanatsu-Shinohara et al., 2008; Ko et al., 2009).

The characterization of GSC-derived pluripotent cell lines in comparison to ESCs on global gene expression level revealed both similarities and differences between the cells of different research groups. The pluripotent cells generated by Kanatsu-Shinohara et al. (2004) displayed $\sim 97 \%$ identity to ESCs (Kanatsu-Shinohara et al., 2008), whereas cells from Guan et al. (2006) and Ko et al. (2009) displayed $\sim 99 \%$ and $\sim 98 \%$ identity, respectively (Meyer et al.) suggesting their pluripotent cell characteristics. In contrast to these observations, cells generated by Izadyar et al., (2008) showed only $\sim 62-65 \%$ of identity to ESCs on transcriptome level. On the other hand, analysis of DNA methylation at imprinting control regions (ICRs) in GSC-derived pluripotent cells revealed marked differences between cells of various research groups. The imprinting status of GSC-derived pluripotent cells of Kanatsu-Shinohara et al., (2004), Guan et al., (2006) and Shin et al., (2011) displayed a pattern reflecting the resetting of methylation imprints in GSCs which has been only initiated but is not yet complete (Zechner et al., 2009). Strikingly, these cells are different to those of Izadyar et al. (2008) and Ko et al. (2009), who showed rather androgenic imprinting pattern. These observed differences may be partly due to different stages of the isolated GSCs or defects in reprogramming of GSCs to pluripotent state using different culture conditions.

\subsection{Comparative analysis of global and gene-specific histone modification profiles in maGSCs and ESCs}

It is known that chromatin modifications contribute to maintenance of pluripotency, self-renewal and differentiation (Loh et al., 2006). In general, pluripotent ESCs contain less heterochromatin (low level of H3K9me2/3), and more dynamic chromatin structure with higher global levels of histone acetylation as well as overexpression of chromatin remodelling proteins like Chd1 compared to lineage-committed cells (Boyer et al., 2006; Efroni et al., 2008; Gaspar-Maia et al., 2009; Mattout and Meshorer, 2010). Two antagonistic methyltransferase enzyme groups, Polycomb Group (PcG) and Trithorax 
Group (TrxG) play an important role in chromatin remodelling. TrxG proteins play a role in transcriptional initiation by catalysing the methylation of H3K4 (Petruk et al., 2001; Smith et al., 2004) whereas PcG enzymes catalyze tri-methylation of H3K27 with their two chromatin remodelling complexes; PRC1 and PRC2 which mediates the transcriptional repression. The PRC2 core components Ezh2, Suz12, and EeD catalyse di- and trimethylation of histone $\mathrm{H} 3$ at lysine-27 and promotes the recruitment of PRC1 (Kirmizis et al., 2004; Boyer et al., 2006; Schuettengruber et al., 2007). PRC1 in turn mediates monoubiquitination of histone $\mathrm{H} 2 \mathrm{~A}$ at lysine-119 and thus promotes chromatin condensation (Wang et al., 2004). In the undifferentiated stage of ESCs, PcG proteins maintain the pluripotency by binding to the promoters of developmental regulators in order to establish the repression marks (H3K27me3) leading to the suppression of gene expression and differentiation.

Histone acetyltransferases (HATs) play a role in pluripotency networks by promoting the transcriptional activity of pluripotency regulators such as Oct4, Sox2, and Nanog by acetylating histones H3 and H4 (Bartova et al., 2008; Chen et al., 2008). Further, histone deacetylases (HDACs) including the class 1 HDAC (Hdac1) facilitate the induction of ESC differentiation (Thiagalingam et al., 2003). Taken together, during differentiation the expression of pluripotency-related genes is getting repressed first by the recruitment of a complex containing histone methyltransferase G9a (Feldman et al., 2006), together with HDACs which causes deacetylation of local histones. Additionally, H3K4 is getting demethylated and $\mathrm{H} 3 \mathrm{~K} 9$ methylated. The methylation of $\mathrm{H} 3 \mathrm{~K} 9$ serves as a binding site for the chromodomain protein heterochromatin protein $\underline{1}$ (HP1), thus generating a form of local heterochromatin. Further, G9a recruits the methylases DNMT3A and DNMT3B, which mediate methylation of the underlying DNA (Fuhrmann et al., 2001; Feldman et al., 2006; Epsztejn-Litman et al., 2008; Cedar and Bergman, 2009) (Fig. 4.1). Finally, the DNA methylation completes the epigenetic silencing of key pluripotency transcription factors upon differentiation.

Previously, several studies have already reported the comparison of induced pluripotent cell lines, lineage-committed and carcinoma cells with ESCs on chromatin modification level (Kimura et al., 2004; Azuara et al., 2006; O'Neill et al., 2006; Takahashi and Yamanaka, 2006; Mikkelsen et al., 2007; Takahashi et al., 2007; Wernig et al., 2007; Santos et al., 2010). However, till now there are no studies comparing the GSC-derived pluripotent stem cells to ESCs on epigenetic level in relation to histone modifications. 


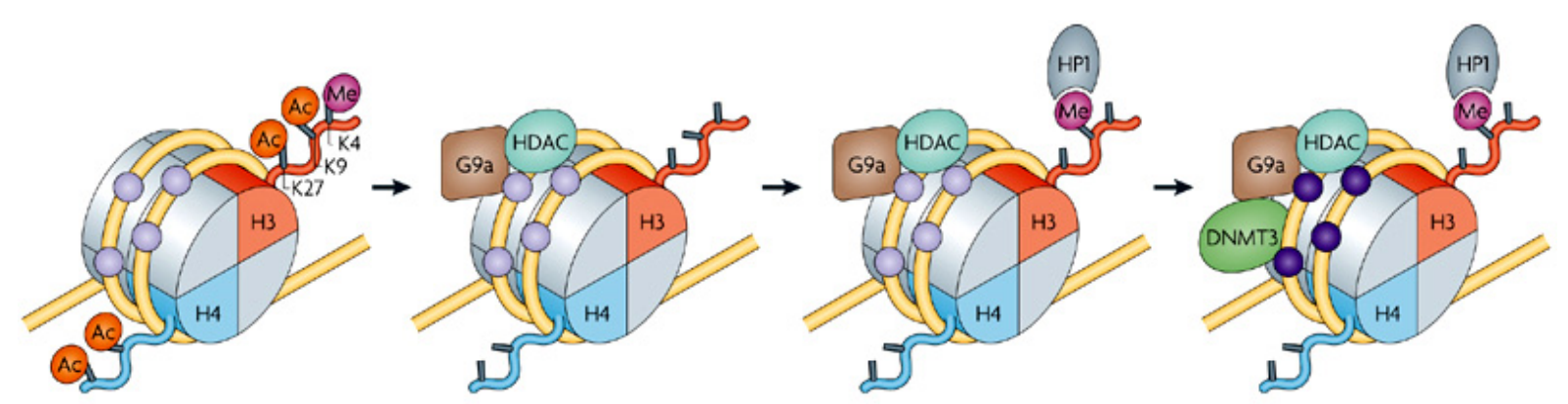

Figure 4.1. Chromatin remodeling processes of pluripotency genes during differentiation. In undifferentiated ESCs, the promoter regions of pluripotency related genes such as Oct4 and Nanog have unmethylated $\mathrm{CpG}$ islands (lilac circles) and are associated with acetylation (Ac) on histone $\mathrm{H} 3$ and $\mathrm{H} 4$ as well as with methylation (Me) on H3K4. During the differentiation histone deacethylase (HDAC) deacetylates local histones and G9a catalyses the tri-methylation of histone H3K9. This modification serves as a binding site fore the chromodomain protein heterochromatin protein 1 (HP1). Additionally demethylated H3K4 together with deacetylation generates a form of local heterochromatin. Finally, G9a recruits the methylases DNMT3A and DNMT3B, which leads to de novo DNA methylation (purple circles) of the underlying DNA. (Figure adopted from: Cedar and Bergman, 2009).

To analyze the histone modification profiles of maGSCs in our present study (Khromov et al., 2011), we compared maGSCs and ESCs of three different genetic backgrounds (129Sv, Stra8-EGFP and C57Bl/6) to each other to examine the similarities and differences (Fig. 4.2). First, we analysed the global histone modification levels using a resent introduced flow cytometric approach (Obier and Muller, 2010). Our flow cytometric measurements of the global active (H3K4me3 and $\mathrm{H} 3 \mathrm{~K} 9 \mathrm{ac})$ and repressive (H3K427me and $\mathrm{H} 3 \mathrm{~K} 9 \mathrm{me} 3$ ) chromatin modifications revealed almost identical levels in maGSCs and ESCs. These results were further confirmed by western blot analysis using MEFs as a control. Our results correlate well with those in previous reports, which showed the global levels of histone modifications in undifferentiated ESCs and iPSCs in comparison to differentiated cells and carcinoma cells (Kimura et al., 2004; Azuara et al., 2006; Meshorer and Misteli, 2006; O'Neill et al., 2006; Mikkelsen et al., 2007; Takahashi et al., 2007; Wernig et al., 2007; Santos et al., 2010). 


\section{ESR1 (129Sv) \\ ES- Stra8-EGFP $\longleftrightarrow$ maGSCs Stra8-EGFP \\ ES-C57BL/6 $\longleftrightarrow$ maGSCs-C57BL/6}

Figure 4.2. Scheme to analyze the epigenetic features in ESC and maGSCs of three different genetic backgrounds.

Moreover, the immunofluorescence experiments aimed to analyze the nuclear localisation and staining patterns of four histone modifications (active: H3K4me3 and H3K9ac, and repressive: H3K427me and $\mathrm{H} 3 \mathrm{~K} 9 \mathrm{me} 3)$ revealed very high similarities between ESCs and maGSCs. These observations are in agreement with the reported findings in ESCs (Lehnertz et al., 2003; Kimura et al., 2004; Meshorer et al., 2006). The study of Kimura et al., (2004) proved the global histone modification by immunocytochemical as well as a gene specific ChIP analysis in ESCs, thymocytes (derivates of bone marrow hematopoietic progenitor's cells) and their hybrids. The authors verified the acetylation of $\mathrm{H} 3 / \mathrm{H} 4$, di-/trimethylation of $\mathrm{H} 3 \mathrm{~K} 4$ and $\mathrm{H} 3 \mathrm{~K} 9$ as well as trimethylation of $\mathrm{H} 3 \mathrm{~K} 27$. The ESC specific chromatin marks found in this study are concordant with our observed results in ESCs and maGSCs of 129Sv/Stra8-EGFP/C57B1/6 backgrounds, such as $\mathrm{H} 3 \mathrm{~K} 9 \mathrm{me} 3$ positive signals in condensed heterochromatin regions displayed by discrete spots in nuclei. Next, we performed ChIP with specific antibodies against activating (H3K4me3 and $\mathrm{H} 3 \mathrm{~K} 9 \mathrm{ac})$ and repressing (H3K27me3 and H3K9me3) histone modifications on chromatin of ESCs and maGSCs. The qRT-PCR analysis of ChIP precipitated DNA for the promoter region of pluripotency related genes (Oct4, Sox2, and Nanog) revealed the enrichment of activating marks H3K4me3 and H3K9ac and low levels of two repressive modifications $\mathrm{H} 3 \mathrm{~K} 9 \mathrm{me} 3$ and $\mathrm{H} 3 \mathrm{~K} 27 \mathrm{me} 3$. Our results are in accordance with previous reports, where the promoter regions of pluripotency related genes were shown to be associated with the active chromatin (Hattori et al., 2004; Kimura et al., 2004; Azuara et al., 2006; O'Neill et al., 2006). Further, in our analysis Hoxa11, one of the numerous key developmental genes that was previously described to be associated simultaneously with permissive $\mathrm{H} 3 \mathrm{~K} 4 \mathrm{me} 3$ and the repressive $\mathrm{H} 3 \mathrm{~K} 27$ me 3 modifications, in mouse ESC (Bernstein et al., 2006) showed also the same bivalent modification pattern in 
maGSCs. As reported, we also could not observe the enrichment of repressive H3K9me3 in the promoter region of Hoxal1 (Bernstein et al., 2006). Additionally, we performed the ChIP assay with two more lineage specific genes (Pax5 and Zfpm2), and obtained the similar "bivalent" chromatin structure in both pluripotent cell lines (Fig. 4.3) as it was previously reported (Wernig et al., 2007). These authors reported the bivalent chromatin structure at the promoter regions Zfpm2 and Pax5 in ESCs and induced pluripotent stem cells (iPSCs).
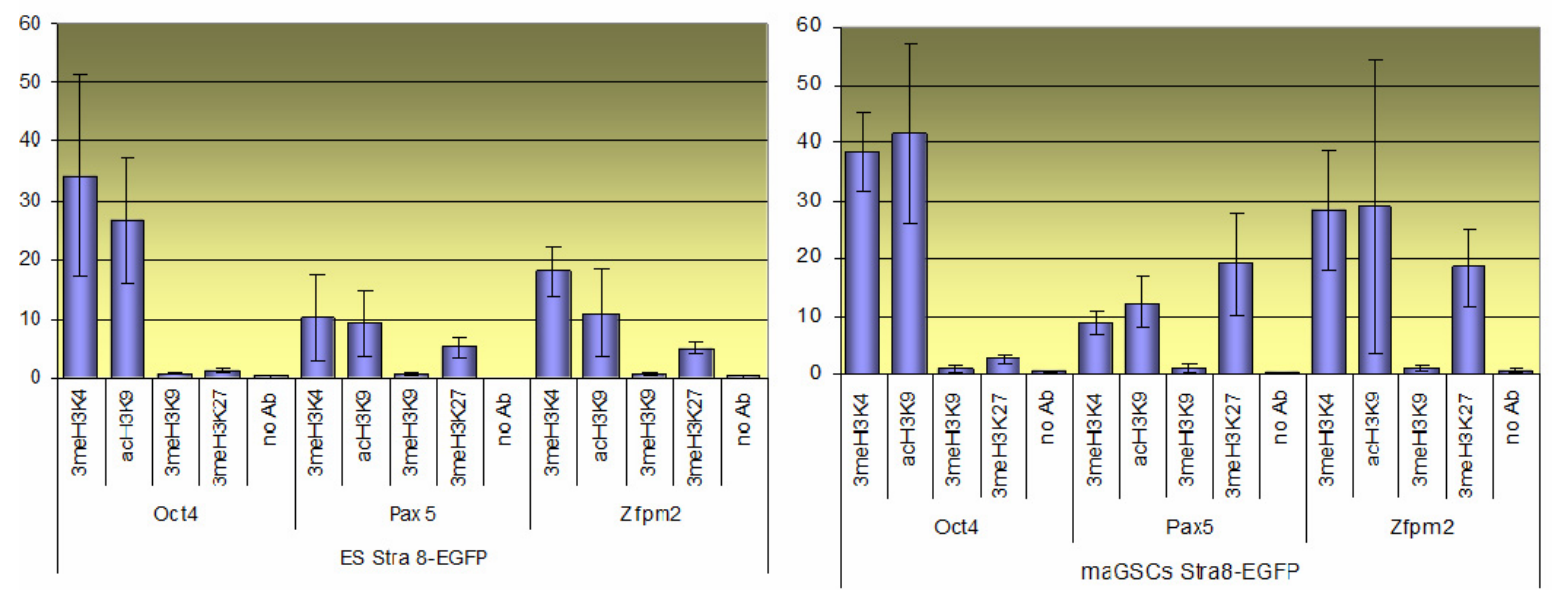

Figure 4.3. Analysis of histone modification levels at Oct4, Pax5 and Zfpm2 in ESCs and maGSCs The chromatin of ESCs and maGSCs from Stra8-EGFP background was subjected to ChIP analysis using antibodies against the four different histone modifications. The precipitated DNA was analysed by qPCR for abundance of the various modifications at the promoter regions of the key pluripotency gene Oct4 and the key developmental lineage-control genes Pax5 and Zfpm2. The qPCR data are presented as percentage of input DNA.

The co-occurrence of both repressive and active histone modifications are thus called "bivalent marks" and the genes associated with these marks are kept prepared for expression but halted by these opposing modifications in the undifferentiated stage. During differentiation, these bivalent modifications will be resolved and transformed to either active or repressive configuration depending on the lineage direction (Fig. 4.4). The balance between pluripotency and differentiation is thus regulated by interplay between pluripotency specific transcription factors and lineage specific factors through epigenetic mechanisms involving methylation of DNA and chromatin histone modification. 


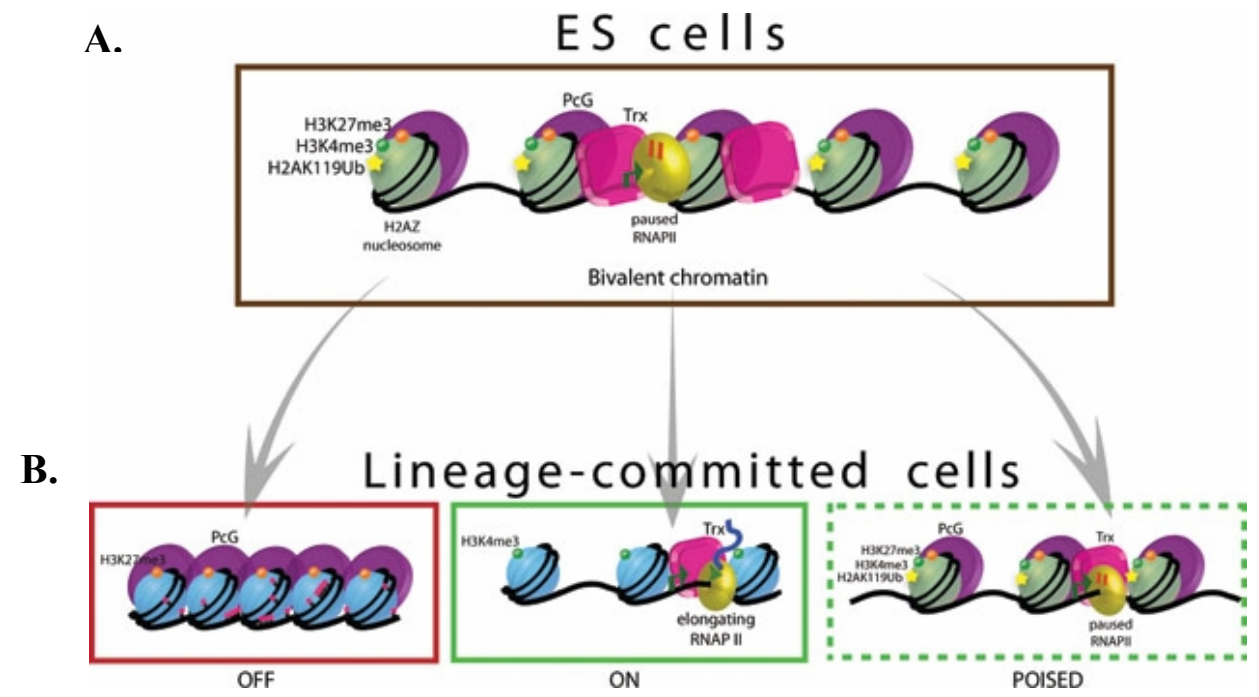

Figure 4.4. The bivalent chromatin signature of pluripotent cells. A: Bivalent chromatin domains (presence of both active (H3K4me3) end repressive (H3K27me3)) mark the promoter regions of developmentally important genes in pluripotent ES cells. B: PcG and TrxG proteins catalyze the trimethylation of histone $\mathrm{H} 3$ on lysine 27 and 4, respectively. PRC1, a complex of PcG, is also recruited to many of these genes and can mono-ubiquitinylate histone $\mathrm{H} 2 \mathrm{~A}$ on lysine 119, a modification that is thought to be important for gene silencing. As such, bivalent genes are said to be silent, yet poised for activation. Upon differentiation, the bivalent histone marks can be resolved to monovalent modifications in which the gene is either "ON" or "OFF". Bivalent domains can also be maintained or newly established in lineagecommitted cells. Blue nucleosome: resolved chromatin state. Green nucleosome: bivalent chromatin confirmation. (Figure adopted from: Sha and Boyer, 2009).

In summary, we could describe the global and gene specific histone modification patterns in maGSCs to be very similar to the epigenetic profile of ESCs. These results further add an additional layer of information to the existing data of maGSCs' pluripotent nature.

\subsection{Comparative analysis of the apoptosis-related gene expression profiles of mouse ESCs and maGSCs}

In a viable organism apoptosis or programmed cell death is a process to eliminate cells without evoking an inflammation or immune response. Apoptosis can be induced by two major pathways: the intrinsic pathway, which is induced by anticancer drugs or by stimuli such as DNA damage and is controlled by mitochondrial membrane permeabilisation, and the extrinsic pathway, in which a death receptor triggers the apoptotic cascade (Iannolo et al., 2008). The pathway through which p53 promotes 
apoptosis is associated with mitochondrial dependent signalling cascade (Mihara et al., 2003) through mitochondrial cytochrome c release and activation of Apaf1-/caspase9 containing "apoptosome" (Schuler et al., 2000; Soengas et al., 1999). This pathway involves transcriptional regulation of target genes as well as transcription-independent function of $\mathrm{p} 53$. Depending on the cell type, p53 functions in multiple processes to retain the genomic integrity by either cell cycle arrest (in G1 or G2 phase), DNA repair or apoptosis induction (Hall et al., 1996; Levine, 1997).

In normal stem cells once DNA damage is detected, it can initiate different reactions: either it will be repaired or tolerated otherwise it induces signalling cascades which lead to the removal of the DNA damaged cells by apoptosis (Kruse et al., 2007). In the most lethal DNA lesions there are DSBs (double stranded breaks) that are recognized by proteins with both signalling (kinase) and repairing activity. ATM (ataxia telangiectatsia mutated), a representative member of this sensor family is immediately activated when DSBs are induced by ionising radiation or radiomimetic drugs (Momcilovic et al., 2010). ATM has several known substrates, mostly associated with cell cycle checkpoints or the induction of apoptosis, such as p53, CHK1/2, histone H2AX and BRCA1 (Cortez et al., 1999; Ahn et al., 2000; Fernandez-Capetillo et al., 2002). Depending on the number of DSBs, p53 can activate pro-apoptotic genes such as PUMA (p53 upp-regulated modulator of apoptosis) and BAX (ㅁcl-2-asssociated $\underline{X}$ protein) (Lane, 1992; Iannolo et al., 2008). The family this two proteins belong to, play a central role in controlling the intrinsic (mitochondrial) pathway which ultimately results in DNA fragmentation and apoptosis (Lane, 1992; Iannolo et al., 2008). Moreover, recent data demonstrate that p53 accumulation in the cytoplasm as a result of DNA-damage may have a direct effect on mitochondrial release of cytochrome $c$ by directly binding to and blocking the antiapoptotic function of Bcl-xL (Chipuk et al., 2005).

Stem cells in the developing embryo proliferate and differentiate while maintaining the genomic integrity, failing of which may lead to accumulation of mutations and subsequent damage to the embryo. In line with this view, it was reported that ESCs, the in vitro counterpart of embryo derived stem cells are highly sensitive to genotoxic stress and eliminate the defected cells by efficient DNA damage repair or by provoking apoptosis, thus maintaining genomic integrity. In agreement with this fact, spontaneous mutation and mitotic recombination frequencies in mouse ESCs were shown to be manifold lower than in adult somatic cells/fibroblasts (Hong et al., 2006). The high genetic stability of ESCs 
might be attributed to the cellular localization of the "guardian of the genome", p53 (Lane, 1992). In ESCs it is mainly cytoplasmic (Sabapathy et al., 1997) which refrain p53 from inducing cell-cycle arrest or apoptosis by transcriptional activation of downstream target genes following DNA damage (Aladjem et al., 1998). Several studies suggest that beside the transcription-dependent induction of apoptosis, p53 also induces apoptosis through mitochondrial pathway in human and mouse stem cells (Qin et al., 2007). The study of Lin et al. (2005), reported the induction of differentiation as an alternative mechanism to maintain genetic stability in ESCs. However, the genotoxicity and apoptosis-related processes in GSC-derived pluripotent cells, maGSCs, is currently unknown.

In our present study (Khromov et al., manuscript submitted) we analysed the apoptosis-related gene expression profile in undifferentiated ESCs and maGSCs of 129Sv and Stra8-EGFP genetic background and found a high similarity in their expression profile. The closer look at those apoptosis-related genes expressed in undifferentiated cells showed a high number of genes associated with mitochondrial apoptosis pathway. Moreover, we could also detect the clear downregulation of anti apoptotic genes after differentiation (Table 4.1).

The expression of extrinsic pathway related genes was observed in differentiated cells but not in undifferentiated cells. These results are in parallel with previous findings, where the expression of Fas and its ligand were undetectable in undifferentiated mouse and human ESCs (Ginis et al., 2004). It was shown that many of the apoptosis related genes in murine ESCs which are expressed at detectable levels are associated with the p53 pathway. This pathway, in response to DNA damage, induces cell growth inhibition and cell death (Gottifredi et al., 2000; Schuler et al., 2000). The high expression of Growth Arrest and DNA Damage (GADD45) was also detected only in mouse ESCs. p53 and survivin (Birc5) were also highly expressed in mouse ESCs which correlates with our observation in the Oligo array of the analysed murine ESCs and maGSCs. The expression of two proapoptotic genes Mcll and Bax could also be found in both human and mouse ES cell types (Ginis et al., 2004) which again agrees with the observation of the expression in our comparative analysis. Although, these two pro-apoptotic genes are expressed in differentiated cells the expression levels were much lower compared to undifferentiated ESCs and maGSCs. In agreement to the study of Ginis et al., (2004), we could also observe the absence of the Casp-14 in both murine cell lines, in contrast to the expression in human ESCs. Except Casp-2, we could not detect the expression of any other caspases spotted on 
the array. To conclude, we can suggest that the apoptotic related genes expressed in mouse ESCs and maGSCs are associated with the intrinsic pathway of apoptosis.

\begin{tabular}{|l|l|l|l|}
\hline \multicolumn{2}{|c|}{$\begin{array}{c}\text { ES-RI/ES-Stra 8/maGSC-129Sv/ } \\
\text { maGSC-Stra 8 }\end{array}$} & \multicolumn{2}{c|}{ dES-RI diff./maGSC-129Sv diff. } \\
\hline \multicolumn{1}{|c|}{ pro apoptotic } & \multicolumn{1}{|c|}{ anti apoptotic } & \multicolumn{1}{c|}{ pro apoptotic } & anti apoptotic \\
\hline Pycard & Akt1 & Pycard & Akt1 \\
\hline Bax & Api5 & Bax & Api5 \\
\hline Cradd & Atf5 & Bnip2 & Atf5 \\
\hline Bid & Bag1 & Bnip3 & Bad1 \\
\hline Bnip3 & Birc2 & Casp2 & Dad1 \\
\hline Bok & Dad1 & Ltbr & Faim \\
\hline Casp2 & Faim & Nikb & Mcl1 \\
\hline Nfkb1 & Hells & Tnfrsf12a & Zc3hc1 \\
\hline Tnfrsf12a & Mapk8ip1 & Fas & Prdx2 \\
\hline Trp53inp1 & Mcl1 & Tnfsf11b & Rnf7 \\
\hline Trp53/p53 & Zc3hc1 & Traf3 & \\
\hline & Pim2 & Traf4 & \\
\hline & Polb & & \\
\hline & Birc5 & & \\
\hline & Prdx 2 & & \\
\hline & Rnf7 & & \\
\hline & & & \\
\hline
\end{tabular}

Table 4.1. The list of pro- and anti-apoptotic genes detected in undifferentiated and differentiated ESCs and maGSCs. Green marked rows emphasise the genes involved in mitochondrial pathway.

To examine, whether the maGSCs are responding to apoptotic induction in the same manner as ESCs, we treated both undifferentiated cell lines with the substance produced in the fungal genera Penicillium and Monascus in secondary metabolites as mycotoxin, citrinin (CTN). CTN is known to induce apoptosis in embryonic stem cells via ROS (reactive oxygen species) generation which consequent mitochondria-dependent apoptotic

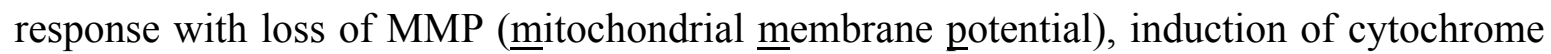
$c$ release and activation of Casp-3 (Chan, 2007). In our study, treatment of ESCs and maGSCs with CTN induced apoptosis successfully as we could observe on morphological features of both cell lines after $24 \mathrm{~h}$. Annexin-V and 7-AAD staining demonstrated $\sim 40 \%$ of early apoptotic cells, however maGSCs showed slightly reduced amount of apoptotic but 
more vital cells, what can be partly due to higher expression level of p53, which we detected in OligoGEArray. After induction of both undifferentiated cell lines with different concentration of CTN (200 and $250 \mu \mathrm{M})$ for $24 \mathrm{~h}$ we detected the cleaved and consequently active form of Casp-9 in both ESC and maGSCs (Fig. 4.5), which confirms the mitochondrial pathway activation.

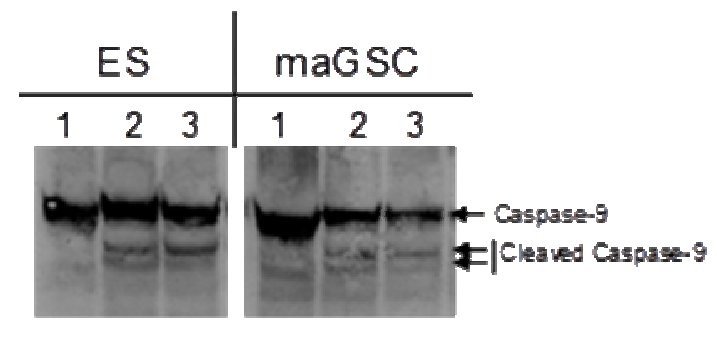

$$
\begin{array}{ll}
\text { 1. Control } \\
\text { 2. } 200 \text { pu CTN } \\
\text { 3. } 250 \text { m CTN }
\end{array}
$$

Figure 4.5. Western blot analysis of Casp-9 activation. WB showing the expression of the cleaved form of Casp-9 in ESCs and maGSCs after treatment with indicated concentrations of CTN for $24 \mathrm{~h}$.

Further to broaden our comparative analysis of the gene expression profile in maGSCs and ESCs in apoptotic response, we performed the genome wide transcriptome from both CTN treated cell lines. To get a pure population of early-apoptotic cells, we sorted out the cells which were positive for Annexin V but at the same time negative for 7AAD labelling. Further, this subset of cells was utilized for the whole genome transcriptome analysis (20985 genes) to determine similarities or differences of gene expression between maGSCs and ESCs in response to apoptotic induction. Moreover we wanted to identify and examine the novel genes expressed in both cell lines whose relative enrichment was drastically changed during early-apoptosis. The genes which are highly up or down regulated during mitochondrial and genotoxicity mediated apoptosis might play an important role in maintenance of genomic integrity in pluripotent cells. Therefore we compared the transcriptome data of early apoptotic cells with the transcriptome of wild type undifferentiated ESCs and maGSCs performed previously by our group (Meyer et al., 2010). Overall we could observe only minor differences in the gene expression between apoptotic maGSCs and ES cells but big divergence in the gene expression between apoptotic and non-apoptotic. 
In frame with the comparative analysis of early-apoptotic ESCs and maGSCs with their wild type counterparts we could identify two genes: Fibroblast growth factor $4(F g f 4)$ and Myeloid cell nuclear differentiation antigen (Mnda) which were found to be highly down-regulated in apoptotic cells. These two genes might play a role in mitochondrial and genotoxicity mediated apoptosis especially in pluripotent cells. To examine their role in apoptosis we performed overexpression and down regulation studies in context of apoptosis and DNA damage induction studies.

\subsection{Putative apoptosis related genes in pluripotent ESCs and maGSCs}

\subsubsection{Fibroblast growth factor 4 (Fgf4)}

Fgf4 belongs to the FGF super family and plays an important role in various stages of embryonic development, regulation of proliferation and differentiation in embryonic stem cells and tissue stem cells (Kosaka et al., 2009). Since the role of Fgf4 during induced apoptosis/genotoxicity in undifferentiated ESCs is not yet explored, we induced apoptosis/genotoxicity in Fgf4 overexpressing and knock-out (Fgf4-OE and Fgf4-KO, respectively) ESCs. Interestingly, Fgf4-KO cells appeared to be partially protected against DNA damage induced apoptosis. It has been reported that ESCs with DNA damage can induce differentiation by p53 dependent suppression of Nanog, which leads to the effective elimination of these differentiated cells by p53 dependent cell cycle arrest and apoptosis (Lin et al., 2005). This mechanism of elimination of damaged cells through differentiation is more efficient than the canonical cell cycle arrest and apoptosis in undifferentiated ESCs. In this context it is interesting to note that depletion of Fgf4 is known to block the differentiation and increase the cell survival (Kosaka et al., 2009). Hence, we hypothesize that Fgf4-KO cells might be resistant to DNA damage induced differentiation and subsequent apoptosis by p53 dependent mechanisms. Although Fgf4-KO cells are resistant to apoptosis, we speculate that these cells might carry mutations, which otherwise would have been eliminated through p53 dependent mechanisms in Fgf4 intact cells.

\subsubsection{Myeloid cell nuclear differentiation antigen (Mnda)}

Mnda is a member of the interferon (IFN)-regulated 200 family of proteins that contain a partially conserved 220-amino acid domain and is thought to interact specifically with other transcriptional regulators (Johnstone and Trapani, 1999). Moreover, several 
proteins of this family, including human MNDA, were shown to promote programmed cell death in several experimental conditions (Wen et al., 2000; D'Souza et al., 2001; Aglipay et al., 2003; Briggs et al., 2006; Fotouhi-Ardakani et al., 2010). Since the expression pattern and the role of mouse Mnda is not yet known and it is highly downregulated during CTNinduced apoptosis, we sought to analyze the function of this protein in responses to genotoxicity. We did not observe any significant differences in protection or sensitivity to apoptosis between control and either Mnda overexpressing and Mnda downregulation (Mnda-OE or Mnda-DN) cells when apoptosis was induced through CTN. Interestingly, induction of DNA damage in Mnda-OE and Mnda-DN cells exhibited prolonged G2/M arrest and delayed cell cycle progression. It has been reported that during constitutive apoptosis of human neutrophils, MNDA is accumulated in the cytoplasm, where it enhances degradation of the anti-apoptotic protein Mcl-1, thereby accelerating apoptosis (Fotouhi-Ardakani et al., 2010). Further, this study suggested that impaired cytoplasmic MNDA accumulation contributes to delayed neutrophil apoptosis in patients with severe sepsis. Our results suggest that the imbalanced expression levels of Mnda in ESCs might sense the DNA damage leading to the prolonged cell cycle arrest in G2/M phase. The delay in cell cycle progression might provide a wide window for repairing the damaged DNA thus conferring genomic stability. Through our results and the observations from FotouhiArdakani et al. (2010), we can conclude that Mnda influences the delay of cell cycle and the subsequent apoptosis. 


\subsection{Future endeavors and perspectives}

In the present study, we show the existence of ESC-characteristic epigenetic histone modification profiles and apoptosis-related properties in maGSCs. Our analysis of the gene-specific histone modification profiles of maGSCs were performed for some pluripotency-and development-related genes. Further studies aiming at the genome-wide analysis of DNA methylation and histone modifications at single-base-pair resolution using ChIP and next generation sequencing techniques (ChIP-seq) are necessary to obtain a more detailed picture of the epigenetic landscape of maGSCs. Furthermore, global and gene-specific histone modification profiles during spontaneous differentiation of maGSCs can be performed to examine the gain or loss of histone modifications in comparison to ESCs.

The genotoxicity and apoptosis-related properties of pluripotent stem cells are unique in nature. The identification of the molecular pathway and the mechanism responsible for the observed resistance of Fgf4 deficient ESCs to induced apoptosis might help to better understand pluripotent cells and their therapeutic usage. Mnda is known to translocate from the nucleus and accumulate in the cytoplasm during apoptosis to trigger the cell death, like it is known for p53. In this context, it is interesting to analyse their possible interaction and the existence of either common or independent mechanisms of apoptosis activation in pluripotent cells.

We identified Mmp10 (Matrix Metalloproteinase-10 or Stromelysin-2) as a pluripotent cell-specific and apoptosis-related gene but the function of this protein was not analyzed further in this thesis. Mmp10 belongs to proteins of the matrix metalloproteinase (MMP) family which are involved in many physiological processes such as embryonic development, reproduction, and tissue remodelling, as well as in pathological processes such as inflammation and cancer. It was also reported that oxidative stress plays an important role in regulating the activities of MMPs that are involved in various cellular processes such as cellular proliferation, angiogenesis, cancer invasion and metastasis (Swarnakar et al., 2010). It is interesting to note that many of the chemicals and physical treatments induce apoptosis by stimulating oxidative stress via the generation of reactive oxygen species (ROS) (Halliwell et al., 1990; Hsuuw et al., 2005; Cia et al., 2006; Pathak et al., 2006; Chan et al., 2007). Melatonin, a hormone acting as an antioxidant (Poeggeler et al., 1993) and anti-inflammatory molecule is also known to regulate MMPs expression and inhibition of mitochondria mediated apoptosis (Hoijman et al., 2004; Swarnakar et al., 
2010). Till now there is no reported connection between Mmp10 as well as Mnda to the regulation of pluripotency or genomic integrity in ESCs. Further studies analyzing the role of Mmp10 in pluripotency and apoptosis or genotoxicity process will shed light on its function in pluripotent cells. 


\section{References}

Aglipay JA, Lee SW, Okada S, Fujiuchi N, Ohtsuka T, Kwak JC, et al. A member of the Pyrin family, IFI16, is a novel BRCA1-associated protein involved in the p53mediated apoptosis pathway. Oncogene 2003; 22: 8931-8.

Ahn YH, Koh JY, Hong SH. Protein synthesis-dependent but Bcl-2-independent cytochrome $\mathrm{C}$ release in zinc depletion-induced neuronal apoptosis. J Neurosci Res 2000; 61: 508-14.

Aladjem MI, Spike BT, Rodewald LW, Hope TJ, Klemm M, Jaenisch R, et al. ES cells do not activate p53-dependent stress responses and undergo p53-independent apoptosis in response to DNA damage. Curr Biol 1998; 8: 145-55.

Avilion AA, Nicolis SK, Pevny LH, Perez L, Vivian N, Lovell-Badge R. Multipotent cell lineages in early mouse development depend on SOX2 function. Genes Dev 2003; 17: $126-40$.

Azuara V, Perry P, Sauer S, Spivakov M, Jorgensen HF, John RM, et al. Chromatin signatures of pluripotent cell lines. Nat Cell Biol 2006; 8: 532-8.

Bartova E, Krejci J, Harnicarova A, Galiova G, Kozubek S. Histone modifications and nuclear architecture: a review. J Histochem Cytochem 2008; 56: 711-21.

Becker KA, Ghule PN, Therrien JA, Lian JB, Stein JL, van Wijnen AJ, et al. Self-renewal of human embryonic stem cells is supported by a shortened G1 cell cycle phase. J Cell Physiol 2006; 209: 883-93.

Bernstein BE, Mikkelsen TS, Xie X, Kamal M, Huebert DJ, Cuff J, et al. A bivalent chromatin structure marks key developmental genes in embryonic stem cells. Cell 2006; 125: 315-26.

Blanpain C, Fuchs E. Epidermal homeostasis: a balancing act of stem cells in the skin. Nat Rev Mol Cell Biol 2009; 10: 207-17.

Boyer LA, Plath K, Zeitlinger J, Brambrink T, Medeiros LA, Lee TI, et al. Polycomb complexes repress developmental regulators in murine embryonic stem cells. Nature 2006; 441: 349-53.

Briggs RC, Shults KE, Flye LA, McClintock-Treep SA, Jagasia MH, Goodman SA, et al. Dysregulated human myeloid nuclear differentiation antigen expression in myelodysplastic syndromes: evidence for a role in apoptosis. Cancer Res 2006; 66: 4645-51. 
Brons IG, Smithers LE, Trotter MW, Rugg-Gunn P, Sun B, Chuva de Sousa Lopes SM, et al. Derivation of pluripotent epiblast stem cells from mammalian embryos. Nature 2007; 448: 191-5.

Burdon T, Chambers I, Stracey C, Niwa H, Smith A. Signaling mechanisms regulating self-renewal and differentiation of pluripotent embryonic stem cells. Cells Tissues Organs 1999; 165: 131-43.

Burdon T, Smith A, Savatier P. Signalling, cell cycle and pluripotency in embryonic stem cells. Trends Cell Biol 2002; 12: 432-8.

Cartwright P, McLean C, Sheppard A, Rivett D, Jones K, Dalton S. LIF/STAT3 controls ES cell self-renewal and pluripotency by a Myc-dependent mechanism. Development 2005; 132: 885-96.

Cedar H, Bergman Y. Linking DNA methylation and histone modification: patterns and paradigms. Nat Rev Genet 2009; 10: 295-304.

Chambers I, Colby D, Robertson M, Nichols J, Lee S, Tweedie S, et al. Functional expression cloning of Nanog, a pluripotency sustaining factor in embryonic stem cells. Cell 2003; 113: 643-55.

Chambers I, Smith A. Self-renewal of teratocarcinoma and embryonic stem cells. Oncogene 2004; 23: 7150-60.

Chan WH. Citrinin induces apoptosis via a mitochondria-dependent pathway and inhibition of survival signals in embryonic stem cells, and causes developmental injury in blastocysts. Biochem J 2007; 404: 317-26.

Chen X, Vega VB, Ng HH. Transcriptional regulatory networks in embryonic stem cells. Cold Spring Harb Symp Quant Biol 2008; 73: 203-9.

Chipuk JE, Bouchier-Hayes L, Kuwana T, Newmeyer DD, Green DR. PUMA couples the nuclear and cytoplasmic proapoptotic function of p53. Science 2005; 309: 1732-5.

Chuykin IA, Lianguzova MS, Pospelova TV, Pospelov VA. Activation of DNA damage response signaling in mouse embryonic stem cells. Cell Cycle 2008; 7: 2922-8.

Conrad S, Renninger M, Hennenlotter J, Wiesner T, Just L, Bonin M, et al. Generation of pluripotent stem cells from adult human testis. Nature 2008; 456: 344-349. Erratum in: Nature 460: 1044.

Cortez D, Wang Y, Qin J, Elledge SJ. Requirement of ATM-dependent phosphorylation of brcal in the DNA damage response to double-strand breaks. Science 1999; 286: 1162-6. 
D'Souza S, Xin H, Walter S, Choubey D. The gene encoding p202, an interferon-inducible negative regulator of the p53 tumor suppressor, is a target of p53-mediated transcriptional repression. J Biol Chem 2001; 276: 298-305.

Dani C, Smith AG, Dessolin S, Leroy P, Staccini L, Villageois P, et al. Differentiation of embryonic stem cells into adipocytes in vitro. J Cell Sci 1997; 110 (Pt 11): 1279-85.

Dihazi H, Dihazi GH, Nolte J, Meyer S, Jahn O, Muller GA, et al. Multipotent adult germline stem cells and embryonic stem cells: comparative proteomic approach. J Proteome Res 2009; 8: 5497-510.

Dinsmore J, Ratliff J, Deacon T, Pakzaban P, Jacoby D, Galpern W, et al. Embryonic stem cells differentiated in vitro as a novel source of cells for transplantation. Cell Transplant 1996; 5: 131-43.

Doetschman TC, Eistetter H, Katz M, Schmidt W, Kemler R. The in vitro development of blastocyst-derived embryonic stem cell lines: formation of visceral yolk sac, blood islands and myocardium. J Embryol Exp Morphol 1985; 87: 27-45.

Drab M, Haller H, Bychkov R, Erdmann B, Lindschau C, Haase H, et al. From totipotent embryonic stem cells to spontaneously contracting smooth muscle cells: a retinoic acid and db-cAMP in vitro differentiation model. Faseb J 1997; 11: 905-15.

Draper JS, Moore HD, Ruban LN, Gokhale PJ, Andrews PW. Culture and characterization of human embryonic stem cells. Stem Cells Dev 2004; 13: 325-36.

Efroni S, Duttagupta R, Cheng J, Dehghani H, Hoeppner DJ, Dash C, et al. Global transcription in pluripotent embryonic stem cells. Cell Stem Cell 2008; 2: 437-47.

Epsztejn-Litman S, Feldman N, Abu-Remaileh M, Shufaro Y, Gerson A, Ueda J, et al. De novo DNA methylation promoted by G9a prevents reprogramming of embryonically silenced genes. Nat Struct Mol Biol 2008; 15: 1176-83.

Evans MJ, Kaufman MH. Establishment in culture of pluripotential cells from mouse embryos. Nature 1981; 292: 154-6.

Feldman N, Gerson A, Fang J, Li E, Zhang Y, Shinkai Y, et al. G9a-mediated irreversible epigenetic inactivation of Oct-3/4 during early embryogenesis. Nat Cell Biol 2006; 8: 188-94.

Fernandez-Capetillo O, Chen HT, Celeste A, Ward I, Romanienko PJ, Morales JC, et al. DNA damage-induced G2-M checkpoint activation by histone H2AX and 53BP1. Nat Cell Biol 2002; 4: 993-7. 
Finch BW, Ephrussi B. Retention of multiple developmental potentialities by cells a mouse testicular teratocarcinoma during prolonged culture in vitro and their extinction upon hybridisation with cells of permanent lines. Proc Natl Acad Sci 1967; 57 (3): $615-21$.

Fluckiger AC, Marcy G, Marchand M, Negre D, Cosset FL, Mitalipov S, et al. Cell cycle features of primate embryonic stem cells. Stem Cells 2006; 24: 547-56.

Fotouhi-Ardakani N, Kebir DE, Pierre-Charles N, Wang L, Ahern SP, Filep JG, et al. Role for myeloid nuclear differentiation antigen in the regulation of neutrophil apoptosis during sepsis. Am J Respir Crit Care Med; 182: 341-50.

Fuhrmann G, Chung AC, Jackson KJ, Hummelke G, Baniahmad A, Sutter J, et al. Mouse germline restriction of Oct4 expression by germ cell nuclear factor. Dev Cell 2001; 1: $377-87$.

Galan-Caridad JM, Harel S, Arenzana TL, Hou ZE, Doetsch FK, Mirny LA, et al. Zfx controls the self-renewal of embryonic and hematopoietic stem cells. Cell 2007; 129: 345-57.

Gaspar-Maia A, Alajem A, Polesso F, Sridharan R, Mason MJ, Heidersbach A, et al. Chd1 regulates open chromatin and pluripotency of embryonic stem cells. Nature 2009; 460: $863-8$.

Geijsen N, Horoschak M, Kim K, Gribnau J, Eggan K, Daley GQ. Derivation of embryonic germ cells and male gametes from embryonic stem cells. Nature 2004; 427: 148-54.

Ginis I, Luo Y, Miura T, Thies S, Brandenberger R, Gerecht-Nir S, et al. Differences between human and mouse embryonic stem cells. Dev Biol 2004; 269: 360-80.

Golestaneh N, Kokkinaki M, Pant D, Jiang J, DeStefano D, Fernandez-Bueno C, et al. Pluripotent stem cells derived from adult human testes. Stem Cells Dev 2009; 18 : 1115-26.

Gottifredi V, Shieh SY, Prives C. Regulation of p53 after different forms of stress and at different cell cycle stages. Cold Spring Harb Symp Quant Biol 2000; 65: 483-8.

Guan K, Nayernia K, Maier LS, Wagner S, Dressel R, Lee JH, et al. Pluripotency of spermatogonial stem cells from adult mouse testis. Nature 2006; 440: 1199-203.

Hall PA, Meek D, Lane DP. p53--integrating the complexity. J Pathol 1996; 180: 1-5.

Hao J, Li TG, Qi X, Zhao DF, Zhao GQ. WNT/beta-catenin pathway up-regulates Stat3 and converges on LIF to prevent differentiation of mouse embryonic stem cells. Dev Biol 2006; 290: 81-91. 
Hattori N, Nishino K, Ko YG, Hattori N, Ohgane J, Tanaka S, et al. Epigenetic control of mouse Oct-4 gene expression in embryonic stem cells and trophoblast stem cells. J Biol Chem 2004; 279: 17063-9.

Hayashi Y, Furue MK, Okamoto T, Ohnuma K, Myoishi Y, Fukuhara Y, et al. Integrins regulate mouse embryonic stem cell self-renewal. Stem Cells 2007; 25: 3005-15.

Hong Y, Cervantes RB, Stambrook PJ. DNA damage response and mutagenesis in mouse embryonic stem cells. Methods Mol Biol 2006; 329: 313-26.

Hong Y, Stambrook PJ. Restoration of an absent G1 arrest and protection from apoptosis in embryonic stem cells after ionizing radiation. Proc Natl Acad Sci U S A 2004; 101 : 14443-8.

Iannolo G, Conticello C, Memeo L, De Maria R. Apoptosis in normal and cancer stem cells. Crit Rev Oncol Hematol 2008; 66: 42-51.

Ivanova N, Dobrin R, Lu R, Kotenko I, Levorse J, DeCoste C, et al. Dissecting selfrenewal in stem cells with RNA interference. Nature 2006; 442: 533-8.

Izadyar F, Pau F, Marh J, Slepko N, Wang T, Gonzalez R, et al. Generation of multipotent cell lines from a distinct population of male germ line stem cells. Reproduction 2008; 135: 771-84.

Jenuwein T, Allis CD. Translating the histone code. Science 2001; 293: 1074-80.

Johnstone RW, Trapani JA. Transcription and growth regulatory functions of the HIN-200 family of proteins. Mol Cell Biol 1999; 19: 5833-8.

Kahan BW, Ephrussi B. Developmental potentialities of clonal in vitro cultures of mouse testicular teratoma. J Natl Cancer Inst 1970; 44(5): 1015-36.

Kanatsu-Shinohara M, Inoue K, Lee J, Yoshimoto M, Ogonuki N, Miki H, et al. Generation of pluripotent stem cells from neonatal mouse testis. Cell 2004; 119 : 1001-12.

Kanatsu-Shinohara M, Lee J, Inoue K, Ogonuki N, Miki H, Toyokuni S, et al. Pluripotency of a single spermatogonial stem cell in mice. Biol Reprod 2008; 78: 681-7.

Khromov T, Pantakani DV, Nolte J, Wolf M, Dressel R, Engel W, et al. Global and genespecific histone modification profiles of mouse multipotent adult germline stem cells. Mol Hum Reprod 2011; 17: 166-74.

Kim J, Chu J, Shen X, Wang J, Orkin SH. An extended transcriptional network for pluripotency of embryonic stem cells. Cell 2008; 132: 1049-61. 
Kimura H, Tada M, Nakatsuji N, Tada T. Histone code modifications on pluripotential nuclei of reprogrammed somatic cells. Mol Cell Biol 2004; 24: 5710-20.

Kirmizis A, Bartley SM, Kuzmichev A, Margueron R, Reinberg D, Green R, et al. Silencing of human polycomb target genes is associated with methylation of histone H3 Lys 27. Genes Dev 2004; 18: 1592-605.

Kleinsmith LJ, Pierce Jr. GB. Multipotentiality of single embryoid carcinoma cells. Cancer Res 1964; 24: 1544-51

Ko K, Tapia N, Wu G, Kim JB, Bravo MJ, Sasse P, et al. Induction of pluripotency in adult unipotent germline stem cells. Cell Stem Cell 2009; 5: 87-96.

Kosaka N, Sakamoto H, Terada M, Ochiya T. Pleiotropic function of FGF-4: its role in development and stem cells. Dev Dyn 2009; 238: 265-76.

Kossack N, Meneses J, Shefi S, Nguyen HN, Chavez S, Nicholas C, et al. Isolation and characterization of pluripotent human spermatogonial stem cell-derived cells. Stem Cells 2009; 27: 138-149.

Kruse JJ, Svensson JP, Huigsloot M, Giphart-Gassler M, Schoonen WG, Polman JE, et al. A portrait of cisplatin-induced transcriptional changes in mouse embryonic stem cells reveals a dominant p53-like response. Mutat Res 2007; 617: 58-70.

Kunath T, Saba-El-Leil MK, Almousailleakh M, Wray J, Meloche S, Smith A. FGF stimulation of the Erk1/2 signalling cascade triggers transition of pluripotent embryonic stem cells from self-renewal to lineage commitment. Development 2007; 134: 2895-902.

Lane DP. Cancer. p53, guardian of the genome. Nature 1992; 358: 15-6.

Lehnertz B, Ueda Y, Derijck AA, Braunschweig U, Perez-Burgos L, Kubicek S, et al. Suv39h-mediated histone H3 lysine 9 methylation directs DNA methylation to major satellite repeats at pericentric heterochromatin. Curr Biol 2003; 13: 1192200.

Levine AJ. p53, the cellular gatekeeper for growth and division. Cell 1997; 88: 323-31.

Lin T, Chao C, Saito S, Mazur SJ, Murphy ME, Appella E, et al. p53 induces differentiation of mouse embryonic stem cells by suppressing Nanog expression. Nat Cell Biol 2005; 7: 165-71.

Loh YH, Wu Q, Chew JL, Vega VB, Zhang W, Chen X, et al. The Oct4 and Nanog transcription network regulates pluripotency in mouse embryonic stem cells. Nat Genet 2006; 38: 431-40. 
Malashicheva AB, Kisliakova TV, Savatier P, Pospelov VA. [Embryonal stem cells do not undergo cell cycle arrest upon exposure to damaging factors]. Tsitologiia 2002; 44: 643-8.

Malashicheva AB, Kislyakova TV, Aksenov ND, Osipov KA, Pospelov VA. F9 embryonal carcinoma cells fail to stop at G1/S boundary of the cell cycle after gammairradiation due to p21WAF1/CIP1 degradation. Oncogene 2000; 19: 3858-65.

Martin C, Zhang Y. The diverse functions of histone lysine methylation. Nat Rev Mol Cell Biol 2005; 6: 838-49.

Martin GR. Isolation of a pluripotent cell line from early mouse embryos cultured in medium conditioned by teratocarcinoma stem cells. Proc Natl Acad Sci U S A 1981; 78: 7634-8.

Matsui Y, Zsebo K, Hogan BL. Derivation of pluripotential embryonic stem cells from murine primordial germ cells in culture. Cell 1992; 70: 841-7.

Mattout A, Meshorer E. Chromatin plasticity and genome organization in pluripotent embryonic stem cells. Curr Opin Cell Biol; 22: 334-41.

Meshorer E, Misteli T. Chromatin in pluripotent embryonic stem cells and differentiation. Nat Rev Mol Cell Biol 2006; 7: 540-6.

Meshorer E, Yellajoshula D, George E, Scambler PJ, Brown DT, Misteli T. Hyperdynamic plasticity of chromatin proteins in pluripotent embryonic stem cells. Dev Cell 2006; 10: 105-16.

Meyer S, Nolte J, Opitz L, Salinas-Riester G, Engel W. Pluripotent embryonic stem cells and multipotent adult germline stem cells reveal similar transcriptomes including pluripotency-related genes. Mol Hum Reprod 2010; 16: 846-55.

Mihara M, Erster S, Zaika A, Petrenko O, Chittenden T, Pancoska P, et al. p53 has a direct apoptogenic role at the mitochondria. Mol Cell 2003; 11: 577-90.

Mikkelsen TS, Ku M, Jaffe DB, Issac B, Lieberman E, Giannoukos G, et al. Genome-wide maps of chromatin state in pluripotent and lineage-committed cells. Nature 2007; 448: 553-60.

Mitsui K, Tokuzawa Y, Itoh H, Segawa K, Murakami M, Takahashi K, et al. The homeoprotein Nanog is required for maintenance of pluripotency in mouse epiblast and ES cells. Cell 2003; 113: 631-42. 
Mizrak SC, Chikhovskaya JV, Sadri-Ardekani H, van Daalen S, Korver CM, Hovingh SE, et al. Embryonic stem cell-like cells derived from adult human testis. Hum Reprod 2010; 25: 158-167.

Narlikar GJ, Fan HY, Kingston RE. Cooperation between complexes that regulate chromatin structure and transcription. Cell 2002; 108: 475-87.

Nayernia K, Nolte J, Michelmann HW, Lee JH, Rathsack K, Drusenheimer N, et al. In vitro-differentiated embryonic stem cells give rise to male gametes that can generate offspring mice. Dev Cell 2006; 11: 125-32.

Nichols J, Zevnik B, Anastassiadis K, Niwa H, Klewe-Nebenius D, Chambers I, et al. Formation of pluripotent stem cells in the mammalian embryo depends on the POU transcription factor Oct4. Cell 1998; 95: 379-91.

Niwa H, Miyazaki J, Smith AG. Quantitative expression of Oct-3/4 defines differentiation, dedifferentiation or self-renewal of ES cells. Nat Genet 2000; 24: 372-6.

Niwa H, Ogawa K, Shimosato D, Adachi K. A parallel circuit of LIF signalling pathways maintains pluripotency of mouse ES cells. Nature 2009; 460: 118-22.

O'Neill LP, VerMilyea MD, Turner BM. Epigenetic characterization of the early embryo with a chromatin immunoprecipitation protocol applicable to small cell populations. Nat Genet 2006; 38: 835-41.

O'Shea KS. Self-renewal vs. differentiation of mouse embryonic stem cells. Biol Reprod 2004; 71: 1755-65.

Obier N, Muller AM. Chromatin flow cytometry identifies changes in epigenetic cell states. Cells Tissues Organs; 191: 167-74.

Ogawa K, Nishinakamura R, Iwamatsu Y, Shimosato D, Niwa H. Synergistic action of Wnt and LIF in maintaining pluripotency of mouse ES cells. Biochem Biophys Res Commun 2006; 343: 159-66.

Okamoto K, Okazawa H, Okuda A, Sakai M, Muramatsu M, Hamada H. A novel octamer binding transcription factor is differentially expressed in mouse embryonic cells. Cell 1990; 60: 461-72.

Orkin SH, Zon LI. Hematopoiesis: an evolving paradigm for stem cell biology. Cell 2008; 132: 631-44.

Palmieri SL, Peter W, Hess H, Scholer HR. Oct-4 transcription factor is differentially expressed in the mouse embryo during establishment of the first two extraembryonic cell lineages involved in implantation. Dev Biol 1994; 166: 259-67. 
Petruk S, Sedkov Y, Smith S, Tillib S, Kraevski V, Nakamura T, et al. Trithorax and dCBP acting in a complex to maintain expression of a homeotic gene. Science 2001; 294: 1331-4.

Qin H, Yu T, Qing T, Liu Y, Zhao Y, Cai J, et al. Regulation of apoptosis and differentiation by p53 in human embryonic stem cells. J Biol Chem 2007; 282: $5842-52$.

Resnick JL, Bixler LS, Cheng L, Donovan PJ. Long-term proliferation of mouse primordial germ cells in culture. Nature 1992; 359: 550-1.

Sabapathy K, Klemm M, Jaenisch R, Wagner EF. Regulation of ES cell differentiation by functional and conformational modulation of p53. Embo J 1997; 16: 6217-29.

Sakaki-Yumoto M, Kobayashi C, Sato A, Fujimura S, Matsumoto Y, Takasato M, et al. The murine homolog of SALL4, a causative gene in Okihiro syndrome, is essential for embryonic stem cell proliferation, and cooperates with Sall1 in anorectal, heart, brain and kidney development. Development 2006; 133: 3005-13.

Santos J, Pereira CF, Di-Gregorio A, Spruce T, Alder O, Rodriguez T, et al. Differences in the epigenetic and reprogramming properties of pluripotent and extra-embryonic stem cells implicate chromatin remodelling as an important early event in the developing mouse embryo. Epigenetics Chromatin 2010; 3: 1.

Sato N, Meijer L, Skaltsounis L, Greengard P, Brivanlou AH. Maintenance of pluripotency in human and mouse embryonic stem cells through activation of Wnt signaling by a pharmacological GSK-3-specific inhibitor. Nat Med 2004; 10: 55-63.

Schuettengruber B, Chourrout D, Vervoort M, Leblanc B, Cavalli G. Genome regulation by polycomb and trithorax proteins. Cell 2007; 128: 735-45.

Schuler M, Bossy-Wetzel E, Goldstein JC, Fitzgerald P, Green DR. p53 induces apoptosis by caspase activation through mitochondrial cytochrome c release. J Biol Chem 2000; 275: 7337-42.

Seandel M, James D, Shmelkov SV, Falciatori I, Kim J, Chavala S, et al. Generation of functional multipotent adult stem cells from GPR125+ germline progenitors. Nature 2007; 449: 346-50.

Sims RJ, 3rd, Nishioka K, Reinberg D. Histone lysine methylation: a signature for chromatin function. Trends Genet 2003; 19: 629-39. 
Slager HG, Freund E, Buiting AM, Feijen A, Mummery CL. Secretion of transforming growth factor-beta isoforms by embryonic stem cells: isoform and latency are dependent on direction of differentiation. J Cell Physiol 1993; 156: 247-56.

Smith AG, Heath JK, Donaldson DD, Wong GG, Moreau J, Stahl M, et al. Inhibition of pluripotential embryonic stem cell differentiation by purified polypeptides. Nature 1988; 336: 688-90.

Smith ST, Petruk S, Sedkov Y, Cho E, Tillib S, Canaani E, et al. Modulation of heat shock gene expression by the TAC1 chromatin-modifying complex. Nat Cell Biol 2004; 6: $162-7$.

Soengas MS, Alarcon RM, Yoshida H, Giaccia AJ, Hakem R, Mak TW, et al. Apaf-1 and caspase-9 in p53-dependent apoptosis and tumor inhibition. Science 1999; 284 : $156-9$.

Stambrook PJ. An ageing question: do embryonic stem cells protect their genomes? Mech Ageing Dev 2007; 128: 31-5.

Stead E, White J, Faast R, Conn S, Goldstone S, Rathjen J, et al. Pluripotent cell division cycles are driven by ectopic Cdk2, cyclin A/E and E2F activities. Oncogene 2002; 21: 8320-33.

Suda Y, Suzuki M, Ikawa Y, Aizawa S. Mouse embryonic stem cells exhibit indefinite proliferative potential. J Cell Physiol 1987; 133: 197-201.

Suwinska A, Czolowska R, Ozdzenski W, Tarkowski AK. Blastomeres of the mouse embryo lose totipotency after the fifth cleavage division: expression of $\mathrm{Cdx} 2$ and Oct4 and developmental potential of inner and outer blastomeres of 16- and 32-cell embryos. Dev Biol 2008; 322: 133-44.

Takahashi K, Tanabe K, Ohnuki M, Narita M, Ichisaka T, Tomoda K, et al. Induction of pluripotent stem cells from adult human fibroblasts by defined factors. Cell 2007; 131: 861-72.

Takahashi K, Yamanaka S. Induction of pluripotent stem cells from mouse embryonic and adult fibroblast cultures by defined factors. Cell 2006; 126: 663-76.

Tesar PJ, Chenoweth JG, Brook FA, Davies TJ, Evans EP, Mack DL, et al. New cell lines from mouse epiblast share defining features with human embryonic stem cells. Nature 2007; 448: 196-9. 
Thiagalingam S, Cheng KH, Lee HJ, Mineva N, Thiagalingam A, Ponte JF. Histone deacetylases: unique players in shaping the epigenetic histone code. Ann N Y Acad Sci 2003; 983: 84-100.

Wang Y, Fischle W, Cheung W, Jacobs S, Khorasanizadeh S, Allis CD. Beyond the double helix: writing and reading the histone code. Novartis Found Symp 2004; 259: 3-17; discussion 17-21, 163-9.

Wen Y, Yan DH, Spohn B, Deng J, Lin SY, Hung MC. Tumor suppression and sensitization to tumor necrosis factor alpha-induced apoptosis by an interferoninducible protein, p202, in breast cancer cells. Cancer Res 2000; 60: 42-6.

Wernig M, Meissner A, Foreman R, Brambrink T, Ku M, Hochedlinger K, et al. In vitro reprogramming of fibroblasts into a pluripotent ES-cell-like state. Nature 2007; 448: 318-24.

Yu J, Vodyanik MA, Smuga-Otto K, Antosiewicz-Bourget J, Frane JL, Tian S, et al. Induced pluripotent stem cell lines derived from human somatic cells. Science 2007; 318: 1917-20.

Zechner U, Nolte J, Wolf M, Shirneshan K, Hajj NE, Weise D, et al. Comparative methylation profiles and telomerase biology of mouse multipotent adult germline stem cells and embryonic stem cells. Mol Hum Reprod 2009; 15: 345-53.

Zovoilis A, Nolte J, Drusenheimer N, Zechner U, Hada H, Guan K, et al. Multipotent adult germline stem cells and embryonic stem cells have similar microRNA profiles. Mol Hum Reprod 2008; 14: 521-9. 


\section{Abbreviations}

${ }^{\circ} \mathrm{C}$

x g

$\mu-$

Ac

bp

c-

cDNA

ChIP

CTN

$\mathrm{kDa}$

DAPI

DMEM

DN

DNA

dpc

DSBs

ECCs

EDTA

EGCs

EGFP

EpiSCs

ESCs

FACS

FCS

Fgf4

FITC

GDNF

GSCs

$\mathrm{h}$

H3K 27

H3K27me3

H3K4 degree Celsius

gravity

micro

Acetylation

base pair

centi

complementary DNA

Chromatin ImmunoPrecipitation

Citrinin

kilo Dalton

4',6-diamidino-2-phenylindole

Dulbecco's modified Eagle's medium

Down regulation

Deoxyribonucleic acid

days post coitum

DNA strand breaks

Embryonic carcinoma cells

Ethylenediaminetetraacetic acid

Embryonic germ cells

Enhanced green fluorescent protein

Epiblast stem cells

Embryonic stem cells

Fluorescence activated cell sorting

Fetal calf serum

Fibroblast growth factor 4

Fluorescein Isothiocyanate

Glial cell-derived neurotrophic factor

Germline stem cells

hour

histone 3 lysine 27

trimethylation of histone 3 lysine 27

histone 3 lysine 4 


\begin{tabular}{|c|c|}
\hline $\mathrm{H} 3 \mathrm{~K} 4 \mathrm{me} 3$ & trimethylation of histone 3 lysine 4 \\
\hline H3K9ac & acetylation of histone 3 lysine 9 \\
\hline H3K9me3 & trimethylation of histone 3 lysine 9 \\
\hline HATs & Histone acetyl transferases \\
\hline HDACs & Histone deacetylases \\
\hline HMT & Histone methyltransferase \\
\hline HRP & Horseradish peroxidase \\
\hline ICC & Immunocytochemistry \\
\hline $\mathrm{ICM}$ & Inner cell mass \\
\hline ICRs & Imprinting control regions \\
\hline iPSCs & induced pluripotent stem cells \\
\hline k- & kilo \\
\hline $\mathrm{KO}$ & Knock-out \\
\hline 1 & liter \\
\hline LIF & Leukemia inhibitory factor \\
\hline m- & milli \\
\hline $\mathrm{m}$ & meter \\
\hline M & Molar \\
\hline maGSCs & multipotent adult germline stem cells \\
\hline $\mathrm{Me}$ & Methylation \\
\hline MEFs & Mouse embryonic fibroblasts \\
\hline mGSCs & multipotent germline stem cells \\
\hline $\min$ & minute \\
\hline miRNA & micro RNA \\
\hline Mmp10 & Matrix metalloproteinase-10 \\
\hline Mnda & Myeloid cell nuclear differentiating agent \\
\hline mRNA & messenger RNA \\
\hline NCS & Neocarzinostatin \\
\hline $\mathrm{OE}$ & Overexpression \\
\hline ORF & Open reading frame \\
\hline PBS & Phosphate buffered saline \\
\hline PcG & Poly-comb group \\
\hline PCA & Principal component analysis \\
\hline
\end{tabular}


PCR Polymerase chain reaction

PFA Paraformaldehyde

PGCs Primordial germ cells

$\mathrm{pH} \quad$ preponderance of hydrogen ions

qRT-PCR quantitative RealTime-PCR

RA Retinoic acid

RNA Ribonucleic acid

RT-PCR Reverse transcriptase PCR

SCs Stem cells

SDS Sodium dodecylsulfate

SDS-PAGE SDS-polyacrylamide gel electrophoresis

siRNA small interfering RNA

SSCs Spermatogonial stem cells

Tris Trihydroxymethylaminomethane

TrxG Trithorax group 


\section{Acknowledgments}

I would like to express my deepest gratitude to Prof. Dr. med. Dr. h. c. Wolfgang Engel for offering the opportunity to work in the Institute of Human Genetics. It was my pleasure to work in such an inspiring and friendly atmosphere in the Institute of Human Genetics under his supervision.

I wish to express my sincere appreciation to PD Dr. Ulrich Zechner for his scientific suggestions and support.

I sincerely thank all my thesis committee members; Prof. Dr. Sigrid HoyerFender, Prof. Dr. med. Wolfgang Wuttke, Prof. Dr. Gregor Bucher, Prof. Dr. Heidi Hahn and Prof. Dr. Ahmed Mansouri for their valuable time to serve as my thesis committee.

My special thanks to Dr. Krishna Pantakani for his support and patience, greatest advices and inspiring discussions throughout my $\mathrm{PhD}$ time.

I would like to thank Dr. Jessica Nolte for her constructive critics and helpful advises throughout my study.

I would like to express my special thanks to Natalie Kling, Phillip Brockmeyer, Sandra Fischer and other close friends who shared ups and downs during my study.

My special thanks goes to Ozanna, Kazik, Pawel, Sandra M, Sandra L, Janine, Lukasz, Xingbo, Tan and all my institute colleagues for their friendship, numerous advices and fantastic working environment.

I want to express my deepest gratitude to my parents and my brother for their moral and financial support.

Last but not least, I thank GOD for guarding and guiding me throughout all these days. 


\section{Curriculum Vitae}

\section{Personal details:}

Name:

Date of birth:

Place of birth:

Nationality:

Address:

E-Mail:
Tatjana Khromov

15.08 .1980

Leningrad (Russia)

German/Russian

Emilienstrasse 8, 37075 Göttingen

tatjanakhromov@aol.com

\section{Education:}

Sep. 1987-May 1993: $\quad$ Primary and secondary school (Leningrad, Russia)

May 1993-Jul. 2001: Secondary school (Paul-Gerhardt Schule, Dassel, Germany)

Oct. 2001-Nov. 2006: Course of Studies: Biology

Georg-August-University Göttingen, Germany

Nov. 2006-Dec. 2007: Diploma thesis: "Functional characterisation of Reticulon1 using mouse as a model system and interaction studies of Reticulon3 with Spastin"

Institute of Human Genetics, Georg-August-University, Göttingen, Germany

Supervisor: Prof. Dr. med. Dr. h. c. Wolfgang Engel

Feb. 2008- May 2008: Scientific assistant,

Institute of Human Genetics, Georg-August-University, Göttingen, Germany

Since May 2008: $\quad$ PhD thesis: "Pluripotency of multipotent adult germ line stem cells: analysis of apoptotic and epigenetic features"

Institute of Human Genetics, Georg-August-University, Göttingen, Germany

Supervisor: Prof. Dr. med. Dr. h. c. Wolfgang Engel 


\section{List of Publications}

1. Khromov T, Pantakani DV, Nolte J, Wolf M, Dressel R, Zechner U, Engel W. (2011) Global and gene-specific histone modification profiles of mouse multipotent adult germline stem cells. Mol Hum Reprod 17(3): 166-174.

2. Xu X, Pantakani DV, Luhrig S, Tan X, Khromov T, Nolte J, Dressel R, Zechner U, Engel W. (2011) Stage-specific germ-cell marker genes are expressed in all mouse pluripotent cell types and emerge early during induced pluripotency. PLoS One 6(7): e22413.

\section{List of Manuscripts in Submission Stage}

1. Tatjana Khromov, D.V. Krishna Pantakani ${ }^{\ddagger}$, Ralf Dressel, Iliana Siamishi, Jessica Nolte and Wolfgang Engel. Apoptosis-related gene expression profiles of mouse ESCs and maGSCs: Identification and implication of Fgf4 and Mnda in pluripotent cell responses to genotoxicity. (Manuscript under review).

2. Krishna Pantakani $\mathrm{DV}^{*}$, Ying Zheng*, Tatjana Khromov, Marieke Wolf, Sandra Meyer, Jessica Nolte, Ulrich Zechner and Wolfgang Engel. STRA8 interacts with chromatin remodeling protein SETD8 and modulates H4K20 mono-methylation levels in embryonic stem cells and pre-meiotic germ cells. (Manuscript in revision). 